\title{
The oxygen sensor Prolyl hydroxylase domain 2 regulates the in vivo suppressive capacity of regulatory $\mathrm{T}$ cells
}

5 Yousra Ajouaou ${ }^{1,2}$, Abdulkader Azouz ${ }^{1,3}$, Anaelle Taquin ${ }^{1,2}$, Sebastien 6 Denanglaire ${ }^{1,2}$, Hind Hussein ${ }^{1,2}$, Mohammad Krayem ${ }^{4,5}$, Fabienne Andris ${ }^{1,2}$, 7 Muriel Moser ${ }^{1,2,}$, Stanislas Goriely ${ }^{1,2,3}$ and Oberdan Leo ${ }^{1,2^{*}}$

${ }^{1}$ U-CRI (ULB Center for Research in Immunology), Université Libre de Bruxelles (ULB), Gosselies, Belgium,

12 Immunobiology laboratory, Université Libre de Bruxelles (ULB), Gosselies, Belgium,

13 Institute for Medical Immunology, Université Libre de Bruxelles (ULB), Gosselies, Belgium,

$14{ }^{4}$ Department of Radiation Oncology, Institut Jules Bordet, Université Libre de Bruxelles,

15 Brussels, Belgium,

$16{ }^{5}$ Laboratory of Clinical and Experimental Oncology (LOCE), Institut Jules Bordet, Université

17 Libre de Bruxelles, Brussels, Belgium.

*Corresponding author: Oberdan Leo (Oberdan.Leo@ulb.be), Immunobiology laboratory, IBMM,

21 Rue des Professeurs Jeener et Brachet 12, 6041 Gosselies (Belgium). 
25 The oxygen sensor PHD2 (prolyl hydroxylase domain 2) plays an important role in cell 26 hypoxia adaptation by regulating the stability of HIF proteins (HIF1 $\alpha$ and HIF2a) in numerous cell types including $\mathrm{T}$ lymphocytes. The role of oxygen sensor on immune cells, in particular on regulatory $T$ cell (Treg) function, has not been fully elucidated. The purpose of our study was to evaluate the role of PHD2 in the regulation of Treg phenotype and function. We demonstrate herein that selective ablation of PHD2 expression in Treg (PHD2 ${ }^{\Delta T r e g}$ mice) leads to a spontaneous systemic inflammatory syndrome, as evidenced by weight loss, development of a rectal prolapse, splenomegaly, shortening of the colon and elevated expression of IFN- $\gamma$ in the mesenteric lymph nodes, intestine and spleen. PHD2 deficiency in Tregs led to an increased number of activated CD4 conventional T cells expressing a Th1-like effector phenotype. Concomitantly, the expression of innate-type cytokines such as $\|11 b\|$,$12 a ,$ $1 / 12 b$ and Tnfa was found to be elevated in peripheral (gut) tissues and spleen. $\mathrm{PHD}^{\Delta \mathrm{Treg}}$ mice also displayed an enhanced sensitivity to DSS-induced colitis and to toxoplasmosis, suggesting that PHD2-deficient Tregs did not efficiently control inflammatory response in vivo, in particular those characterized by IFN- $\gamma$ production. Further analysis revealed that Treg dysregulation was largely prevented in PHD2-HIF2 $\alpha$ (PHD2-HIF2 $\alpha^{\Delta \text { Treg }}$ mice), but not in PHD2-HIF1a (PHD2-HIF1 ${ }^{\Delta \text { Treg }}$ mice) double KOs, suggesting an important and possibly selective role of the PHD2-HIF2 $\alpha$ axis in the control of Treg function. Finally, the transcriptomic analysis of PHD2-deficient Tregs identified the STAT1 pathway as a target of the PHD2-HIF2 $\alpha$ axis in regulatory T cell 46 phenotype and in vivo function.

Key words: Regulatory T cells/ Oxygen sensor/ Hypoxia inducible factor/ Inflammation 
$\mathrm{CD}^{+}$regulatory $\mathrm{T}$ cells (Tregs), accounting for approximately $5-10 \%$ of total circulating $\mathrm{CD}^{+} \mathrm{T}$ cells, represent a critical subset of $\mathrm{T}$ lymphocytes involved in immune homeostasis. Through a broad set of effector mechanisms, these cells contribute to immune tolerance to self-constituents and to mucosal antigens derived from the commensal microflora and food ${ }^{1,2}$. Tregs also participate in the resolution of inflammatory responses ${ }^{3}$ and play an important role in maternal immunotolerance against the semi-allogeneic fetus ${ }^{4}$. While critical to maintain tissue integrity, excessive activation of Tregs impedes adequate immune responses to tumors and pathogens, suggesting a tight control of their suppressive activity and tissue localization ${ }^{5-7}$. Although uniformly characterized by the expression of the lineage-specific, Foxp3 transcription factor $^{1}$, regulatory $T$ cells display a wide range of phenotypic and functional properties that allow them to migrate to specific sites and suppress a variety of immune reactions including inflammatory ${ }^{8}$ and humoral responses ${ }^{9}$. Although diverse, the mechanisms whereby Tregs antagonize the activity of immune effectors are largely paracrine in nature $^{10}$. Short-range suppressive mechanisms include competition for nutrients and/or growth factors (mostly cytokines), secretion of immunosuppressive factors and direct, contact-mediated, inactivation of antigen presenting cells ${ }^{11}$. These findings suggest that Tregs have to adapt to multiple lymphoid and non-lymphoid environments and suppress immune responses in a context and tissue-dependent fashion ${ }^{12,13}$.

Oxygen represents an essential component of cellular bioenergetics and biochemistry. Because oxygen tension varies according to tissues and pathophysiological states ${ }^{14}$, cells need to adapt to fluctuations in oxygen availability in order to maintain an adequate functional and metabolic status. Of note, low oxygen availability (hypoxia) plays a critical role in the pathophysiology of many immune disorders ${ }^{15,16}$. Inflammation, in particular, is thought to reduce oxygen availability to tissues by affecting microvascular form and function, and through the recruitment of highly oxygen consuming inflammatory cells producing NADPH oxidase-derived reactive oxygen species ${ }^{17}$.

Immune cells patrolling through lymphoid and non-lymphoid tissues need therefore to readily adapt to varying oxygen concentration levels in order to exert their function ${ }^{18}$, suggesting an important role for oxygen sensors in immune regulation. Several hypoxiasensitive pathways are known to enable single cell survival in low oxygen settings. In particular, reduced oxygen levels are directly sensed by a family of oxygen-dependent prolyl hydroxylases (PHD encoded by Egln gene, comprising three members) ${ }^{19}$, although other mechanisms mediated by oxygen-sensitive histone lysine demethylases (KDM) and the cysteamine dioxygenase/ $\mathrm{N}$-degron pathway have been recently uncovered $^{20}$. Hypoxia-inducible factors (HIFs), a set of evolutionary conserved 
transcriptional regulators, represent the best-described substrates of PHDs. These factors are heterodimers composed of a HIFa subunit whose stability is directly controlled by oxygen availability, and a constitutively expressed HIF1 $\beta$ subunit (also known as ARNT) ${ }^{21}$. Following the initial characterization of the first member of HIFa family (HIF1 $\alpha$ ), two additional members, HIF2 $\alpha$ and HIF3 $\alpha$ have been identified and shown to be similarly regulated by $\mathrm{O}_{2}$ availability and to bind to $\mathrm{HIF} 1 \beta^{22}$. In normoxia, PHDs, whose affinity for oxygen is low and comparable to atmospheric concentrations, catalyze the prolyl-hydroxylation of HIFa subunits ${ }^{23}$. This post-translational modification allows recognition and ubiquitination of HIFa subunits by the E3 ubiquitin ligase Von Hippel-Lindau protein ( $\mathrm{pVHL}$ ) and subsequent degradation by the proteasome ${ }^{24}$. In hypoxia, non-hydroxylated alpha subunits escape degradation, and translocate to the nucleus where they bind to constitutively expressed and stable beta subunits to constitute an active heterodimer able to regulate gene expression. This process promotes transcriptional regulation of numerous genes ultimately leading to increased oxygen supply (such as angiogenesis) and promotion of anaerobic metabolism ${ }^{25}$.

Multiple levels of complexity of this major regulatory axis have been recently uncovered. As previously suggested, the presence of several members of the PHD and HIF families suggests specialized functions of PHD-HIF pairs during ontogeny and in selected tissues ${ }^{26}$. In particular, while HIF1a appears as ubiquitously expressed in all metazoans, HIF2 $\alpha$ represents a late acquisition of vertebrates, displaying a more restricted tissue expression pattern ${ }^{27}$. Although these factors bind to similar sequence motifs (hypoxia response elements or HREs) and regulate the expression of a shared set of genes, both HIF1 $\alpha$ and HIF2 $\alpha$ specific gene targets have been identified in multiple tissues ${ }^{25,28,29}$. Further complexity in this pathway stems from the possible occurrence of additional, non-HIF-related, PHD substrates ${ }^{30-37}$, a set of findings that 112 however has not been confirmed in more rigorous in vitro settings using well defined 113 synthetic substrates ${ }^{38}$.

Hypoxia plays a dual role in inflammation and in the regulation of immune responses. In most settings, hypoxia promotes inflammation, while in some instances, such as in tumor sites, low oxygen levels generally cause unresponsiveness of immune effectors, thus favoring tumor growth. The often-opposing effects displayed by HIF activation on the activity of immune cells equally match this complexity ${ }^{39}$. Previous work has indeed highlighted the important role of the PHD-HIF axis in regulating both innate and adaptive immune effectors ${ }^{26}$. The role of HIF1 $\alpha$ in regulating $T$ cell activity has been described in many studies, and mainly linked to the capacity of this hypoxia-induced transcription factor to promote glycolysis (for a review see McGettrick \& O'Neill ${ }^{40}$ ). Accordingly, HIF1a expression favors the development of highly glycolytic inflammatory Th17 cells, while inhibiting the development of Tregs which rely mostly on aerobic metabolism ${ }^{41}$. HIF1a 
126 Rorc $^{42}$. The role of HIF1a in Th1 development appears as more complex, and context127 dependent. Hypoxia decreases IFN-y production of Th1-like cells in a HIF1a dependent 128 fashion $^{43}$, while sustained expression of this transcription factor in normoxia (as 129 observed in mice lacking PHDs expression ${ }^{44}$ ) leads to an increase in IFN- $\gamma$ secreting $130 \mathrm{CD}^{+} \mathrm{T}$ cells. Of note, expression of HIF1a can be upregulated in normoxia both by $131 \mathrm{TCR}^{45}$ and cytokine-initiated signals ${ }^{42}$, confirming that HIF1 $\alpha$ may play a role in Th1 cells development both in hypoxia and normoxia.

The role of hypoxia-induced factors in Treg development and function is presently not fully elucidated. As previously discussed, HIF1a-deficiency improves Treg cell development, possibly a consequence of the limited requirement for glycolysis of this cell subset ${ }^{41}$. However, hypoxia promotes Foxp3 expression in a HIF1a dependent fashion ${ }^{46}$ (and expression of HIF1a is required for adequate regulatory T cell function ${ }^{47}$ ). Similarly, a recent report has identified HIF2 $\alpha$ as an important mediator of Treg function in vivo, further stressing the important role of these hypoxia-induced factors in the control of in vivo inflammatory manifestations ${ }^{48}$. In agreement with these conclusions, PHDs proteins have also been shown to play a role in the differentiation of peripheral (but not thymic-derived) Tregs ${ }^{44}$. Expression of these proteins appears to redundantly regulate Th1 vs iTreg development, mostly by limiting the accumulation of HIF1a. In contrast to this study, a recent publication has highlighted a selective role of the PHD2 isoform in the regulation of Treg function ${ }^{49}$. ShRNA mediated knockdown of PHD2 expression in Foxp3-expressing cells (PHD2-KD Tregs) led to a systemic inflammatory syndrome characterized by mononuclear cell infiltration in several organs. PHD2-KD Tregs displayed reduced suppressive capacities both in vitro and in vivo, suggesting an important and intrinsic role of PHD2 in this cell subset. Of interest, loss of HIF2 $\alpha$ expression reversed the phenotype of these mice bearing PHD2-KD Tregs, suggesting an important role of the PHD2-HIF2 $\alpha$ axis in regulating Treg function.

To better delineate the role of PHD2, HIF1 $\alpha$ and HIF2 $\alpha$ in the regulation of Treg development and function, we have generated a set of conditional mouse strains lacking expression of these hypoxia responsive proteins in Foxp $3^{+}$cells. Using these tools, we confirm herein that mice in which expression of PHD2 is selectively inactivated in regulatory $\mathrm{T}$ cells display a spontaneous inflammatory syndrome characterized by altered immune homeostasis at the steady-state and high sensitivity to Th1-type inflammatory diseases. This proinflammatory phenotype was accentuated by the concomitant loss of PHD2 and HIF1a, but almost completely alleviated in mice dually deficient for PHD2 and HIF2 $\alpha$. Transcriptome analysis confirmed a marginal role for HIF1a-dependent enhanced glycolysis in the regulation of Treg function and allowed us to identify STAT1 as a potential target of the PHD2-HIF2 $\alpha$ axis in maintaining immune homeostasis and preventing excessive Th1-mediated inflammation. 
168 Deletion of PHD2 in Tregs leads to a systemic, type-1-like, inflammatory syndrome associated to altered Treg numbers and phenotype.

170 Based on the predominance of Egln1 (PHD2) expression in Tregs over other 171 members of the prolyl hydroxylases family, we generated a mouse strain lacking PHD2 172 expression in Tregs (identified as $\mathrm{PHD}^{\Delta \mathrm{Treg}}$ ) (Figure $\mathbf{1}$ and Figure 1-figure 173 supplement 1), as described in the Methods section. These mice displayed a strongly reduced expression of Egln1 mRNA in Tregs, while retaining control level expression of 175 this enzyme in other, non-Treg spleen and peripheral lymph node cells (Figure 1-figure 176 supplement 1). Upregulation of GLUT1 expression, a well-known target of HIF1a, was also only found in Foxp3-expressing cells in these mice, further supporting the selective depletion of PHD2 in Tregs vs T convs (Figure 1-figure supplement 1). While fertile and viable, over $70 \%$ of these mice developed a spontaneous inflammatory syndrome, characterized by weight loss, episodes of anal prolapse, reduced colon length, splenomegaly and hemorrhagic abdomen (Figure 1a-e). This last feature is most likely due to an increased blood hematocrit (with enhanced numbers of circulating red blood cells) associated to an elevation in vascular permeability, as shown in Figure 1-figure supplement 2. Although the frequency of $\mathrm{CD}^{+}$and $\mathrm{CD}^{+}$conventional $\mathrm{T}$ lymphocytes (see Figure 1-figure supplement $\mathbf{3}$ for gating strategy) in several lymphoid organs were not significantly altered in PHD2 ${ }^{\Delta T r e g}$ mice (Figure 1f), the total number of CD4 ${ }^{+}$cells was increased in the peripheral lymphoid organs of these mice (Figure 1-figure supplement 4). Moreover, these lymphocytes displayed clear signs of spontaneous activation, as evidenced by the significant increase in the expression of markers (i.e CD44) associated to an effector-like phenotype (Figure 1g, h). Confirming these findings, intracellular staining of short-term stimulated $T$ cells (using pharmacological agents bypassing TCR signaling) revealed an increased capacity of conventional T cells from $\mathrm{PHD} 2^{\Delta T r e g}$ mice to produce IFN- $\gamma$, while retaining control-like production of IL-17 (Figure 1i). The ex-vivo evaluation of mRNA abundance in whole, unfractionated, $\mathrm{mLNs}$ similarly showed a significantly elevated expression of type 1-associated adaptive and innate cytokines including Ifng, $/ / 1 \mathrm{~b}$, both $/ 112$ subunits and Tnfa (Figure 1j). Overall, these observations point to the establishment of a Th1-like, pro-inflammatory environment in mice possessing PHD2-deficient Tregs.

Much to our surprise, flow cytometric analysis of lymphoid organs from naive animals revealed an increased frequency of Treg cells in the spleen, lymph nodes and lamina propria of PHD2 ${ }^{\Delta T r e g}$ mice, when compared to control animals (Figure 2a). To evaluate the possible influence of PHD2 deletion on Treg development, thymic cell suspensions were analyzed for the expression of early Treg markers including Foxp3, CD25 and 
$\mathrm{CD} 24^{50}$. Recent studies have revealed that mature Foxp3 ${ }^{\text {high }} \mathrm{CD} 25^{+}$Tregs can differentiate from two distinct thymic precursors identified as respectively $\mathrm{CD}^{2} 5^{+}$Foxp $3^{-}$ and CD25 Foxp3 ${ }^{\text {low }}$ precursor Tregs (pre-Tregs). Analysis of thymic cell suspensions revealed an accumulation of the Foxp $3^{\text {low }}$ pre-Tregs and a reduction in the number of mature Tregs in PHD2-deficient, Foxp3-expressing cells, suggesting an early role for PHD2 in the generation of thymic-derived Tregs (Figure 2b, c). Accordingly, PHD2deficient, Foxp3-expressing cells retained higher expression of CD24 (Figure 2d), a marker associated to a thymic immature state ${ }^{50}$, further confirming a putative role for PHD2 in the development of thymic-derived Tregs. No difference in the relative frequency of Treg subsets identified by the co-expression of Foxp3 with either naive and memory markers (Figure 2e) or with master transcription factors T-bet, GATA3 or RORyt (Figure 2f) was noted in these mice. The phenotype of splenic, PHD2-deficient Tregs was however significantly altered, showing a slight, but statistically significant reduction in the expression of Foxp3 (Figure $\mathbf{2 g}$ ), accompanied by reduced expression of the CD25, ICOS, and CD44 markers and enhanced expression of PD-1 (Figure 2h). Of note, neither CTLA-4 (Figure $\mathbf{2 h}$ ) nor $\mathbf{l 1 0}$ (Figure 2i) expression was altered in PHD2-deficient Tregs. To evaluate the functional consequences of PHD2-deletion on peripheral Treg development, we generated Tregs from naive, conventional T cells using a well-established in vitro protocol. In keeping with in vivo observations, culture of CD4 ${ }^{+}$ $T$ conv from PHD2 ${ }^{\Delta T r e g}$ mice led to a consistently higher yield of Foxp3-expressing cells when activated in the presence of Treg-inducing cytokines (Figure $\mathbf{2 j}, \mathbf{k}$ ). In contrast to their in vivo counterparts, these induced Tregs displayed control level expression of Foxp3 (Figure 2l).

To evaluate whether the altered phenotype of PHD2-deficient Tregs was a cellautonomous phenomenon, heterozygous Foxp $3^{\text {cre/ }+}$ Egln $1^{\mathrm{fl} / \mathrm{fl}}$ mice in which both PHD2sufficient (YFP-negative) and PHD2-deficient (YFP-positive) Tregs co-exist were examined (Figure 3). These mice did not display any sign of inflammation or hematological dysfunction and were morphologically (cf weight, colon length and spleen size) indistinguishable from Foxp3 ${ }^{\text {cre }}$ or Foxp3 ${ }^{\text {cre/t }}$ mice (this latter strain displaying the expected 1:1 ratio of YFP-pos:YFP-neg cells). Surprisingly, WT Tregs outcompeted PHD2-deficient Tregs in all compartments examined in Foxp3 $3^{\text {cre/t }}$ Egln $1^{\text {tilfl }}$ mice (i.e. thymus, spleen, and peripheral lymph nodes, Figure 3a). A similar trend was observed following the transfer of an equal mix of WT and PHD2-deficient Tregs in Rag2-deficient mice (data not shown), strongly suggesting that PHD2 expression plays a role in Treg fitness and survival in the periphery. As previously shown in Figure 2, PHD2-deficient Tregs expressed lower levels of Foxp3, CD25 and CD44, indicative of an intrinsic role of PHD2 in regulating Treg phenotype (Figure $3 \mathbf{b}-\mathbf{e}$ ). However, expression of CTLA-4 was not altered in PHD2-deficient Tregs (Figure 3b, f). Whether the altered fitness / capacity to repopulate the periphery of PHD2-deficient Tregs is due to reduced expression of CD25 remains to be established. 
245 To evaluate the suppressive capacity of PHD2-deficient Tregs cells, ex-vivo purified 246 CD45.2 expressing Tregs from control and PHD2 ${ }^{\Delta \text { Treg }}$ mice were adoptively cotransferred into syngeneic Rag-deficient mice with CFSE-labelled, CD45.1-expressing $248 \mathrm{CD}^{+}$naive $\mathrm{T}$ lymphocytes (Figure 4a). In the absence of Tregs, transferred naive cells rapidly divided and acquired an effector-like phenotype, a well-established consequence of homeostatic proliferation in a lymphopenic environment (Figure 4b). Addition of WT Tregs in the inoculum led to a significant reduction of conventional $\mathrm{T}$ cell proliferation and phenotype switch, while PHD2-deficient Tregs appeared functionally impaired in this assay (Figure $\mathbf{4 b - d}$ ). Lack of suppressive activity of these Tregs was not a consequence of reduced viability and/or in vivo survival, as shown by the normal recovery rate of both Treg-populations at the time of assay read-out (Figure 4e). In contrast, when tested in vitro, PHD2-deficient Tregs consistently displayed a fully functional suppressive activity (Figure 4f, g).

\section{Increased susceptibility of PHD2 ${ }^{\Delta \text { Treg }}$ mice to type-1 experimental inflammation}

A series of experimental acute and chronic inflammatory models were employed to further evaluate the capacity of $\mathrm{PHD}^{\Delta \mathrm{Treg}}$ mice to sustain an in vivo inflammatory challenge. We first exposed mice to a chemical-induced colitis protocol. This assay revealed an increased sensitivity of $P H D 2^{\Delta T r e g}$ mice to most DSS-induced inflammatory manifestations, including weight loss (Figure 5a), survival (Figure 5b), clinical score (Figure 5c) and colon length (Figure 5d). No difference was noted however in crypt morphology induced by DSS in both mouse strains (Figure 5e). Similar observations were made when mice were acutely infected with Toxoplasma gondii, a model of infection-induced pathology (Figure 5f). Infected PHD2 ${ }^{\Delta T r e g}$ mice displayed increased weight loss (Figure $\mathbf{5 g}$ ), reduced colon length (Figure $\mathbf{5 h}$ ) and increased frequency of activated cells characterized by an effector-like phenotype (Figure 5i) and IFN- $\gamma$ secretion capacity (Figure $5 \mathbf{j}$ ). Infected $\mathrm{PHD}^{\mathrm{\Delta Treg}}$ mice also displayed a decrease in Treg T-bet ${ }^{+}$frequency, a population known to control Th1 inflammation during toxoplasmosis $^{51}$ (Figure 5k). Overall, PHD2 ${ }^{\Delta T r e g}$ mice displayed an uncontrolled expansion of Th1-like cells following experimental toxoplasmosis. In contrast, both PHD2-deficient and sufficient mouse strains were equally sensitive to enteritis induced upon injection of anti-CD3 antibodies (Figure 5-figure supplement 1), a model known to induce the predominant expansion of Th17-like, inflammatory effectors in vivo ${ }^{52}$. The role of uncontrolled IFN-y secretion in mediating the pro-inflammatory status of this mouse strain was further confirmed by the observation that ubiquitous loss of Ifng gene expression largely reversed the phenotypical and cellular altered status of PHD2 ${ }^{\Delta T r e g}$ mice (Figure 5-figure supplement 2). 
283 Concomitant loss of HIF2 $\alpha$, but not HIF1 $\alpha$, expression partially corrects the pro284 inflammatory phenotype of PHD2 ${ }^{\Delta \text { Treg }}$ mice.

\section{Transcriptomic analysis identifies cell survival, response to chemokines and STAT1-mediated signaling as target pathways of the PHD2-HIF2 $\alpha$ axis in Tregs.} we established a series of conditional KOs mouse strains to identify the molecular pathway responsible for the decreased functional activity of PHD2-deficient Tregs at steady state (Figure 6) (see Figure 6-figure supplement 1 for strain validation). Tregselective deletion of HIF1 $\alpha$ and HIF2 $\alpha$ expression alone did not significantly alter colon length (used as a proxy for spontaneous inflammation) nor general $\mathrm{T}$ cell immune homeostasis (Figure 6-figure supplement 1). The same observation was made for double HIF1 $\alpha$ and HIF2 $\alpha$ KOs (data not shown). In marked contrast, combined deletion of PHD2 and HIF2 $\alpha$ reversed some of the inflammatory symptoms observed in $\mathrm{PHD}^{\Delta \mathrm{Treg}}$ mice, such as splenomegaly, colon length (Figure $6 \mathbf{a}, \mathbf{b}$ ) and hematocrit counts (Figure 1-figure supplement 2). Treg specific, PHD2-HIF1a double KOs were virtually indistinguishable from $\mathrm{PHD}^{\Delta T r e g}$ according to these morphological criteria. Noteworthy however, Treg-specific PHD2-HIF1a double KOs mice were born at submendelian ratios, and displayed a marked weight loss during adult life and reduced viability, indicative of a more pronounced pro-inflammatory status (data not shown). This mouse strain also displayed a tendency toward increased expansion of Th1-like cells in peripheral lymph nodes (Figure 6e). PHD2-HIF1 $\alpha$-HIF2 $\alpha$ triple KOs and PHD2-HIF2 $\alpha$ double KOs displayed a similar phenotype, establishing a predominant role for HIF2 $\alpha$ over HIF1 $\alpha$ in mediating the effects of PHD2 on the capacity of Treg to regulate immune homeostasis at rest. Similarly, lack of HIF2 $\alpha$ expression largely reversed the altered phenotype of conventional T cells induced by loss of Treg-associated PHD2 expression. Indeed, cells from double (PHD2-HIF2 $\alpha$ ) and triple (PHD2-HIF1 $\alpha-H I F 2 \alpha)$ Treg specific KOs displayed a near normal phenotype (based on CD62L and CD44 expression) and propensity to secrete IFN-y (Figure 6c-e). Finally, loss of Treg-associated expression of HIF2 $\alpha$ also reversed the expansion of Treg numbers (Figure 6f) and restored Foxp3 protein expression to near-control levels (Figure 6g).

Collectively, the previous observations suggest that the PHD2-HIF2 $\alpha$ regulatory axis confers to Tregs the capacity to control the spontaneous, type-1 like, activity of conventional $\mathrm{T}$ cells. To identify PHD2-dependent signaling pathways operating in Tregs, splenic Foxp3-expressing cells were purified from all mouse strains described in this manuscript and their transcriptome analyzed following bulk RNA-seq. A set of 532 genes were found differentially expressed between WT and PHD2-deficient Tregs (Figure 7) (a summary-list of upregulated and downregulated pathways in $\mathrm{PHD}^{\Delta \mathrm{Treg}}$ mice vs Foxp3 ${ }^{\text {cre }}$ mice is provided in Figure 7-figure supplement 1). Differential gene 
322 expression analysis between all mouse strains studied identified 1868 genes 323 differentially expressed between groups. An unsupervised clustering of the differentially 324 expressed genes led to the identification of 20 clusters, as shown in Figure 7a. To 325 identify gene clusters that were specifically involved in the immune homeostatic control 326 of naive mice, the RNA-seq data were filtered and grouped by k-mean clustering. We 327 next searched for sets of genes whose expression best correlated with an arbitrary 328 inflammatory index, established based on previously described findings (mostly colon 329 length, splenomegaly and spontaneous conventional $\mathrm{T}$ cell activation status) and 330 summarized in Figure $\mathbf{7 b}$. In particular, while concomitant deletion of HIF1a expression 331 worsened the inflammatory status of PHD2 ${ }^{\Delta T r e g}$ mice, loss of HIF2 $\alpha$ expression mitigated 332 most inflammatory-related parameters at rest. We therefore clustered genes according 333 to a "gradient of disease severity" and grouped them in sets of gene whose expression 334 decreased (cluster 10, Figure 7c) or increased (cluster 11, Figure 7d) accordingly. 335 Gene ontology analysis of these clustered gene sets revealed the following. Reduced 336 expression of cell death-related and gain of survival-associated gene expression correlated with the increased frequency of Tregs in the corresponding mouse strains (Figure 7c, d). Not surprisingly, the expression of genes associated with antiinflammatory responses was gradually lost according to the same severity gradient. Finally, genes, associated with $\mathrm{T}$ cell migration, including several chemokine receptors, also displayed an ordered loss of expression along the same gradient (Figure 7c). For comparison purposes, genes whose expression was restored to control levels upon combined deletion of PHD2 and HIF1a were also examined. As expected from previously published findings, these HIF1a-dependent biological pathways included glycolysis and angiogenesis (Figure 7e).

Ingenuity Pathway Analysis (IPA) was performed in order to identify possible upstream regulators affecting expression of downstream genes identified in clusters 10 and 11. This analysis led to the identification of STAT1 as a putative upstream transcription factor regulating the expression of a set of genes whose expression was altered in PHD2-deficient Tregs (Figure 8a). Since Stat1 mRNA expression was not altered by PHD2 invalidation (as revealed by RNA-Seq analysis), we tested the capacity of STAT1 to undergo phosphorylation in response to IFN- $y$. This set of experiments led to the identification of a defective, accumulation of phopho-STAT1 in PHD2-deficient Tregs (Figure $\mathbf{8 b}, \mathbf{c}$ ), while the levels of total STAT1 protein appeared unaffected (Figure 8d). Noteworthy, concomitant deletion of HIF2 $\alpha$ restored a near control response to IFN-y in PHD2 deficient Tregs (Figure 8b-d). In keeping with the observed pro-inflammatory phenotype associated with these mouse strains, conventional $T$ cells from PHD2 ${ }^{\Delta T r e g}$ mice displayed an augmented response to IFN-Y (as judged by PSTAT1 accumulation), partially reversed in mice bearing Tregs lacking both PHD2 and HIF2 $\alpha$ expression (Figure $\mathbf{8 b}$, left panel). Finally, the proportion of Tregs expressing CXCR3, a well described STAT1-dependent chemokine receptor ${ }^{53}$ was reduced in a HIF2 $\alpha$ - 
362 dependent manner in PHD2-deficient Tregs (Figure 8e), further strengthening the 363 conclusion that PHD2 expression controls the response of Tregs to IFN-y.

\section{Discussion}

The present study highlights the important role of the prolyl-hydroxylase PHD2 in the regulation of Treg development and function. Deletion of PHD2 in developing, Tregs led to the accumulation of the subset of Treg precursor characterized by low expression of Foxp3, at the expenses of the mature, Foxp $3^{+} \mathrm{CD} 25^{+}$Treg population (Figure 2c). PHD2-deficient Tregs were nevertheless found in increased numbers in vivo at steady state (Figure 2a), albeit with an altered phenotype. In particular, the expression of molecules known to be associated with optimal suppressive activity (such as Foxp3, ICOS and CD25) ${ }^{1,54,55}$ was marginally decreased, while expression of PD-1, a marker associated with altered functional activity of many immune cells including Tregs ${ }^{56,57}$ was augmented. Of note, other molecules known to play an important role in Treg function were expressed at optimal levels (cf CTLA4 and IL-10).

Although we have not specifically addressed the role of PHD2 in thymic vs peripherally induced Tregs, it is noteworthy that lack of PHD2 expression altered Treg thymic development, without any major effect on the generation of iTreg in vitro, suggesting a more pronounced role of PHD2 on thymic vs peripherally generated Tregs, although this conclusion should be strengthened by additional studies.

Mice selectively lacking PHD2-expression in Treg displayed a proinflammatory phenotype (with early manifestations of gastrointestinal tract inflammation), associated to an elevated hematocrit, enhanced vascular permeability and an altered homeostatic profile of splenic conventional T cells. In marked contrast to WT Tregs, PHD2-deficient Tregs express relatively high levels of Vegfa transcripts (as established from RNAseq analysis), a factor known to both increase vascular permeability ${ }^{58}$, and induce erythropoietin (Epo) production from perivascular stromal cells in several organs ${ }^{59}$. Alternatively, since expression of the YFP-Cre allele was found in a minor, proportion of CD45-negative cells in all organs examined (see Figure 8-figure supplement 1). PHD2-deletion could result in elevated expression of Epo from a non-hematopoietic source. In any event, analysis of several organs (including spleen, liver and kidney) from PHD2 $^{\text {Treg }}$ mice failed to reveal any increase in Epo mRNA accumulation (our own unpublished observations), and further studies will therefore be required to identify the mechanism underlying the observed hematological alterations in $\mathrm{PHD}^{\Delta \mathrm{Treg}}$ mice. Several observations however strongly indicate that the major, proinflammatory phenotype observed in these mice were due to the specific impairment in Treg function consequent to the loss of PHD2 activity. Despite previous reports describing the stochastic activity of the Foxp3-Cre-YFP allele in non-Tregs leading to the recombination 
401 of some, but not all alleles ${ }^{60}$, we consistently found a control-level expression of PHD2 in 402 all conventional T cell subset tested (Figure 1-figure supplement 1). Secondly, co403 transfer of highly purified Tregs with WT naive CD4 ${ }^{+}$conventional target cells clearly demonstrated an intrinsic role of PHD2 in regulating Treg function. Finally, and this will be discussed further below, mice bearing double PHD2-HIF2 $\alpha$-deficient Tregs recover a near-control phenotype, further excluding a major influence of the genetic background on the observed phenotype. Our observations confirm and further extends observations from a study published during completion of our work ${ }^{49}$, indicating a specific, nonredundant role for PHD2 in controlling Treg activity in vivo.

410 Based on the notion that hypoxia-induced factors represent major substrates of PHD2, we generated a series of mouse strains to evaluate the relative role of HIF1 $\alpha$ and HIF2 $\alpha$ in regulating Treg phenotype and function. The combined loss of PHD2 and HIF2 $\alpha$ but not HIF1 $\alpha$, corrected some, but not all abnormalities found in the PHD2 ${ }^{\Delta T r e g}$ mouse strain. To uncover the mechanism whereby the PHD2-HIF2 $\alpha$ axis regulates the capacity of Tregs to exert a homeostatic control over conventional $\mathrm{T}$ cells, a large transcriptomic analysis was undertaken. To be able to isolate genes specifically involved in the control of Treg activity in naive animals, we took advantage of the graded proinflammatory status of the mouse strain generated (based on colon length and spontaneous activation of Tconv cells, see Figure 6) to identify gene clusters whose expression correlated with Treg-mediated immune homeostasis. This analysis led us to identify important pathways providing mechanistic insights into the role of the PHD2HIF2 $\alpha$ axis in Treg biology. In particular, loss of PHD2 led to an altered expression of genes coding for chemokine receptors and adhesion molecules, suggesting a potential role of this oxygen sensor in chemotaxis and traffic. This conclusion is of particular interest in light of two observations described in this study. As previously discussed, $\mathrm{PHD}^{\Delta \text { Treg }}$ mice displayed a selective expansion of Th1-prone effectors in all lymphoid organs examined (Figure 1). Accordingly, ubiquitous loss of IFN-y expression strongly attenuated the pro-inflammatory phenotype of mice with PHD2-deficient Tregs (Figure 5-figure supplement 2), thus suggesting a specific role for PHD2 in endowing Tregs to control Th1-like immune responses in vivo. Secondly, the IPA analysis conducted on the transcriptomic data led to the identification of STAT1 as a potential common regulator of many genes whose expression was under the control of the PHD2-HIF2 $\alpha$ axis, including in particular CXCR3 ${ }^{53,61}$. Based on well-described role for Treg-expressed CXCR3 in modulating Th1-like responses in vivo ${ }^{62,63}$, and the reduced expression of this chemokine receptor described in the present study (Figure 8e), it is tempting to speculate that the reduced capacity of PHD2-deficient Tregs to control Th1 responses is a consequence of an altered STAT1-signaling pathway, leading to reduced CXCR3 expression. It is noteworthy that response to CXCR3 ligands has been recently shown to determine the precise positioning of effector and memory CD8 cells in peripheral lymph 
441 since the expression of many potential chemokine receptors (including CXCR4, known 442 to exert inhibitory function over other chemokine receptors ${ }^{65}$ ) and adhesion molecules 443 (such as Ly6a or CD44) appears under the control of the PHD2-HIF2 $\alpha$ axis in Tregs. 444 Whether altered positioning of Tregs within lymphoid organs represents an important factor contributing to the proinflammatory phenotype of $\mathrm{PHD} 2^{\Delta \mathrm{Treg}}$ mice remains however to be thoroughly examined. Similarly, the potential mechanistic link between HIF2 $\alpha$ and STAT1 activation remains to be firmly established by further investigations.

$448 \quad$ Collectively, the observations reported in this study demonstrate a non-redundant role for PHD2 in controlling survival, phenotype, migration properties and the capacity of Tregs to control Th1-like responses. These biological responses appear under the control of HIF2 $\alpha$, and largely independent of HIF1 $\alpha$-regulated metabolic pathways. Although the role of the PHD2-HIF2 $\alpha$ axis has been previously highlighted by Yamamoto and colleagues using an alternative, shRNA-based approach ${ }^{49}$, our observations do not fully concur with the previous study on two grounds. First, in contrast to PHD2 knockdown (PHD2-KD) cells, PHD2-genetically deficient Tregs retained full suppressive capacities in vitro. Secondly, no sign of reversal to an effector state were found in PHD2$\mathrm{KO}$ regulatory $\mathrm{T}$ cells, whereas downregulation of PHD2 expression led to an increased expression of T-bet, GATA-3 and TNFa. Notably, PHD2-KD Tregs were able to induce skin-graft rejection in the absence of bona-fide effector cells, suggesting a possible acquisition of effector function by these cells. Although these observations are compatible with a possible gene-dosage effect of PHD2 on Treg biology, further studies are needed to identify the mechanism at work in these two experimental models.

In any events, both studies concur in identifying a possible deleterious role of HIF2 $\alpha$ overactivation in the control of regulatory $T$ cell function. These findings appear at odds with a recent publication by Tzu-Sheng Hsu and colleagues in which deletion of HIF2a, but not HIF1a, expression was found to negatively affect Treg function ${ }^{48}$. Of note, concomitant deletion of both HIF1 $\alpha$ and HIF2 $\alpha$ restored the suppressive activity of Tregs $^{48}$. An elegant hypothesis, put forward by these authors, may help reconcile some of these apparently contradictory observations. Most experimental evidence concurs with a dual role of HIF1a in Treg differentiation and stability. In setting of sub-optimal Treg-inducing conditions, HIF1a may promote adequate expression of Foxp3 by differentiating Tregs. Once the Treg phenotype has been fully acquired, HIF1a protein expression is reduced following interaction with Foxp $3^{47}$, thus explaining the relative lack of influence of HIF1 $\alpha$ on differentiated Tregs. As a consequence, HIF1a-KO Tregs retain full suppressive activity ${ }^{48}$. The interaction between HIF1a and Foxp3 can however also lead to Foxp3 protein degradation, and thus Treg instability. Therefore, forced stabilization of HIF1a (such as observed in triple PHD KOs ${ }^{44}$ or pVHL-deficient Tregs ${ }^{66}$ ) leads to loss of Foxp3 expression and Treg identity and acquisition of pro-inflammatory functions. Inflammation observed in these mouse strains can be largely attributed to the 
pro-inflammatory influence of ex-Tregs. As discussed for HIF1 $\alpha$, HIF2 $\alpha$ also appears to 482 regulate Treg stability, albeit in a different direction. Despite a normal phenotype at rest, 483 mice displaying HIF2 $\alpha$-deficient Tregs were largely defective in suppressing 484 inflammation in the gut and in the lungs ${ }^{48}$. This pro-inflammatory phenotype was largely explained by the HIF1a-dependent reprogramming of HIF2 $\alpha$-deficient Tregs into IL-17 secreting cells. Collectively, the available literature points to a central role for HIF1 $\alpha$ in determining Treg stability and function in vivo. Depending on the biological pathway leading to its increased expression and/or protein stabilization, HIF1 $\alpha$ promotes the differentiation of Tregs into IFN- $y$ (in triple PHD KOs or pVHL-deficient Tregs) or IL-17 (in HIF2a-deficient Tregs) secreting cells. Although the mechanism underlying the acquisition of Th1 vs Th17-like profiles in these models remains to be established, the induction of a glycolytic metabolism is probably instrumental in mediating Treg instability ${ }^{67}$.

In the present study, loss of HIF1a expression did not revert the phenotype of PHD2HIF2 $\alpha$-deficient Tregs, despite reestablishing a control-like expression of pro-glycolytic genes (Figure 7e). Accordingly, PHD2-deficient Tregs did not acquire the capacity to produce pro-inflammatory cytokines (Figure 1-figure supplement 1), nor displayed any significant loss of Foxp3 expression upon in vitro culture (Figure $\mathbf{2 k}$, I) or in vivo transfer (Figure 4e). Thus, the available evidence suggests that in PHD2-sufficient cells, HIF2a allows adequate Treg function by negating the influence of HIF1 $\alpha$ on Foxp3-expression, while overactivation of HIF2 $\alpha$ activity secondary to the loss of PHD2 expression leads to altered Treg phenotype, most probably via a STAT1-dependent pathway.

Considering the specific role of PHD2, it is worth mentioning that both the transcriptomic data and our own unpublished observations (indicating an increased sensitivity of triple PHD2-HIF1a-HIF2a Tregs specific KO mice to chemical induced colitis) suggest that while the capacity of Tregs to control tissue homeostasis in the naive state is under the predominant control of the PHD2-HIF2 $\alpha$ axis, other, non-HIFs PHD2-substrates ${ }^{30-37}$ probably play an important role in Treg biology under strong inflammatory settings. Finally, the present study suggests that some caution should be exerted in the administration of PHD inhibitors presently considered for the treatment of renal anemia ${ }^{68}$, inflammatory bowel diseases ${ }^{69}$ as well as Parkinson's disease ${ }^{70}$, as these compounds may display some pro-inflammatory effects via the alteration of Treg phenotype and function in vivo. 


\section{Methods}

\section{Key Resources Table}

\begin{tabular}{|c|c|c|c|c|}
\hline $\begin{array}{l}\text { Reagent type } \\
\text { (species) or } \\
\text { resource }\end{array}$ & Designation & $\begin{array}{l}\text { Source or } \\
\text { reference }\end{array}$ & Identifiers & $\begin{array}{l}\text { Additional } \\
\text { information }\end{array}$ \\
\hline $\begin{array}{l}\text { Genetic reagent } \\
\text { (M. musculus) }\end{array}$ & C57BL/6 & Envigo & $\begin{array}{l}\text { RRID:MGl:5658 } \\
455\end{array}$ & $\begin{array}{l}\text { Horst, The } \\
\text { Netherlands }\end{array}$ \\
\hline $\begin{array}{l}\text { Genetic reagent } \\
\text { (M. musculus) }\end{array}$ & $E g \ln 1^{\mathrm{f} / \mathrm{f}}$ & $\begin{array}{l}\text { The Jackson } \\
\text { Laboratory }\end{array}$ & $\begin{array}{l}\text { RRID:IMSR_NM } \\
\text {-CKO-2100497 }\end{array}$ & $\begin{array}{l}\text { P. Carmeliet } \\
\text { (VIB-KULeuven) }\end{array}$ \\
\hline $\begin{array}{l}\text { Genetic reagent } \\
\text { (M. musculus) }\end{array}$ & $\begin{array}{l}\text { Foxp3-Cre- } \\
\text { YFP }\end{array}$ & $\begin{array}{l}\text { PMID: } \\
18387831\end{array}$ & $\begin{array}{l}\text { RRID:IMSR_JA } \\
\text { X:016959 }\end{array}$ & $\begin{array}{l}\text { A. Liston } \\
\text { (KULeuven) }\end{array}$ \\
\hline $\begin{array}{l}\text { Genetic reagent } \\
\text { (M. musculus) }\end{array}$ & $\begin{array}{l}\text { Hif1a }^{\mathrm{f} / \mathrm{f}} \\
\text { (Hif1 atm3Rsjo/ } \\
\text { J) }\end{array}$ & $\begin{array}{l}\text { The Jackson } \\
\text { Laboratory }\end{array}$ & $\begin{array}{l}\text { RRID:IMSR_JA } \\
\text { X:007561 }\end{array}$ & $\begin{array}{l}\text { F. Bureau (Liege } \\
\text { University) }\end{array}$ \\
\hline $\begin{array}{l}\text { Genetic reagent } \\
\text { (M. musculus) }\end{array}$ & $\begin{array}{l}\text { Epas }^{\mathrm{f} / \mathrm{f}} \\
\text { (Epas1tm1Mcs } \\
/ \mathrm{J})\end{array}$ & $\begin{array}{l}\text { The Jackson } \\
\text { Laboratory }\end{array}$ & $\begin{array}{l}\text { RRID:IMSR_JA } \\
\text { X:008407 }\end{array}$ & $\begin{array}{l}\text { J.A. Lopez } \\
\text { (Madrid } \\
\text { University) }\end{array}$ \\
\hline $\begin{array}{l}\text { Genetic reagent } \\
\text { (M. musculus) }\end{array}$ & Ifng $^{-1-}$ & $\begin{array}{l}\text { The Jackson } \\
\text { Laboratory }\end{array}$ & $\begin{array}{l}\text { RRID:IMSR_CA } \\
\text { RD:178 }\end{array}$ & $\begin{array}{l}\text { Bar Harbor, ME, } \\
\text { USA }\end{array}$ \\
\hline $\begin{array}{l}\text { Genetic reagent } \\
\text { (M. musculus) }\end{array}$ & $\begin{array}{l}\text { CD45.1 } \\
\text { (B6.SJL- } \\
\text { Ptprca } \\
\text { Pepcb/BoyJ) }\end{array}$ & $\begin{array}{l}\text { The Jackson } \\
\text { Laboratory }\end{array}$ & $\begin{array}{l}\text { RRID:IMSR_JA } \\
\text { X:002014 }\end{array}$ & $\begin{array}{l}\text { Bar Harbor, ME, } \\
\text { USA }\end{array}$ \\
\hline $\begin{array}{l}\text { Genetic reagent } \\
\text { (M. musculus) }\end{array}$ & $\operatorname{Rag} 2^{/-}$ & $\begin{array}{l}\text { The Jackson } \\
\text { Laboratory }\end{array}$ & $\begin{array}{l}\text { RRID:IMSR_JA } \\
\text { X:008449 }\end{array}$ & $\begin{array}{l}\text { Bar Harbor, ME, } \\
\text { USA }\end{array}$ \\
\hline Antibody & $\begin{array}{l}\text { anti-mouse } \\
\text { CD278 (Icos)- } \\
\text { biotin } \\
\text { (C398.4A, } \\
\text { mouse } \\
\text { monoclonal) }\end{array}$ & eBioscience & $13-9949-82$ & $(1: 100)$ \\
\hline Antibody & $\begin{array}{l}\text { anti-mouse } \\
\text { CD27-PeCy7 } \\
\text { (LG.7F9, } \\
\text { mouse } \\
\text { monoclonal) }\end{array}$ & eBioscience & $25-0271-82$ & $(1: 250)$ \\
\hline Antibody & $\begin{array}{l}\text { anti-mouse } \\
\text { Foxp3-FITC } \\
\text { (FJK-16s, } \\
\text { mouse } \\
\text { monoclonal) }\end{array}$ & eBioscience & $71-5775-40$ & $(1: 100)$ \\
\hline Antibody & $\begin{array}{l}\text { anti-mouse } \\
\text { RORyt-PE } \\
\text { (B2D, mouse } \\
\text { monoclonal) }\end{array}$ & eBioscience & $12-6981-82$ & $(1: 100)$ \\
\hline Antibody & $\begin{array}{l}\text { anti-mouse T- } \\
\text { bet-PE (4B10, }\end{array}$ & eBioscience & $12-5825-82$ & $(1: 100)$ \\
\hline
\end{tabular}




\begin{tabular}{|c|c|c|c|c|}
\hline & $\begin{array}{l}\text { mouse } \\
\text { monoclonal) }\end{array}$ & & & \\
\hline Antibody & $\begin{array}{l}\text { anti-mouse } \\
\text { PD1-PECF594 } \\
\text { (J43, mouse } \\
\text { monoclonal) }\end{array}$ & $\begin{array}{l}\text { BD } \\
\text { Biosciences }\end{array}$ & $\begin{array}{l}562523 \\
\text { RRID : } \\
\text { AB_2737634 }\end{array}$ & $(1: 100)$ \\
\hline Antibody & $\begin{array}{l}\text { anti-mouse } \\
\text { CXCR3-APC } \\
\text { (CXCR3-173, } \\
\text { mouse } \\
\text { monoclonal) }\end{array}$ & $\begin{array}{l}\text { BD } \\
\text { Biosciences }\end{array}$ & $\begin{array}{l}562266 \\
\text { RRID : } \\
\text { AB_11153500 }\end{array}$ & $(3: 500)$ \\
\hline Antibody & $\begin{array}{l}\text { anti-mouse } \\
\text { CD24- } \\
\text { PECF594 } \\
\text { (M1/69, mouse } \\
\text { monoclonal) }\end{array}$ & $\begin{array}{l}\text { BD } \\
\text { Biosciences }\end{array}$ & $\begin{array}{l}562477 \\
\text { RRID : } \\
\text { AB_11151917 }\end{array}$ & $(1: 100)$ \\
\hline Antibody & $\begin{array}{l}\text { anti-mouse } \\
\text { CD25-BB515 } \\
\text { (PC61, mouse } \\
\text { monoclonal) }\end{array}$ & $\begin{array}{l}\text { BD } \\
\text { Biosciences }\end{array}$ & $\begin{array}{l}564424 \\
\text { RRID : } \\
\text { AB_2738803 }\end{array}$ & $(1: 100)$ \\
\hline Antibody & $\begin{array}{l}\text { anti-mouse } \\
\text { CD44-PECy7 } \\
\text { (IM7, mouse } \\
\text { monoclonal) }\end{array}$ & $\begin{array}{l}\text { BD } \\
\text { Biosciences }\end{array}$ & $\begin{array}{l}560569 \\
\text { RRID : } \\
\text { AB_1727484 }\end{array}$ & $(1: 100)$ \\
\hline Antibody & $\begin{array}{l}\text { anti-mouse } \\
\text { CD4-A700 } \\
\text { (RM4-5, } \\
\text { mouse } \\
\text { monoclonal) }\end{array}$ & $\begin{array}{l}\text { BD } \\
\text { Biosciences }\end{array}$ & $\begin{array}{l}557956 \\
\text { RRID : } \\
\text { AB_396956 }\end{array}$ & $(3: 500)$ \\
\hline Antibody & $\begin{array}{l}\text { anti-mouse } \\
\text { CD8-A700 (53- } \\
6.7 \text {, mouse } \\
\text { monoclonal) }\end{array}$ & $\begin{array}{l}\text { BD } \\
\text { Biosciences }\end{array}$ & $\begin{array}{l}557959 \\
\text { RRID : } \\
\text { AB_396959 }\end{array}$ & $(3: 500)$ \\
\hline Antibody & $\begin{array}{l}\text { anti-mouse } \\
\text { CD4-PB (RM4- } \\
5, \text { mouse } \\
\text { monoclonal) }\end{array}$ & $\begin{array}{l}\text { BD } \\
\text { Biosciences }\end{array}$ & $\begin{array}{l}558107 \\
\text { RRID : } \\
\text { AB_397030 }\end{array}$ & $(1: 100)$ \\
\hline Antibody & $\begin{array}{l}\text { anti-mouse } \\
\text { CD62L-A700 } \\
\text { (MEL-14, } \\
\text { mouse } \\
\text { monoclonal) }\end{array}$ & $\begin{array}{l}\text { BD } \\
\text { Biosciences }\end{array}$ & $\begin{array}{l}560517 \\
\text { RRID : } \\
\text { AB_1645210 }\end{array}$ & $(1: 100)$ \\
\hline Antibody & $\begin{array}{l}\text { anti-mouse } \\
\text { GATA3-PE } \\
\text { (L50-823, } \\
\text { mouse } \\
\text { monoclonal) }\end{array}$ & $\begin{array}{l}\text { BD } \\
\text { Biosciences }\end{array}$ & $\begin{array}{l}560074 \\
\text { RRID : } \\
\text { AB_1645330 }\end{array}$ & $(1: 10)$ \\
\hline Antibody & $\begin{array}{l}\text { anti-mouse } \\
\text { RORyt- } \\
\text { PECF594 }\end{array}$ & $\begin{array}{l}\text { BD } \\
\text { Biosciences }\end{array}$ & $\begin{array}{l}562684 \\
\text { RRID : } \\
\text { AB_2651150 }\end{array}$ & $(1: 200)$ \\
\hline
\end{tabular}




\begin{tabular}{|c|c|c|c|c|}
\hline & $\begin{array}{l}\text { (Q31-378, } \\
\text { mouse } \\
\text { monoclonal) }\end{array}$ & & & \\
\hline Antibody & $\begin{array}{l}\text { anti-mouse } \\
\text { STAT1 } \\
\text { (pY701)- } \\
\text { A488(4a, } \\
\text { mouse } \\
\text { monoclonal) }\end{array}$ & $\begin{array}{l}\text { BD } \\
\text { Biosciences }\end{array}$ & $\begin{array}{l}612596 \\
\text { RRID : } \\
\text { AB_399879 }\end{array}$ & $(1: 10)$ \\
\hline Antibody & $\begin{array}{l}\text { anti-mouse } \\
\text { IFNy-PE } \\
\text { (XMG1.2, } \\
\text { mouse } \\
\text { monoclonal) }\end{array}$ & $\begin{array}{l}\text { BD } \\
\text { Biosciences }\end{array}$ & $\begin{array}{l}554412 \\
\text { RRID : } \\
\text { AB_395376 }\end{array}$ & $(1: 100)$ \\
\hline Antibody & $\begin{array}{l}\text { anti-mouse IL- } \\
\text { 10-APC } \\
\text { (JES5-16E3, } \\
\text { mouse } \\
\text { monoclonal) }\end{array}$ & $\begin{array}{l}\text { BD } \\
\text { Biosciences }\end{array}$ & $\begin{array}{l}554468 \\
\text { RRID : } \\
\text { AB_398558 }\end{array}$ & $(1: 100)$ \\
\hline Antibody & $\begin{array}{l}\text { anti-mouse IL- } \\
17-P e r C P- \\
\text { Cy5.5 (N49- } \\
653, \text { mouse } \\
\text { monoclonal) }\end{array}$ & $\begin{array}{l}\text { BD } \\
\text { Biosciences }\end{array}$ & $\begin{array}{l}560799 \\
\text { RRID : } \\
\text { AB_2033981 }\end{array}$ & $(1: 100)$ \\
\hline Antibody & $\begin{array}{l}\text { anti-CD3 } \\
\text { antibody } \\
\text { (2c11, mouse } \\
\text { monoclonal) }\end{array}$ & BioXcell & $145-2 \mathrm{c} 11$ & $20 \mu \mathrm{g} /$ mouse \\
\hline $\begin{array}{l}\text { peptide, } \\
\text { recombinant } \\
\text { protein }\end{array}$ & $\begin{array}{l}\text { streptavidin- } \\
\text { PECy } 7 .\end{array}$ & $\begin{array}{l}\text { BD } \\
\text { Biosciences }\end{array}$ & $\begin{array}{l}\text { RRID :557598 } \\
\text { AB_10049577 }\end{array}$ & $(1: 100)$ \\
\hline $\begin{array}{l}\text { peptide, } \\
\text { recombinant } \\
\text { protein }\end{array}$ & IFN-y protein & Peprotech & $315-05$ & $50 \mathrm{ng} / \mathrm{mL}$ \\
\hline $\begin{array}{l}\text { Chemical } \\
\text { compound, drug }\end{array}$ & Evans blue & Sigma & $314-13-6$ & $0.5 \%$ \\
\hline $\begin{array}{l}\text { Chemical } \\
\text { compound, drug }\end{array}$ & Brefeldin-A & eBioscience & $00-4506-51$ & $(1: 1000)$ \\
\hline $\begin{array}{l}\text { Chemical } \\
\text { compound,drug }\end{array}$ & $\begin{array}{l}\text { Dextran } \\
\text { Sodium } \\
\text { Sulfate, colitis } \\
\text { grade }(36,000 \\
-50,000 \mathrm{Da})\end{array}$ & MP Biomedical & 160110 & $2 \%$ \\
\hline $\begin{array}{l}\text { Commercial } \\
\text { assay or kit }\end{array}$ & LIVE/DEAD kit & Invitrogen & L10119 & $(1: 1000)$ \\
\hline $\begin{array}{l}\text { Commercial } \\
\text { assay or kit }\end{array}$ & $\begin{array}{l}\text { anti-CD90.2 } \\
\text { beads MACS }\end{array}$ & Miltenyi & $130-121-278$ & $(1: 5)$ \\
\hline $\begin{array}{l}\text { Commercial } \\
\text { assay or kit }\end{array}$ & $\begin{array}{l}\text { anti-CD4 } \\
\text { beads MACS }\end{array}$ & Miltenyi & $130-117-043$ & $(1: 3)$ \\
\hline
\end{tabular}




\begin{tabular}{|c|c|c|c|c|}
\hline $\begin{array}{l}\text { Sequence-based } \\
\text { reagent }\end{array}$ & $\begin{array}{l}\text { Egln1 } \\
(P H D 2) \_F\end{array}$ & This paper & PCR primers & $\begin{array}{l}\text { AGGCTATGTCC } \\
\text { GTCACGTTG }\end{array}$ \\
\hline $\begin{array}{l}\text { Sequence-based } \\
\text { reagent }\end{array}$ & $\begin{array}{l}\text { Egln1 } \\
(P H D 2) \_R\end{array}$ & This paper & PCR primers & $\begin{array}{l}\text { TACCTCCACTT } \\
\text { ACCTTGGCG }\end{array}$ \\
\hline $\begin{array}{l}\text { Sequence-based } \\
\text { reagent }\end{array}$ & $\begin{array}{l}\text { Egln2 } \\
(P H D 1) \_F\end{array}$ & This paper & PCR primers & $\begin{array}{l}\text { TCACGTGGACG } \\
\text { CAGTAATCC }\end{array}$ \\
\hline $\begin{array}{l}\text { Sequence-based } \\
\text { reagent }\end{array}$ & $\begin{array}{l}\text { Egln2 } \\
(P H D 1) \_R\end{array}$ & This paper & PCR primers & $\begin{array}{l}\text { CGCCATGCACC } \\
\text { TTAACATCC }\end{array}$ \\
\hline $\begin{array}{l}\text { Sequence-based } \\
\text { reagent }\end{array}$ & $\begin{array}{l}E g \ln 3 \\
(P H D 3) \_F\end{array}$ & This paper & PCR primers & $\begin{array}{l}\text { AGGCAATGGTG } \\
\text { GCTTGCTAT }\end{array}$ \\
\hline $\begin{array}{l}\text { Sequence-based } \\
\text { reagent }\end{array}$ & $\begin{array}{l}\text { Egln3 } \\
(P H D 3) \_R\end{array}$ & This paper & PCR primers & $\begin{array}{l}\text { GACCCCTCCGT } \\
\text { GTAACTTGG }\end{array}$ \\
\hline $\begin{array}{l}\text { Sequence-based } \\
\text { reagent }\end{array}$ & Hif1a_F & This paper & PCR primers & $\begin{array}{l}\text { CATCAGTTGCC } \\
\text { ACTTCCCCA }\end{array}$ \\
\hline $\begin{array}{l}\text { Sequence-based } \\
\text { reagent }\end{array}$ & Hif1a_R & This paper & PCR primers & $\begin{array}{l}\text { GGCATCCAGAA } \\
\text { GTTTTCTCACA } \\
\text { C }\end{array}$ \\
\hline $\begin{array}{l}\text { Sequence-based } \\
\text { reagent }\end{array}$ & $\begin{array}{l}\text { Epas1 } \\
\text { (HIF2a)_F }\end{array}$ & This paper & PCR primers & $\begin{array}{l}\text { ACGGAGGTCTT } \\
\text { CTATGAGTTGG } \\
\text { C }\end{array}$ \\
\hline $\begin{array}{l}\text { Sequence-based } \\
\text { reagent }\end{array}$ & $\begin{array}{l}\text { Epas1 } \\
\text { (HIF2a)_R }\end{array}$ & This paper & PCR primers & $\begin{array}{l}\text { GTTATCCATTTG } \\
\text { CTGGTCGGC }\end{array}$ \\
\hline $\begin{array}{l}\text { Sequence-based } \\
\text { reagent }\end{array}$ & Ifng_F & This paper & PCR primers & $\begin{array}{l}\text { TGCCAAGTTTG } \\
\text { AGGTCAACA }\end{array}$ \\
\hline $\begin{array}{l}\text { Sequence-based } \\
\text { reagent }\end{array}$ & Ifng_R & This paper & PCR primers & $\begin{array}{l}\text { GAATCAGCAGC } \\
\text { GACTCCTTT }\end{array}$ \\
\hline $\begin{array}{l}\text { Sequence-based } \\
\text { reagent }\end{array}$ & II12a_F & This paper & PCR primers & $\begin{array}{l}\text { CCTCAGTTTGG } \\
\text { CCAGGGTC }\end{array}$ \\
\hline $\begin{array}{l}\text { Sequence-based } \\
\text { reagent }\end{array}$ & II12a_R & This paper & PCR primers & $\begin{array}{l}\text { CAGGTTTCGGG } \\
\text { ACTGGCTAAG }\end{array}$ \\
\hline $\begin{array}{l}\text { Sequence-based } \\
\text { reagent }\end{array}$ & II10_F & This paper & PCR primers & $\begin{array}{l}\text { CCTGGGTGAGA } \\
\text { AGCTGAAGA }\end{array}$ \\
\hline $\begin{array}{l}\text { Sequence-based } \\
\text { reagent }\end{array}$ & II10_R & This paper & PCR primers & $\begin{array}{l}\text { GCTCCACTGCC } \\
\text { TTGCTCTTA }\end{array}$ \\
\hline $\begin{array}{l}\text { Sequence-based } \\
\text { reagent }\end{array}$ & II17a_F & This paper & PCR primers & $\begin{array}{l}\text { ATCCCTCAAAG } \\
\text { CTCAGCGTGTC }\end{array}$ \\
\hline $\begin{array}{l}\text { Sequence-based } \\
\text { reagent }\end{array}$ & I/17a_R & This paper & PCR primers & $\begin{array}{l}\text { GGGTCTTCATT } \\
\text { GCGGTGGAGA } \\
\text { G }\end{array}$ \\
\hline $\begin{array}{l}\text { Sequence-based } \\
\text { reagent }\end{array}$ & $/ / 1 b \_F$ & This paper & PCR primers & $\begin{array}{l}\text { CAAGCTTCCTT } \\
\text { GTGCAAGTG }\end{array}$ \\
\hline $\begin{array}{l}\text { Sequence-based } \\
\text { reagent }\end{array}$ & II1b_R & This paper & PCR primers & $\begin{array}{l}\text { AGGTGGCATTT } \\
\text { CACAGTTGA }\end{array}$ \\
\hline $\begin{array}{l}\text { Sequence-based } \\
\text { reagent }\end{array}$ & II4_F & This paper & PCR primers & $\begin{array}{l}\text { ATGCACGGAGA } \\
\text { TGGATGTG }\end{array}$ \\
\hline $\begin{array}{l}\text { Sequence-based } \\
\text { reagent }\end{array}$ & I/4_R & This paper & PCR primers & $\begin{array}{l}\text { AATATGCGAAG } \\
\text { CACCTTGGA }\end{array}$ \\
\hline $\begin{array}{l}\text { Sequence-based } \\
\text { reagent }\end{array}$ & II6_F & This paper & PCR primers & $\begin{array}{l}\text { GTTCTCTGGGA } \\
\text { AATCGTGGA }\end{array}$ \\
\hline
\end{tabular}




\begin{tabular}{|l|l|l|l|l|}
\hline $\begin{array}{l}\text { Sequence-based } \\
\text { reagent }\end{array}$ & This paper $R$ & PCR primers & $\begin{array}{l}\text { GCAAGTGCATC } \\
\text { ATCGTTGTT }\end{array}$ \\
\hline $\begin{array}{l}\text { Sequence-based } \\
\text { reagent }\end{array}$ & Rp/32_F & This paper & PCR primers & $\begin{array}{l}\text { ACATCGGTTAT } \\
\text { GGGAGCAAC }\end{array}$ \\
\hline $\begin{array}{l}\text { Sequence-based } \\
\text { reagent }\end{array}$ & Rp/32_R & This paper & PCR primers & $\begin{array}{l}\text { TCCAGCTCCTT } \\
\text { GACATTGT }\end{array}$ \\
\hline $\begin{array}{l}\text { Sequence-based } \\
\text { reagent }\end{array}$ & Tnfa_F & This paper & PCR primers & $\begin{array}{l}\text { GCCTCCCTCTC } \\
\text { ATCAGTTCTA }\end{array}$ \\
\hline $\begin{array}{l}\text { Sequence-based } \\
\text { reagent }\end{array}$ & Tnfa_R $R$ & This paper & PCR primers & $\begin{array}{l}\text { GCTACGACGTG } \\
\text { GGCTACAG }\end{array}$ \\
\hline $\begin{array}{l}\text { Sequence-based } \\
\text { reagent }\end{array}$ & II12b_F & This paper & PCR primers & $\begin{array}{l}\text { ATGTGTCCTCA } \\
\text { GAAGCTAACC }\end{array}$ \\
\hline $\begin{array}{l}\text { Sequence-based } \\
\text { reagent }\end{array}$ & II12b_R & This paper & PCR primers & $\begin{array}{l}\text { CTAGGATCGGA } \\
\text { CCCTGCAGGGA } \\
\text { AC }\end{array}$ \\
\hline $\begin{array}{l}\text { Software, } \\
\text { algorithm }\end{array}$ & Prism 6 & GraphPad & $\begin{array}{l}\text { RRID:SCR_002 } \\
798\end{array}$ & Version 6.0 \\
\hline
\end{tabular}

519

520

521

522

523

524

525

526

527

528

529

530

531

532

533

534

535

536

537

538

539

540

541

542

543

544

545

Mice. C57BL/6 mice were purchased from Envigo (Horst, The Netherlands). Egln $1^{\mathrm{f} / \mathrm{f}}$ mice were provided by P. Carmeliet (VIB-KULeuven, Leuven, Belgium); Foxp3-Cre-YFP mice, developed by A. Rudensky ${ }^{71}$ were kindly provided by A. Liston (KULeuven, Leuven, Belgium); Hif1atm3Rsjo/J $\left(H i f 1 a^{\mathrm{f} / \mathrm{f}}\right)$ mice were kindly provided by $\mathrm{F}$. Bureau (Liege University, Liege, Belgium); Epas1tm1Mcs/J (Epas ${ }^{\mathrm{f} / f}$ ) mice were provided by J.A. Lopez (Madrid University, Madrid, Spain); Ifng ${ }^{-/}$, CD45.1 (B6.SJL-Ptprc ${ }^{\text {a }}$ Pepc $^{b} /$ Boy $^{J}$ ) and Rag $^{-/}$mice were obtained from The Jackson Laboratory (Bar Harbor, ME, USA). All mice were backcrossed for more than 10 generations into a C57BL/6 background and housed in individually ventilated cages. Foxp3-Cre-YFP mice were crossed with $E_{g} \ln ^{\mathrm{f} / \mathrm{f}}$, Hif1a ${ }^{\mathrm{f} / \mathrm{f}}$, Epas $^{\mathrm{f} / \mathrm{f}}$ to produce mice with Treg-specific deletion of PHD2, HIF1a, HIF2a, PHD2-HIF1a, PHD2-HIF2 $\alpha$ or PHD2-HIF1 $\alpha-H I F 2 \alpha$. Heterozygous Foxp3 ${ }^{\text {cre/+ }}$ Egnl1 $1^{\mathrm{fl} / \mathrm{fl}}$ mice were generated by crossing the Foxp3-Cre-YFP mice with Egln $1^{\mathrm{f} / \mathrm{f}} \mathrm{mice}$. All mice were used between 8 and 14 weeks of age. PHD2-sufficient mice (expressing Foxp3-Cre-YFP, or floxed forms of PHD2, HIF1a and HIF2 $\alpha$-encoding alleles and generated as littermates in our colony) were used as appropriate controls in the early stages of this work. These mice displayed a phenotype indistinguishable from WT mice and were therefore considered as a single experimental group throughout this study in order to reach statistical significance in all experiments. The experiments were carried out in compliance with the relevant laws and institutional guidelines and were approved by the Université Libre de Bruxelles Institutional Animal Care and Use Committee (protocol number CEBEA-4).

Antibodies, intracellular staining and flow cytometry. The following monoclonal antibodies were purchased from eBioscience: CD278 (ICOS)-biotin, CD27-PeCy7, Foxp3-FITC, RORyt-PE, T-bet-PE; or from BD Biosciences: PD1-PECF594, CXCR3APC, CD24-PECF594, CD25-BB515, CD44-PECy7, CD4-A700, CD8-A700, CD4-PB, 
546 CD62L-A700, GATA3-PE, RORyt-PECF594, STAT1 (pY701)-A488, IFNy-PE, IL-10547 APC, IL-17-PerCP-Cy5.5, streptavidin-PECy7. Live/dead fixable near-IR stain 548 (ThermoFisher) was used to exclude dead cells. For transcription factor staining, cells were stained for surface markers, followed by fixation and permeabilization before nuclear factor staining according to the manufacturer's protocol (Foxp3 staining buffer set from eBioscience). For cytokine staining, cells were stimulated in media containing phorbol 12-myristate 13-acetate $(50 \mathrm{ng} / \mathrm{mL}$, Sigma-Aldrich), ionomycin $(250 \mathrm{ng} / \mathrm{mL}$, Sigma-Aldrich) and brefeldin-A (1/100, eBioscience) for $3 \mathrm{~h}$. After stimulation, cells were stained for surface markers, followed by fixation and permeabilization before intracellular staining according to the manufacturer's protocol (cytokine staining buffer set from BD Biosciences). For phosphorylation staining, cells were stimulated with IFN-y ( $50 \mathrm{ng} / \mathrm{mL}$, Peprotech) for $30 \mathrm{~min}$, fixed with formaldehyde and permeabilized with methanol before staining. Flow cytometric analysis was performed on a Canto II (BD Biosciences) and analyzed using FlowJo software (Tree Star). T cell cultures. After removal of Peyer's patches and mesenteric fat, intestinal tissues were washed in HBSS $3 \%$ FCS and PBS, cut in small sections and incubated in HBSS $3 \%$ FCS containing $2,5 \mathrm{mM}$ EDTA and $72,5 \mu \mathrm{g} / \mathrm{mL}$ DTT for 30 min at $37^{\circ} \mathrm{C}$ with agitation to remove epithelial cells, and then minced and dissociated in RPMI containing liberase $\left(20 \mu \mathrm{g} / \mathrm{ml}\right.$, Roche) and DNase $\left(400 \mu \mathrm{g} / \mathrm{ml}\right.$, Roche) at $37^{\circ} \mathrm{C}$ for $30 \mathrm{~min}$. Leukocytes were collected after a 30\% Percoll gradient (GE Healthcare). Lymph nodes and spleens were mechanically disrupted in culture medium. $\mathrm{CD}^{+} \mathrm{T}$ cells were positively selected from organ cell suspensions by magnetic-activated cell sorting using CD4 beads (MACS, Miltenyi) according to the manufacturer's protocol, and purified as CD4 ${ }^{+}$ CD44 ${ }^{\mathrm{l}} \mathrm{CD} 62 \mathrm{~L}^{\mathrm{hi}} \mathrm{CD} 25^{-}$or $\mathrm{CD}^{+}{ }^{\mathrm{CD}} 44^{\mathrm{lo}} \mathrm{CD} 2 \mathrm{~L}^{\text {hi }} \mathrm{YFP}^{-}$by fluorescence activated cell sorting. $T$ cells were cultured at $37^{\circ} \mathrm{C}$ in RPMI supplemented with $5 \%$ heat-inactivated FBS (Sigma-Aldrich), 1\% non-essential amino acids (Invitrogen), $1 \mathrm{mM}$ sodium pyruvate (Invitrogen), $2 \mathrm{mM}$ L-glutamin (Invitrogen), $500 \mathrm{U} / \mathrm{mL}$ penicillin $/ 500 \mu \mathrm{g} / \mathrm{ml}$ streptomycin (Invitrogen), and $50 \mu \mathrm{M} \beta$-mercaptoethanol (Sigma-Aldrich). To generate iTreg cells, cells were cultured in 24 well plates coated with $5 \mu \mathrm{g} / \mathrm{mL}$ anti-CD3 (BioXcell, clone 145$2 \mathrm{C} 11)$ at $37^{\circ} \mathrm{C}$ for $72 \mathrm{~h}$. The culture was supplemented with anti-CD28 $(1 \mu \mathrm{g} / \mathrm{mL}$, BioXcell, clone 37.51), TGF- $\beta$ (3 ng/ml, eBioscience) and IL-2 (10 ng/mL, Peprotech) for optimal iTreg cell polarization.

Treg cell suppression assays. In vitro assay: $\mathrm{CD} 4{ }^{+} \mathrm{CD} 44^{\mathrm{lo}} \mathrm{CD} 62 \mathrm{~L}^{\mathrm{hi}} \mathrm{CD} 25^{-}$naive $\mathrm{T}$ cells were isolated from the spleen of $\mathrm{CD} 45.1^{+}$mice by cell sorting after positive enrichment for $\mathrm{CD}^{+}$cells using MACS LS columns (Miltenyi) and labelled with carboxyfluorescein diacetate succinimidyl ester (CFSE, ThermoFisher). CD4 ${ }^{+} \mathrm{YFP}^{+}$Treg cells were isolated from the spleen of $\mathrm{Foxp}^{\text {cre }}$ or $\mathrm{PHD}^{\mathrm{\Delta Treg}}$ mice by cell sorting. Splenocytes from wild-type B6 mice were depleted in T cells (anti-CD90.2 beads, MACS, Miltenyi) using MACS LS columns (Miltenyi) and used as feeder cells. $4 \times 10^{4}$ CFSE-labelled naive T cells were cultured for $72 \mathrm{~h}$ with feeder cells $\left(1 \times 10^{5}\right)$ and 
soluble anti-CD3 $(0,5 \mu \mathrm{g} / \mathrm{mL})$ in the presence or absence of various numbers of Treg 588 cells as indicated.

589 In vivo assay: $\operatorname{Rag}^{/-}$mice were injected i.v with a mixture of naive, CFSE labeled, CD4 ${ }^{+}$ 590 T cells $\left(\mathrm{CD} 45.1^{+} \mathrm{CD}^{+} \mathrm{CD} 44^{\mathrm{lo}} \mathrm{CD} 2 \mathrm{~L}^{\mathrm{hi}} \mathrm{CD} 25^{-}\right)\left(1 \times 10^{6}\right)$ and splenic Treg from Foxp3 ${ }^{\text {cre }}$ 591 or PHD2 ${ }^{\Delta \text { Treg }}$ mice $\left(3.3 \times 10^{5}\right)$. Six days after the injection, Rag2/- mice were sacrificed

DSS-induced colitis. Foxp3 ${ }^{\text {cre }}$ or PHD2 ${ }^{\Delta \text { Treg }}$ mice were provided with $2 \%$ DSS (MP Biomedical, 160110) in tap water for five days. On day 5, the DSS-containing water was replaced with normal drinking water and mice were followed during 14 days for body weight, survival, and colitis severity. Colitis severity score was assessed by examining weight loss, feces consistency and hematochezia (Hemoccult SENSA, Mckesson Medical-Surgical, 625078) as described in ref ${ }^{72}$. Colon samples were washed with PBS and rolled from the distal to proximal end, transected with a needle and secured by bending the end of the needle and fixed in fresh $4 \%$ paraformaldehyde (Sigma-Aldrich) overnight and further subjected to routine histological procedures for embedment in paraffin and hematoxylin and eosin (H\&E) staining. Tissues were analyzed and scored in a blinded fashion by an independent histopathologist and representative images were subsequently chosen to illustrate key histological findings.

Toxoplasma infection. ME-49 type II Toxoplasma gondii was kindly provided by Dr De Craeye (Scientific Institute of Public Health, Belgium) and was used for the production of tissue cysts in C57BL/6 mice previously (1-3 month) inoculated with three cysts by gavage. Animals were killed, and the brains were removed. Tissue cysts were counted and mice were infected by intragastric gavage with 10 cysts. Mice were sacrificed at day 8 after infection.

Anti-CD3 mAb-induced enteritis. Mice were injected i.p. with a CD3-specific antibody (clone 145-2C11, BioXcell $20 \mu \mathrm{g} /$ mouse) on days 0 and 2 and weighted daily. Mice were sacrificed on day 3 and cytokine production evaluated by qPCR as indicated in the figure legend.

Hematological analysis. Mice blood was obtained from the submandibular vein and collected into heparin prefilled tubes. Blood samples were analyzed using a Sysmex KX$21 \mathrm{~N}$ Automated Hematology Analyzer.

Evans blue assay._Blood vessel permeability was assesed as previously described ${ }^{73}$. Briefly, $200 \mu \mathrm{L}$ of a $0.5 \%$ sterile solution of Evans blue (Sigma) in PBS was i.v injected in mice. After $30 \mathrm{~min}$, organs were colleted, weighted and were put in formamide. After 24 hours in a $55^{\circ} \mathrm{C}$ water bath, absorbance was mesuread at $600 \mathrm{~nm}$.

RT-qPCR. RNA was extracted using the TRIzol method (Invitrogen) and reverse transcribed with Superscript II reverse transcriptase (Invitrogen) according to the manufacturer's instructions. Quantitative real-time RT-PCR was performed using the SYBR Green Master mix kit (ThermoFisher). Primer sequences were as follows: 
632 Rp/32 (F) ACATCGGTTATGGGAGCAAC; Rp/32 (R) TCCAGCTCCTTGACATTGT; $/ 11 \mathrm{~b}$

633 (F) CAAGCTTCCTTGTGCAAGTG; //1b (R) AGGTGGCATTTCACAGTTGA; $/ 110$ (F)

634 CCTGGGTGAGAAGCTGAAGA; $\quad$ /10 (R) GCTCCACTGCCTTGCTCTTA; Ifng (F)

635 TGCCAAGTTTGAGGTCAACA; Ifng (R) GAATCAGCAGCGACTCCTTT; $1 / 6$ (F)

636 GTTCTCTGGGAAATCGTGGA; $\quad 1 / 6$ (R) GCAAGTGCATCATCGTTGTT; $1 / 17 a$ (F)

637 ATCCCTCAAAGCTCAGCGTGTC; I/17a (R) GGGTCTTCATTGCGGTGGAGAG; I/12a

638 (F) CCTCAGTTTGGCCAGGGTC; /12a (R) CAGGTTTCGGGACTGGCTAAG; $/ 12 b$ (F)

639 ATGTGTCCTCAGAAGCTAACC; II2b (R) CTAGGATCGGACCCTGCAGGGAAC; Tnfa

640 (F) GCCTCCCTCTCATCAGTTCTA; Tnfa (R) GCTACGACGTGGGCTACAG; Egln1 (F)

641 AGGCTATGTCCGTCACGTTG; Egln1 (R) TACCTCCACTTACCTTGGCG; Hif1a (F)

642 CATCAGTTGCCACTTCCCCA; Hif1a (R) GGCATCCAGAAGTTTTCTCACAC; Epas1

643 (F) ACGGAGGTCTTCTATGAGTTGGC; Epas1 (R) GTTATCCATTTGCTGGTCGGC.

RNA Sequencing and analysis. All RNA-Seq analyses were performed using $\geq 2$ biological replicates. Total RNA was prepared from purified splenic Treg cells using the TRIzol method (Invitrogen). $200 \mathrm{ng}$ of total RNA was subsequently used to prepare RNA-Seq library by using TruSeq RNA sample prep kit (Illumina) according to manufacturer's instructions. Paired-end RNA sequencing was performed on a Novaseq 6000 (Illumina) (BRIGHTcore joint facility, ULB-VUB, Brussels, Belgium). Sequenced reads were aligned to the mouse genome (NCBI37/mm9) and uniquely mapped reads were used to calculate gene expression. Data analysis was performed using $\mathrm{R}$ program (Deseq2 package). Differentially expressed genes are considered significant when the FDR (false discovery rate or adjusted $p$-value) $<0.05$ and the $\log _{2} \mathrm{FC}$ (fold change) $>$ 0.5. Upstream regulators analysis was performed following Ingenuity pathway analysis (IPA). IPA predicts functional regulatory networks from gene expression data and provides a significance score ( $p$-value) for each network according to the fit of the network to the set of genes in the database.

Statistical analysis. All statistical analyses were conducted using GraphPad Prism (GraphPad Software). Statistical difference between two groups was determined by an unpaired, two-tailed student's $t$ tests. A one-way or two-way ANOVA was used for multigroup comparisons together with Tukey's multiple comparisons post hoc tests. Survival significance in DSS-induced colitis was determined by a Log-rank Mantel-Cox test. Data is judged to be statistically significant when $p$ value $<0.05$. In figures, 0.0001). 


\section{References}

1. Lu, L., Barbi, J. \& Pan, F. The regulation of immune tolerance by FOXP3. Nat. Rev. Immunol. 17, 703-717 (2017).

2. Xing, Y. \& Hogquist, K. A. T-Cell Tolerance: Central and Peripheral. Cold Spring Harb Perspect Biol 4, 1-15 (2012).

3. Dominguez-Villar, M. \& Hafler, D. A. Regulatory T cells in autoimmune disease. Nat. Immunol. 19, 665-673 (2018).

4. Samstein, R. M., Josefowicz, S. Z., Arvey, A., Treuting, P. M. \& Rudensky, A. Y. Extrathymic generation of regulatory $T$ cells in placental mammals mitigates maternal-fetal conflict. Cell 150, 29-38 (2012).

5. Togashi, Y., Shitara, K. \& Nishikawa, H. Regulatory T cells in cancer immunosuppression - implications for anticancer therapy. Nat. Rev. Clin. Oncol. (2019).

6. Aandahl, E. M., Michaëlsson, J., Moretto, W. J., Hecht, F. M. \& Nixon, D. F. Human CD4+ CD25+ Regulatory T Cells Control T-Cell Responses to Human Immunodeficiency Virus and Cytomegalovirus Antigens. J. Virol. 78, 2454-2459 (2004).

7. Van Der Burg, S. H. et al. Association of cervical cancer with the presence of CD4+ regulatory T cells specific for human papillomavirus antigens. PNAS 104, 12087-12092 (2007).

8. Caridade, M., Graca, L. \& Ribeiro, R. M. Mechanisms underlying CD4+ Treg immune regulation in the adult: From experiments to models. Front. Immunol. 4, 1-9 (2013).

9. Clement, R. L. et al. Follicular regulatory T cells control humoral and allergic immunity by restraining early B cell responses. Nat. Immunol. 20, 1360-1371 (2019).

10. Vignali, D. A. A., Collison, L. W. \& Workman, C. J. How regulatory T cells work. Nat. Rev. Immunol. 8, 523-532 (2008).

11. Wardell, C. M., MacDonald, K. N., Levings, M. K. \& Cook, L. Cross talk between human regulatory $T$ cells and antigen-presenting cells: Lessons for clinical applications. Eur. J. Immunol. 51, 27-38 (2021).

12. Shevyrev, D. \& Tereshchenko, V. Treg Heterogeneity, Function, and Homeostasis. Front. Immunol. 10, 1-13 (2020).

13. Panduro, M., Benoist, C. \& Mathis, D. Tissue Tregs. Annu. Rev. Immunol. 34, 609-633 (2016).

14. Ast, T. \& Mootha, V. K. Oxygen and mammalian cell culture: are we repeating the experiment of Dr. Ox? Nat. Metab. 1, 858-860 (2019).

15. McKeown, S. R. Defining normoxia, physoxia and hypoxia in tumours Implications for treatment response. Br. J. Radiol. 87, 1-12 (2014).

16. Bartels, K., Grenz, A. \& Eltzschig, H. K. Hypoxia and inflammation are two sides of the same coin. PNAS 110, 18351-18352 (2013).

17. Nanduri, J. et al. HIF-1 $\alpha$ activation by intermittent hypoxia requires NADPH oxidase stimulation by xanthine oxidase. PLoS One 10, 1-12 (2015).

18. Mempel, T. R. \& Marangoni, F. Guidance factors orchestrating regulatory T cell positioning in tissues during development, homeostasis, and response. Immunol. 
19. Hirota, K. Basic biology of hypoxic responses mediated by the transcription factor HIFs and its implication for medicine. Biomedicines 8, (2020).

20. Baik, A. H. \& Jain, I. H. Turning the Oxygen Dial: Balancing the Highs and Lows. Trends Cell Biol. 30, 516-536 (2020).

21. Wang, G. L. \& Semenza, G. L. Purification and characterization of hypoxiainducible factor. Journal of Biological Chemistry 270, 1230-1237 (1995).

22. James D Webb, M. L. C. \& Pugh, C. W. Hypoxia, hypoxia-inducible factors (HIF), HIF hydroxylases and oxygen sensing. Cell. Mol. Life Sci. 66, 3539-3554 (2009).

23. Semenza, G. L. HIF-1, O2, and the 3 PHDs: How animal cells signal hypoxia to the nucleus. Cell 107, 1-3 (2001).

24. Maxwell, P. H. et al. The tumoursuppressor proteinVHLtargets hypoxia-inducible factors for oxygen-dependent proteolysis. Nature 44, 271-275 (1999).

25. Downes, N. L., Laham-Karam, N., Kaikkonen, M. U. \& Ylä-Herttuala, S. Differential but Complementary HIF1 $\alpha$ and HIF2 $\alpha$ Transcriptional Regulation. Mol. Ther. 26, 1735-1745 (2018).

26. Watts, E. R. \& Walmsley, S. R. Inflammation and Hypoxia: HIF and PHD Isoform Selectivity. Trends Mol. Med. 25, 33-46 (2019).

27. Talks, K. L. et al. The expression and distribution of the hypoxia-inducible factors HIF- $1 \alpha$ and HIF-2 $\alpha$ in normal human tissues, cancers, and tumor-associated macrophages. Am. J. Pathol. 157, 411-421 (2000).

28. Hu, C.-J., Sataur, A., Wang, L., Chen, H. \& Simon, M. C. The N-Terminal Transactivation Domain Confers Target Gene Specificity of Hypoxia-inducible Factors HIF-1 $\alpha$ and HIF-2a. Mol. Biol. Cell 18, 986-994 (2007).

29. Bono, H. \& Hirota, K. Meta-analysis of hypoxic transcriptomes from public databases. Biomedicines 8, (2020).

30. Meneses, A. M. and \& Wielockx, B. PHD2 : from hypoxia regulation to disease progression. Dovepress 53-67 (2016).

31. Mikhaylova, O. et al. The von Hippel-Lindau Tumor Suppressor Protein and Egl-9Type Proline Hydroxylases Regulate the Large Subunit of RNA Polymerase II in Response to Oxidative Stress. Mol. Cell. Biol. 28, 2701-2717 (2008).

32. Denise A. Chan et al. Tumor Vasculature is Regulated by PHD2-mediated Angiogenesis and Bone Marrow-Derived Cell Recruitment. Cancer Cell. 15, 527538 (2009).

33. Romero-Ruiz, A. et al. Prolyl hydroxylase-dependent modulation of eukaryotic elongation factor 2 activity and protein translation under acute hypoxia. J. Biol. Chem. 287, 9651-9658 (2012).

34. Huo, Z. et al. Prolyl hydroxylase domain protein 2 regulates the intracellular cyclic AMP level in cardiomyocytes through its interaction with phosphodiesterase 4D. Biochem. Biophys. Res. Commun. 427, 73-79 (2012).

35. Xie, L. et al. PHD2/3-dependent hydroxylation tunes cardiac response to $\beta$ adrenergic stress via phospholamban. J. Clin. Invest. 125, 2759-2771 (2015).

36. Lee, D. C. et al. A lactate-induced response to hypoxia. Cell 161, 595-609 (2015).

37. Guo, J. et al. pVHL suppresses kinase activity of Akt in a proline-hydroxylationdependent manner. Science 353, 929-932 (2016).

38. Cockman, M. E. et al. Lack of activity of recombinant HIF prolyl hydroxylases (PHDs) on reported non-HIF substrates. Elife 8, 1-27 (2019). 
762

763

764

765

766

767

768

769

770

771

772

773

774

775

776

777

778

779

780

781

782

783

784

785

786

787

788

789

790

791

792

793

794

795

796

797

798

799

800

801

802

803

804

805

806

807

808

39. Corrado, C. \& Fontana, S. Hypoxia and HIF signaling: One axis with divergent effects. Int. J. Mol. Sci. 21, 1-17 (2020).

40. McGettrick, A. F. \& O'Neill, L. A. J. The Role of HIF in Immunity and Inflammation. Cell Metab. 32, 524-536 (2020).

41. Shi, L. Z. et al. HIF1alpha-dependent glycolytic pathway orchestrates a metabolic checkpoint for the differentiation of TH17 and Treg cells. J. Exp. Med. 208, 136776 (2011).

42. Dang, E. V. et al. Control of TH17/Treg balance by hypoxia-inducible factor 1. Cell 146, 772-784 (2011).

43. Shehade, H., Acolty, V., Moser, M. \& Oldenhove, G. Cutting Edge: HypoxiaInducible Factor 1 Negatively Regulates Th1 Function. J. Immunol. 195, 1372-6 (2015).

44. Clever, D. et al. Oxygen Sensing by T Cells Establishes an Immunologically Tolerant Metastatic Niche. Cell 166, 1117-1131.e14 (2016).

45. Lukashev, D., Caldwell, C., Ohta, A., Chen, P. \& Sitkovsky, M. Differential Regulation of Two Alternatively Spliced Isoforms of Hypoxia-inducible Factor-1a in Activated T Lymphocytes. J. Biol. Chem. 276, 48754-48763 (2001).

46. Ben-shoshan, J., Maysel-auslender, S., Mor, A., Keren, G. \& George, J. Hypoxia controls CD4+ CD25+ regulatory T-cell homeostasis via hypoxia-inducible factor-1 a. Eur. J. Immunol. 2412-2418 (2008).

47. Clambey, E. T. et al. Hypoxia-inducible factor-1 alpha - dependent induction of FoxP3 drives regulatory T-cell abundance and function during inflammatory hypoxia of the mucosa. PNAS 109, (2012).

48. Hsu, T. S. et al. HIF-2 $\alpha$ is indispensable for regulatory T cell function. Nat. Commun. 11, 1-16 (2020).

49. Yamamoto, A. et al. Systemic silencing of Phd2 causes reversible immune regulatory dysfunction. J. Clin. Invest. 129, 3640-3656 (2019).

50. Owen, D. L. et al. Thymic regulatory T cells arise via two distinct developmental programs. Nat. Immunol. 20, 195-205 (2019).

51. Wohlfert, E. A., Warunek, J., Jin, R. M. \& Marzullo, B. Tbet - expressing Tregs protect against lethal immunopathology during $T$. gondii infection. J Immunol 204, 2020 (2020).

52. Esplugues, E. et al. Control of TH17 cells occurs in the Small Intestine. Nature 475, 514-518 (2012).

53. Hall, A. O. H. et al. The Cytokines Interleukin 27 and Interferon-y Promote Distinct Treg Cell Populations Required to Limit Infection-Induced Pathology. Immunity 37, 511-523 (2012).

54. Fontenot, J. D., Gavin, M. A. \& Rudensky, A. Y. Foxp3 programs the development and function of CD4+CD25+ regulatory T cells. J. Immunol. 4, 986-992 (2003).

55. Redpath, S. A. et al. ICOS controls Foxp3+ regulatory T-cell expansion, maintenance and IL-10 production during helminth infection. Eur. J. Immunol. 43, 705-715 (2013).

56. Lowther, D. E. et al. PD-1 marks dysfunctional regulatory T cells in malignant gliomas. JCI 1, 1-15 (2016).

57. Tan, C. L. et al. PD-1 restraint of regulatory T cell suppressive activity is critical for immune tolerance. J. Exp. Med. 218, (2021).

58. Bates, D. O. Vascular endothelial growth factors and vascular permeability. 
Cardiovasc. Res. 87, 262-271 (2010).

59. Greenwald, A. C. et al. VEGF expands erythropoiesis via hypoxia-independent induction of erythropoietin in noncanonical perivascular stromal cells. J. Exp. Med. 216, 215-230 (2019).

60. Franckaert, D. et al. Promiscuous Foxp3-cre activity reveals a differential requirement for CD28 in Foxp3 + and Foxp3-T cells. Immunol. Cell Biol. 93, 417423 (2015).

61. Koch, M. A. et al. The transcription factor T-bet controls regulatory T cell homeostasis and function during type 1 inflammation. Nat. Immunol. 10, 595-602 (2009).

62. Levine, A. G. et al. Stability and function of regulatory T cells expressing the transcription factor T-bet. Nature 546, 421-425 (2017).

63. Littringer, K. et al. Common features of regulatory T cell specialization during Th1 responses. Front. Immunol. 9, 1-15 (2018).

64. Duckworth, B. C. et al. Effector and stem-like memory cell fates are imprinted in distinct lymph node niches directed by CXCR3 ligands. Nat. Immunol. (2021).

65. Biasci, D. et al. CXCR4 inhibition in human pancreatic and colorectal cancers induces an integrated immune response. PNAS 117, 28960-28970 (2020).

66. Lee, J. H., Elly, C., Park, Y. \& Liu, Y. C. E3-Ubiquitin Ligase VHL Regulates Hypoxia-Inducible Factor-1a to Maintain Regulatory T Cell Stability and Suppressive Capacity. Immunity 42, 1062-1074 (2015).

67. Shi, H. \& Chi, H. Metabolic Control of Treg Cell Stability, Plasticity, and TissueSpecific Heterogeneity. Front. Immunol. 10, 1-17 (2019).

68. Gupta, N. \& Wish, J. B. Hypoxia-Inducible Factor Prolyl Hydroxylase Inhibitors: Potential New Treatment for Anemia in Patients With CKD. Am. J. Kidney Dis. 69, 815-826 (2017).

69. Marks, E. et al. Oral Delivery of Prolyl Hydroxylase Inhibitor : AKB-4924 Promotes Localized Mucosal Healing in a Mouse Model of Colitis. Inflamm Bowel Dis 21, 267-275 (2015).

70. Li, X. et al. Therapeutic Potential of a Prolyl Hydroxylase Inhibitor FG-4592 for Parkinson's Diseases in Vitro and in Vivo : Regulation of Redox Biology and Mitochondrial Function. Frontiers (Boulder). 10, 1-16 (2018).

71. Rubtsov, Y. P. et al. Regulatory T Cell-Derived Interleukin-10 Limits Inflammation at Environmental Interfaces. Immunity 28, 546-558 (2008).

72. Kim, J. J., Shajib, S., Manocha, M. M. \& Khan, W. I. Investigating Intestinal Inflammation in DSS-induced Model of IBD. Jove 1, 1-6 (2012).

73. Radu, M. \& Chernoff, J. An in vivo assay to test blood vessel permeability. J. Vis. Exp. 2-5 (2013). 


\section{Acknowledgments}

852 We thank Valérie Acolty, Caroline Abdelaziz and Véronique Dissy for animal care and 853 for technical support. The development of mouse models of toxoplasmosis would not

854 have been possible without the kind assistance of Guillaume Oldenhove. This work was 855 supported by the European Regional Development Fund (ERDF) and the Walloon 856 Region (Wallonia-Biomed portfolio, 411132- 957270), a grant from the Fonds Jean 857 Brachet and research credit from the National Fund for Scientific Research, FNRS, 858 Belgium. FA is a Research Associate at the FNRS. YA is recipient of a research 859 fellowship from the FNRS/Télévie. $\mathrm{HH}$ has been supported by a Belgian FRIA 860 fellowship.

861

\section{Additional information}

863 The authors declare that the research was conducted in the absence of any commercial 864 or financial relationships that could be construed as a potential conflict of interest. 


\section{Figure legends}

Figure 1. PHD2 ${ }^{\Delta \mathrm{Treg}}$ mice display a spontaneous Th1-like inflammatory syndrome. a Body weight of naive mice was determined weekly. b At 12 weeks of age, male and female mice were examined for rectal prolapse c splenomegaly and colon length summarized in d. e Representative gross autopsy of an hemorrhagic abdomen, (f-i) Lymphoid cells from spleen, mesenteric $(m L N)$, peripheral $(p L N)$ lymph nodes or the small intestine lamina propria were collected from Foxp3 ${ }^{\text {cre }}$ and $P H D 2^{\Delta T r e g}$ mice. $f$ Frequency of conventional, Foxp3- CD4 and CD8-expressing cells among TCR $\beta$ expressing $T$ lymphocytes. g Representative merged $(n=15)$ t-distributed stochastic neighbor embedding ( $t-S N E)$ plot after dimensionality reduction and unsupervised clustering of flow cytometry data from CD4-expressing spleen cells. Relative distributions of $\mathrm{CD}^{+}$lymphocyte subsets are shown as doughnut charts. $\mathbf{h}$ Frequency of effector-like (CD44 $\left.{ }^{\mathrm{hi}} \mathrm{CD} 62 \mathrm{~L}^{\mathrm{lo}}\right)$ conventional $\mathrm{T}$ lymphocytes in the indicated lymphoid organs. i Frequency of IFN-y (top panel) and IL-17A (bottom panel) producing CD4 ${ }^{+} \mathrm{T}$ cells after in vitro stimulation. j Expression of inflammatory cytokines determined by qPCR on extracts from unfractionated $\mathrm{mLNs}$. Data are representative of at least three independent experiments with $n=9(\mathbf{a}, \mathbf{j}), n=25(\mathbf{d}), n=15(\mathbf{f}-\mathbf{i})$ per group. Values are presented as the mean \pm standard deviation (SD) and were compared by two-tailed unpaired student's t-test. Only significant differences are indicated as follows: *: $p<0.05$, ${ }^{* *}: p<0.01,{ }^{* * *}: p<0.001,{ }^{* * * *}: p<0.0001$. Abbreviations: Naive Tconv (Foxp3 ${ }^{-}$CD44 CD62 $\mathrm{L}^{+}$), Memory Tconv (Foxp3- $\mathrm{CD}^{+} 4^{+} \mathrm{CD} \mathrm{L}^{+}$), Effector Tconv (Foxp3- $\mathrm{CD}^{-} 4^{+}$ $\mathrm{CD}^{2} \mathrm{~L}^{-}$), Memory Treg (Foxp3 ${ }^{+} \mathrm{CD}_{4} 4^{+} \mathrm{CD} \mathrm{L}^{+}$), Effector Treg (Foxp3 $\left.{ }^{+} \mathrm{CD}_{4} 4^{+} \mathrm{CD}^{-} \mathrm{L}^{-}\right)$.

865

866

867

868

869

870

871

872

873

874

875

876

877

878

879

880

881

882

883

Figure 2. Increased number, but altered phenotype of PHD2-deficient Treg cells. Lymphoid cells from the thymus, spleen, mesenteric $(\mathrm{mLN})$ and peripheral $(\mathrm{pLN})$ lymph nodes were collected at 12 weeks of age from Foxp $3^{\text {cre }}$ and PHD2 ${ }^{\Delta T \text { reg }}$ male and female mice and the relative frequency and phenotype of Foxp3-expressing cells were established by flow cytometry or qPCR. a Frequency of Foxp3-expressing cells among CD4-positive T lymphocytes; b Representative flow cytometry expression profiles of Foxp3 and CD25 expression among thymic CD4 ${ }^{+} \mathrm{T}$ cells; c frequency of mature-like $\left(\mathrm{CD}_{25}{ }^{+} \mathrm{Foxp}^{+}\right)$and Treg precursors subsets identified respectively as CD25 Foxp ${ }^{10}$ and $\mathrm{CD}^{2} 5^{+}$Foxp3 $3^{-}$cells among thymic $\mathrm{CD}^{+} \mathrm{T}$ cells; $\mathbf{d}$ frequency of immature-like, $\mathrm{CD}_{24}{ }^{+} \mathrm{Foxp}^{+} \mathrm{T}$ cells in the thymus of adult mice; e frequency of effector (CD62 ${ }^{\text {low }}$ CD44 $\left.{ }^{\text {high }}\right)$, memory (CD62 ${ }^{\text {high }} \mathrm{CD} 44^{\text {high }}$ ) and naive (CD62L high $C D 44^{\text {low }}$ ) splenic Foxp3expressing cells; $\mathbf{f}$ frequency of splenic Tregs expressing the master transcription factors T-bet, GATA3 and RORyt; $\mathbf{g}$ Ratio of the Foxp3 MFI of PHD2-KO splenic Tregs to Foxp3 ${ }^{\text {cre }}$ splenic Tregs. $\mathbf{h}$ Expression of CD25, CD44, ICOS, PD-1 and CTLA-4 in splenic Treg of Foxp3 ${ }^{\text {cre }}$ and PHD2 ${ }^{\Delta T r e g}$ mice. Top panel, representative traces of MFI. Bottom panel, ratios of the MFIs of PHD2-KO Treg to Foxp3 ${ }^{\text {cre }}$ Treg cells are expressed as the mean \pm SD. i //10 gene expression relative to RPL32 by ex-vivo purified Tregs was determined by qPCR. ( $\mathrm{j}-\mathrm{I}) \mathrm{CD}^{+}{ }^{+}$Foxp3 $^{-}$splenic naive $\mathrm{T}$ cells were stimulated in 
884 vitro with anti-CD3/CD28 $\left(5 / 1 \mu \mathrm{g} \mathrm{ml}^{-1}\right)$ in the presence of TGF- $\beta\left(3 \mu \mathrm{g} \mathrm{ml}^{-1}\right)$ and IL-2 $(10$ $885 \mathrm{\mu g} \mathrm{ml}^{-1}$ ) for $72 \mathrm{~h}$ to induce Treg polarization.

886 j Representative flow cytometry expression profiles of Foxp3 expression at the end of the culture period. The first panel represents a typical profile of cells activated in the absence of polarizing cytokines; $\mathbf{k}$ number of $\mathrm{Foxp}^{+}$cells generated in the culture conditions; I Expression (MFI) of Foxp3 by in vitro induced Treg cells. Data are representative of at least two independent experiments with $n=15(\mathbf{a}, \mathbf{e}-\mathbf{g}), n=9(\mathbf{h}, \mathbf{i})$ or $\mathrm{n}=6(\mathbf{c}, \mathbf{d}, \mathbf{k}, \mathbf{l})$ per group. Values are presented as the mean \pm SD and were compared by two-tailed unpaired student's t-test. Only significant differences are indicated as follows: ${ }^{*}: p<0.05,{ }^{* *}: p<0.01,{ }^{* * *}: p<0.001$.

\section{Figure 3. Cell autonomous role of PHD2 in determining Treg cells phenotype.}

Spleen, thymus, mesenteric $(\mathrm{mLN})$ and peripheral $(\mathrm{pLN})$ lymph nodes were collected at 8 weeks of age from Foxp3 $3^{\text {cre } /+}$ Egln $1^{\text {t/f }}$ heterozygous female mice and the relative frequency and phenotype of Foxp3-expressing cells were established by flow cytometry. a Proportion of WT (YFP- cells) or PHD2-KO (YFP+ cells) Treg cells among Foxp3expressing cells. b representative histograms of Foxp3, CD25, CD44 and CTLA-4 expression in splenic WT Tregs (black lines) compared to splenic PHD2-KO Tregs (red lines). c Foxp3 MFI, d CD25 MFI, e CD44 MFI and $\mathbf{f}$ CTLA-4 MFI of WT and PHD2-KO Tregs in lymphoid organs. Data are representative of two independent experiments with $\mathrm{n}=9$ per group. Values are presented as the mean \pm standard deviation (SD) and were compared by two-tailed unpaired student's t-test. Only significant differences are indicated as follows: ${ }^{*}: p<0.05,{ }^{* *}: p<0.01,{ }^{* * *}: p<0.001,{ }^{* * *}: p<0.0001$.

Figure 4. Reduced in vivo but not in vitro suppressive capacity of PHD2-deficient Treg.

a Treg function was assayed following adoptive co-transfer of CD45.2 Foxp3expressing cells with naive, CFSE labeled congenic CD45.1 CD4 ${ }^{+}$lymphocytes (Treg : Tconv ratio 1:3) into syngeneic lymphopenic male mice $\left(\right.$ Rag $\left.^{\prime-}\right)$. Recipient mice were euthanized at day 6 post-transfer, and their spleen and $\mathrm{mLN}$ cells analyzed by flow cytometry. b Representative flow cytometry expression profiles of CFSE labeled cells (CD45.1 gate in the spleen) with or without co-transferred Foxp3 ${ }^{+}$cells from Foxp3 ${ }^{\text {cre }}$ or $\mathrm{PHD}^{\Delta \mathrm{Treg}}$ male mice; c percentage of suppression established from CFSE staining profiles; $\mathbf{d}$ frequency of activated $\left(\mathrm{CD} 4^{+} \mathrm{CD} 45.1^{+} \mathrm{CD} 44^{\mathrm{hi}} \mathrm{CD} 62 \mathrm{~L}^{\mathrm{lo}}\right)$ cells in the indicated lymphoid organs; e frequency of Treg cells in the indicated organs 6 days post-transfer. $(\mathbf{f}, \mathbf{g})$ CFSE-labeled, naive conventional $\mathrm{CD}^{+}{ }^{+} \mathrm{T}$ cells from CD54.1 mice were cocultured with ex-vivo purified Treg cells from Foxp3 $3^{\text {cre }}$ or PHD2 ${ }^{\Delta \text { Treg }}$ mice at the indicated ratios in the presence of anti-CD3 antibodies $\left(0.5 \mu \mathrm{g} \mathrm{ml}^{-1}\right)$ and splenic feeder cells; $\mathbf{f}$ representative flow cytometry profiles of CSFE staining; $\mathbf{g}$ Percent of suppression of proliferation as compared to cultures in which Treg cells were omitted. Data are representative of three independent experiments with $n=15(\mathbf{b}-\mathbf{e})$ or $n=4(\mathbf{f}, \mathbf{g})$ per group. Values are presented as the mean $\pm S D$ and were compared by two-way ANOVA with Tukey's multiple comparisons test (c-e) or by two-tailed unpaired student's t-test $(\mathbf{g})$. Only significant differences are indicated as follows: ${ }^{*}: p<0.05,{ }^{* *}: p<0.01,{ }^{* * *}$ : $\mathrm{p}<0.001$. 
Figure 5. Increased sensitivity of PHD2 ${ }^{\Delta \mathrm{Treg}}$ mice to DSS-induced colitis and toxoplasmosis.

Foxp3 ${ }^{\text {cre }}$ and PHD2 ${ }^{\Delta T r e g}$ male mice were provided with $2 \%$ DSS in tap water for five days. On day 5 , the $2 \%$ DSS water was replaced with normal drinking water and mice were followed during 14 days for a body weight, $\mathbf{b}$ survival, $\mathbf{c}$ colitis severity and $\mathbf{d}$ colon length. e Colons were isolated from untreated mice or 6 days after colitis induction and were fixed and stained with hematoxylin and eosin (H\&E); arrows indicate inflammatory cell infiltrates. $\mathbf{f}$ Foxp $3^{\text {cre }}$ and PHD2 ${ }^{\Delta \text { reg }}$ male mice were infected by intragastric gavage with 10 cysts of ME-49 type II Toxoplasma gondii (control group are Foxp3 ${ }^{\text {cre }}$ mice without treatment) and subsequently followed for $\mathbf{g}$ body weight. $\mathbf{h}$ Mice were sacrificed 8 days after infection to assess colon length; $\mathbf{i}$ frequency of effector-like (CD44 ${ }^{\text {hi }}$ $\mathrm{CD} \mathrm{L}^{10}{ }^{10}$ ) conventional $\mathrm{T}$ lymphocytes in the indicated lymphoid organs; $\mathbf{j}$ frequency of IFN- $y$ producing $\mathrm{CD}^{+} \mathrm{T}$ cells after in vitro stimulation; $\mathbf{k}$ frequency of $\mathrm{T}^{- \text {bet }^{+}}$among Foxp ${ }^{+}($Treg) cells. Data are representative of three independent experiments with $n=$ $20(\mathbf{a}, \mathbf{b}), \mathrm{n}=10-14(\mathbf{c}, \mathbf{d}), \mathrm{n}=5(\mathbf{e})$ or $\mathrm{n}=10(\mathbf{g}-\mathbf{k})$ per group. Values are presented as the mean \pm SD and were compared by two-tailed unpaired student's t-test (a, $\mathbf{c}, \mathbf{g})$, by Mantel-Cox test (b), by one-way ANOVA with Tukey's multiple comparisons test $(\mathbf{d}, \mathbf{h})$ or by two-way ANOVA with Tukey's multiple comparisons test (i-k). Only significant differences are indicated as follows: ${ }^{*}: p<0.05,{ }^{* *}: p<0.01,{ }^{* * *}: p<0.001,{ }^{* * * *}: p<0.0001$.

Figure 6. Concomitant loss of HIF2 $\alpha$ but not HIF1a expression attenuates the proinflammatory phenotype of PHD2 ${ }^{\Delta \mathrm{Treg}}$ mice.

a Representative gross autopsy of spleens and colon length summarized in $\mathbf{b}$ of Foxp3 $^{\text {cre }}$, PHD2 $^{\Delta \text { Treg }}$, PHD2-HIF1 $\alpha^{\Delta \text { Treg }}$, PHD2-HIF2 $\alpha^{\Delta \text { Treg }}$ and PHD2-HIF1 $\alpha-H I F 2 \alpha^{\Delta \text { Treg }}$ (TKO) mice. c Representative merged $(n=15)$ t-distributed stochastic neighbor embedding (t-SNE) plot after dimensionality reduction and unsupervised clustering of flow cytometry data from CD4-expressing spleen cells. Relative distributions of CD4 ${ }^{+}$ lymphocyte subsets are shown as doughnut charts. (d-g) Lymphoid cells from spleen, mesenteric $(\mathrm{mLN})$, peripheral $(\mathrm{pLN})$ lymph nodes or the small intestine lamina propria were collected from Foxp3 $3^{\text {cre }}$, PHD2 $^{\Delta \text { Treg }}$, PHD2-HIF $1 \alpha^{\Delta \text { Treg }}$ mice, PHD2-HIF2 $\alpha^{\Delta \text { reg }}$ and PHD2-HIF1 $\alpha-H I F 2 \alpha^{\Delta T r e g}$ (TKO) male and female mice and the relative frequency and phenotype of Foxp3-positive and Foxp3-negative, conventional $\mathrm{T}$ lymphocytes determined by flow cytometry. d Frequency of effector-like (CD44 ${ }^{\text {hi }}$ CD62L $^{\text {lo }}$ ) conventional $\mathrm{T}$ lymphocytes in the indicated lymphoid organs. e Frequency of IFN-Y producing $\mathrm{CD}^{+} \mathrm{T}$ cells after in vitro stimulation. $\mathbf{f}$ Frequency of Foxp3-expressing cells among CD4-positive T lymphocytes. g Ratio of the Foxp3 MFI of PHD2-KO, PHD2HIF1aKO, PHD2-HIF2aKO or TKO splenic Tregs to Foxp3 ${ }^{\text {cre }}$ splenic Tregs. Data are representative of at least three independent experiments with $n=15$ per groups. Values are expressed as the mean \pm SD and were compared by One-way ANOVA with Tukey's multiple comparisons test $(\mathbf{b}, \mathbf{g})$ or by Two-way ANOVA with Tukey's multiple comparisons test (d-f). Only significant differences are indicated as follows: ${ }^{*}: p<0.05$, ${ }^{* *}: p<0.01,{ }^{* * *}: p<0.001,{ }^{* * * *}: p<0.0001$. 
Figure 7. Anti-inflammatory response, response to chemokines and cell survival pathways represent targets of the PHD2-HIF2 $\alpha$ axis in Tregs. Splenic Treg cells were purified by cell sorting from Foxp3 ${ }^{\text {cre }}(n=3), \operatorname{PHD}^{\Delta T r e g}(n=2)$, PHD2-HIF1 $\alpha^{\Delta \text { Treg }}(n=2)$, PHD2-HIF2 $\alpha^{\Delta T r e g}(n=3)$ and PHD2-HIF1a-HIF2 $\alpha^{\Delta \text { Treg }}$ (TKO) ( $n$ = 3) male mice and total RNA was extracted and sequenced by RNA-sequencing (Illumina). a Heatmap of genes differentially expressed. Values are represented as $\log _{2}$ fold-change obtained from median of each gene and are plotted in red-blue color scale with red indicating increased expression and blue indicating decreased expression. Hierarchical clustering of genes (k mean clustering) show 20 clusters. b Classification of mouse strains according to their spontaneous inflammation severity. c Heatmap of genes downregulated when PHD2 and PHD2-HIF1 $\alpha$ are deleted and whose expression is restored to a control level (close to Foxp3 ${ }^{\text {cre }}$ Treg) following deletion of HIF2 $\alpha$ (Cluster 10, 181 genes). d Heatmap of genes upregulated when PHD2 and PHD2-HIF1a are deleted and whose expression is restored to a control level following deletion of HIF2 $\alpha$ (Cluster 11, 66 genes). e Heatmap of genes upregulated when PHD2 and PHD2-HIF2 $\alpha$ are deleted and whose expression is restored to a control level following deletion of HIF1a (Cluster 3, 98 genes). Cluster 3, 10 and 11 were subjected to functional annotations and regulatory network analysis in the Ingenuity Pathway Analysis (IPA) software. Data were analyzed using Deseq2, a gene is differentially expressed when $\log _{2} \mathrm{FC}$ (Fold change) $>0.5$ and FDR (False discovery rate) $<0.05$.

\section{Figure 8. Identification of STAT1-mediated signaling as a target of the PHD2- HIF2 $\alpha$ axis in Tregs.}

a Upregulated and downregulated genes (cluster 10 and 11 in Figure 6 c-d) were imported into the Ingenuity Pathway Analysis (IPA) software and were subjected to Upstream regulator analysis (URA) prediction algorithms. STAT1 was predicted as an upstream regulators of downregulated genes with a $p$-value $=3 \cdot 10^{-12}$. Phosphorylated form of STAT1 (pSTAT1 (Tyr701)) was assessed by flow cytometry after brief in vitro stimulation (30 $\mathrm{min}$ ) of splenic $\mathrm{CD}^{+} \mathrm{T}$ lymphocytes with recombinant IFN- $\gamma$. b Representative histogram of pSTAT1 MFI for conventional CD4 ${ }^{+} \mathrm{T}$ cells (Tconv) and Treg cells of Foxp3 $3^{\text {cre }}, \mathrm{PHD}^{\Delta \text { Treg }}$ and PHD2-HIF2 $\alpha^{\Delta \text { Treg }}$ male mice. Mean value expression (represented by MFI) of $\mathbf{c}$ pSTAT1 or d STAT1 total protein by splenic Treg of Foxp3 ${ }^{\text {cre }}$, PHD2 $^{\Delta \text { Treg }}$ and PHD2-HIF2 ${ }^{\Delta \text { Treg }}$ mice. e Frequency of Treg cells expressing the CXCR3 receptor. Data are representative of three independent experiments with $n=$ 9 (b-d) or $n=12$ (e) per groups. Values are presented as the mean \pm SD and were

944 compared by one-way ANOVA with Tukey's multiple comparisons. Only significant differences are indicated as follows: ${ }^{* *}: p<0.01,{ }^{* * *}: p<0.001$. 


\section{Figure supplement legends}

Figure 1-figure supplement 1. Treg-restricted loss of Egln1 gene expression in PHD2 $^{\Delta \text { Treg }}$ mice.

a Treg cells from Foxp3 ${ }^{\text {cre }}$ male and female mice were purified by cell sorting from spleen $(n=10)$, mesenteric $(m L N)(n=8)$, peripheral $(p L N)$ lymph nodes $(n=4)$ or the small intestine lamina propria $(n=4)$ and expression of Egln2 (PHD1), Egln1 (PHD2) and EgIn3 (PHD3) analyzed by qPCR. b YFP-positive (YFP ${ }^{+}$) and YFP-negative (YFP) cells from PHD2-sufficient (Foxp3 ${ }^{\text {cre }}$ mice) and PHD2-deficient (PHD2 ${ }^{\Delta \text { Treg }}$ mice) were purified by cell sorting from spleen and mesenteric lymph nodes $(\mathrm{mLN})$ and expression of Egln1 analyzed by qPCR. The graph demonstrates selective loss of Egln1 gene expression in Tregs, but not in Tconvs purified from $\mathrm{PHD}^{\Delta \mathrm{Treg}}$ mice. c Ifng gene expression relative to RPL32 by ex-vivo purified Tregs from spleen and mLN was determined by qPCR. $\mathbf{d}$ Representative flow cytometry expression profile of GLUT1, a specific HIF1a target gene in Foxp3 expressing or non-expressing cells from Foxp3 $3^{\text {cre }}$ and PHD2 ${ }^{\Delta T r e g}$ mice. e Frequency of GLUT1-expressing Tregs in lymphoid organs from Foxp3 ${ }^{\text {cre }}$ and PHD2 ${ }^{\Delta T r e g}$ mice. Data are representative of two independent experiments with $n=6$ per group. Values are presented as the mean $\pm S D$ and were compared by two-tailed unpaired student's t-test. Only significant differences are indicated as follows: ${ }^{*}: p<0.05,{ }^{* *}: p<0.01,{ }^{* * *}: p<0.001,{ }^{* * * *}: p<0.0001$.

Figure 1-figure supplement 2. Increased blood cells counts and elevated hematocrit in PHD2 $^{\Delta \text { Treg }}$ mice associated with an increase in vascular permeability.

a White blood cell (WBC) counts, b red blood cell (RBC) counts, $\boldsymbol{c}$ platelet (PLT) counts and $\mathbf{d}$ hematocrit $(\mathrm{HCT})$ from Foxp3 ${ }^{\text {cre }}, \mathrm{PHD}^{\Delta \text { Treg }}$ and PHD2-HIF2 $\alpha^{\Delta \text { Treg }}$ male mouse blood. To assess vascular permeability mice were i.v injected with a $0,5 \%$ Blue Evans (BE) solution, and the indicated, organs collected after 30 minutes and placed in formamide at $55^{\circ} \mathrm{C}$ during 24 hours. The absorbance of supernatants was measured at $600 \mathrm{~nm}$, e representative image of the colon supernatant after $24 \mathrm{~h}$ in formamide, $\mathrm{f} \mathrm{ng}$ of Blue Evans per $\mathrm{mg}$ of tissue for spleen, mesenteric lymph nodes $(\mathrm{mLN})$, colon and liver of differents groups of mice injected or not with Blue Evans. Data are representative of two (a-d) or three (e-f) independent experiments with $n=7-9$ per group (a-d) or $n=4-6$ per group (e-f). Values are presented as the mean \pm standard deviation (SD) and were compared by one-way ANOVA (a-d) or two-way ANOVA (f) with Tukey's multiple comparisons test. Only significant differences are indicated as follows: ${ }^{*}: p<0.05$, ${ }^{*}$ : $p<0.01,{ }^{* \star *}: p<0.001,{ }^{* * *}: p<0.0001$.

Figure 1-figure supplement 3. Gating strategy for flow cytometry data analysis. Representative flow cytometry dot plots displaying the gating strategy for the identification of conventional $T$ cell populations in Figures 1, 3, 4 and 5 and for identification of regulatory $T$ cell subsets in Figures 2, 4 and 8

Figure 1-figure supplement 4. Absolute cell counts.

Absolute cell counts of a CD4 ${ }^{+} \mathrm{T}$ cells, $\mathbf{b} \mathrm{CD} 8^{+} \mathrm{T}$ cells, $\mathbf{c}$ regulatory $\mathrm{T}$ cells and $\mathbf{d}$ activated conventional $\mathrm{T}$ cells in the spleen, mesenteric $(\mathrm{mLN})$, peripheral $(\mathrm{pLN})$ lymph 
nodes and the small intestine lamina propria of Foxp3 ${ }^{\text {cre }}$ and $\mathrm{PHD}^{\Delta \mathrm{Treg}}$ male and female mice. Data are representative of at least three independent experiments with, $n$ $=15$ per group. Values are presented as the mean \pm standard deviation (SD) and were compared by two-tailed unpaired student's t-test. Only significant differences are indicated as follows: ${ }^{*}: p<0.05,{ }^{* *}: p<0.01,{ }^{* * *}: p<0.001,{ }^{* * *}: p<0.0001$.

Figure 5-figure supplement $1 . \mathrm{PHD}^{\mathrm{\Delta T} r e g}$ mice display a near-normal response to anti-CD3-induced enteritis.

Foxp3 ${ }^{\text {cre }}$ and PHD2 ${ }^{\Delta T r e g}$ female mice were injected twice i.p. with anti-CD3 mAbs $(20 \mu \mathrm{g})$ at two days interval and weighted daily. a Weight loss was found similar in both mouse strains tested; $\mathbf{b}$ relative expression of inflammatory mediators evaluated by qPCR on whole, unfractionated mesenteric lymph nodes. A similar, Th17-like response was observed in both mouse strains. Data are representative of two independent experiments with $n=6$ per group. Values are presented as the mean \pm SD and were compared by one-way ANOVA with Tukey's multiple comparisons test. Only significant differences are indicated as follows: ${ }^{*}: p<0.05,{ }^{* *}: p<0.01$.

Figure 5-figure supplement 2. Loss of Ifng gene expression attenuates the proinflammatory phenotype of PHD2 ${ }^{\Delta \mathrm{Treg}}$ mice

$\mathrm{PHD}^{\Delta \mathrm{Treg}}$ mice were crossed with IFN-yKO mice (PHD2 ${ }^{\Delta T r e g} \mathrm{IFN}-\mathrm{\gamma}^{\mathrm{KO}}$ mice) and were compared to Foxp3 ${ }^{\text {cre }}$ and PHD2 ${ }^{\Delta T r e g}$ male and female mice and analyzed for a colon length; $\mathbf{b}$ frequency of effector-like $\left(\mathrm{CD} 44^{\text {hi }} \mathrm{CD} \mathrm{LL}^{\mathrm{lo}}\right)$ conventional T lymphocytes in the indicated lymphoid organs; c frequency of IFN- $\gamma$ production after in vitro stimulation; $\mathbf{d}$ frequency of IL-17A-producing cells after in vitro stimulation and e frequency of Foxp3 ${ }^{+}$ cells in the indicated lymphoid organs. Data are representative of three independent experiments with $n=10$ per groups. Values are expressed as the mean $\pm S D$ and were compared by One-way ANOVA with Tukey's multiple comparisons test (a) or by Twoway ANOVA with Tukey's multiple comparisons test (b-e). Only significant differences are indicated as follows: ${ }^{*}: p<0.05,{ }^{* *}: p<0.01,{ }^{* * *}: p<0.001,{ }^{* * *}: p<0.0001$.

Figure 6-figure supplement 1 . Treg-selective HIF1 $\alpha$ or HIF2 $\alpha$ deficiency does not affect immune homeostasis in naive mice.

a Splenic Treg cells were purified by cell sorting from Foxp3 ${ }^{\text {cre }}(n=3), \operatorname{PHD}^{\Delta \text { Treg }}(n=2)$, PHD2-HIF1 $\alpha^{\Delta \text { Treg }}(n=2)$, PHD2-HIF2 $\alpha^{\Delta \text { Treg }}(n=3)$, PHD2-HIF1 $^{2}-H I F 2 \alpha^{\Delta T r e g}($ TKO) $(n=$ 3), $\mathrm{HIF}_{1} \alpha^{\Delta \text { Treg }}(n=3)$ and HIF2 $\alpha^{\Delta \text { Treg }}(n=3)$ male mice and their genotype verified by qPCR on the extracted total RNA fraction. $\mathbf{b}$ representative gross autopsy findings revealing normal spleen and colon size (summarized in panel c) in 12 weeks aged male and female mice. $\mathbf{d}$ frequency of $\mathrm{CD} 4^{+}$Foxp3 $3^{-} \mathrm{CD} 44^{\mathrm{hi}} \mathrm{CD}^{\mathrm{C}} \mathrm{L}^{\mathrm{lo}}$ cells in lymphoid organs; e frequency of $\mathrm{CD}^{+}$lymphocytes producing IFN- $\gamma$ upon in vitro stimulation; $\mathbf{f}$ frequency of Foxp3 ${ }^{+}$cells in the indicated lymphoid organs; $g$ Ratio of the Foxp3 MFI of HIF1aKO or HIF2aKO splenic Tregs to Foxp3 ${ }^{\text {cre }}$ splenic Tregs. Data are representative of three independent experiments with $n=10$. Values are presented as the mean $\pm S D$ and were compared by one-way ANOVA with Tukey's multiple comparisons test $(\mathbf{c}, \mathbf{g})$ or by Two-way ANOVA with Tukey's multiple comparisons test (d-f). No statistical difference were found between groups. 
Figure 7-figure supplement 1. Signaling pathways affected by loss of PHD2expression in Treg.

a Top significantly downregulated pathways in PHD2-deficient Tregs compared to Tregs from Foxp3 ${ }^{\text {cre }}$ mice $\mathbf{b}$ top significantly upregulated pathways in PHD2-deficient Tregs compared to Tregs from Foxp3 ${ }^{\text {cre }}$ mice. Affected pathways were determined by over representation analysis (ORA analysis) in R program after Deseq2 analysis. Dots color and size represent respectively FDR (false discovery rate) and the number of genes affected in a given pathway.

Figure 8-figure supplement 1. Gating strategy for identification of $\mathrm{YFP}^{+}$cells. Representative flow cytometry dot plots displaying the gating strategy for the identification of YFP positive populations in the: a spleen, $\mathbf{b} \mathrm{mLN}, \mathbf{c}$ thymus and $\mathbf{d}$ liver. Although the majority of YFP-expressing cells also expressed Foxp3, a minor population (from 1 to $3 \%$ depending on the organ considered) of YFP cells lacked expression of both CD45 and Foxp3, suggesting a possible expression of the Crerecombinase in non-hematopoietic cells in PHD2 ${ }^{\Delta \text { Treg }}$ mice.

\section{Source data files}

Figure 1- source data 1

Figure 2- source data 1

Figure 3- source data 1

Figure 4- source data 1

Figure 5- source data 1

Figure 6- source data 1

Figure 7- source data 1

Figure 8- source data 1

Figure 1-figure supplement 1 - source data 1 Figure 1-figure supplement 2- source data 1 Figure 1-figure supplement 4- source data 1 Figure 5-figure supplement 1 - source data 1 Figure 5-figure supplement 2- source data 1 Figure 6-figure supplement 1- source data 1 Figure 7-figure supplement 1 - source data 1 


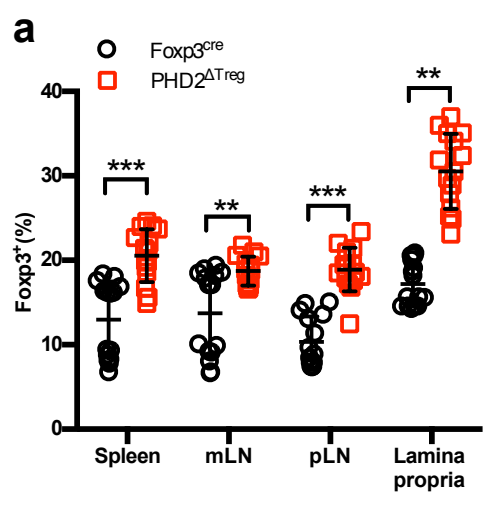

b

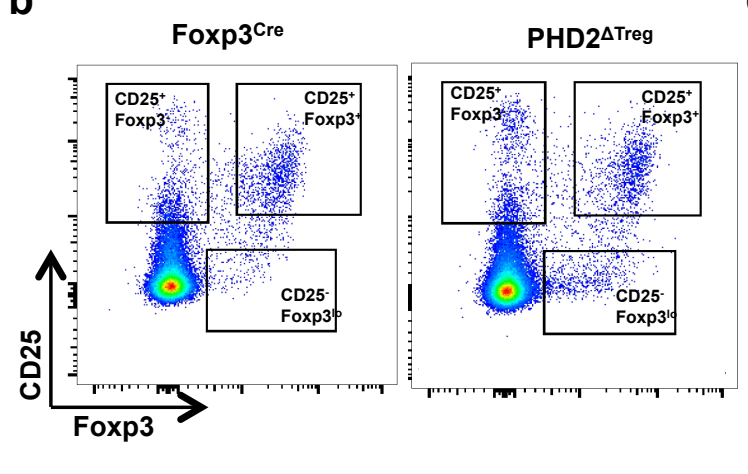

d

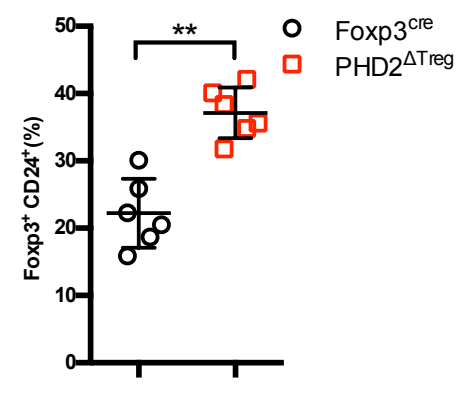

e

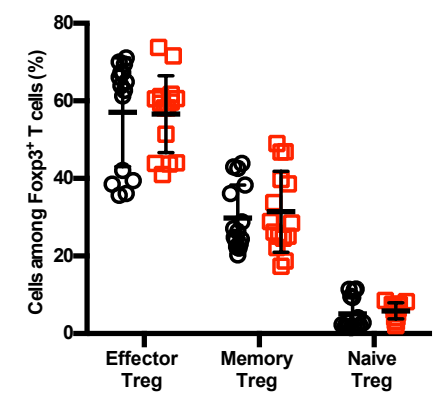

C

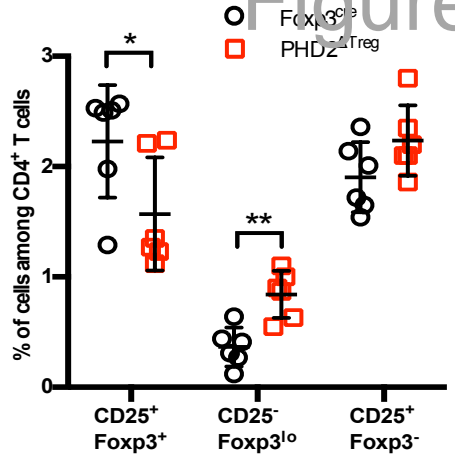

h
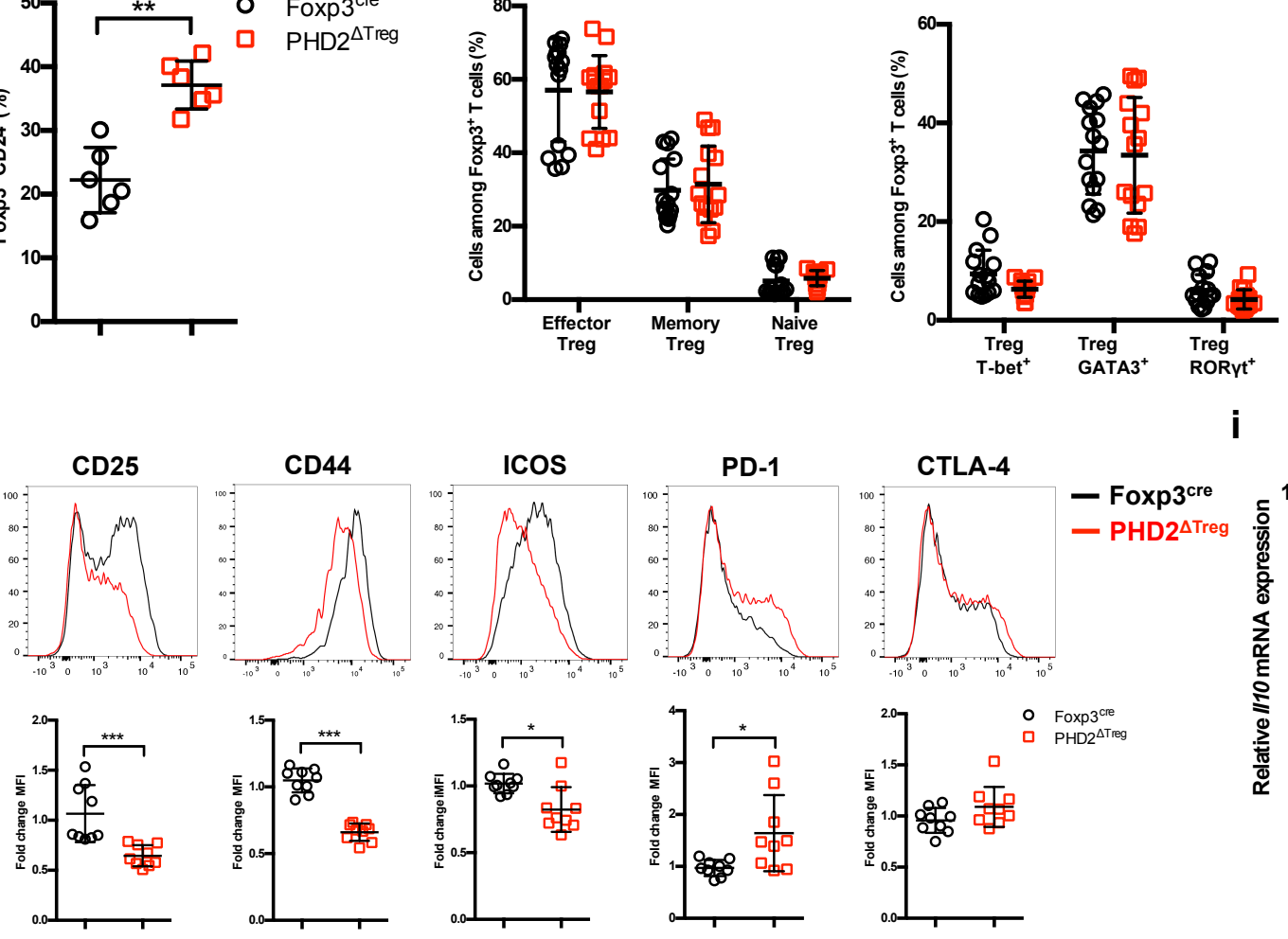

g

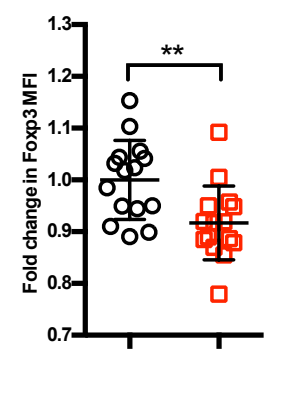

i
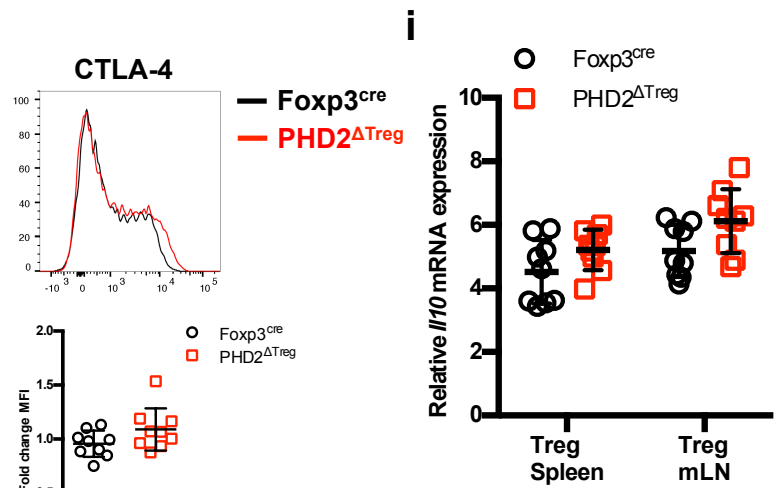

j
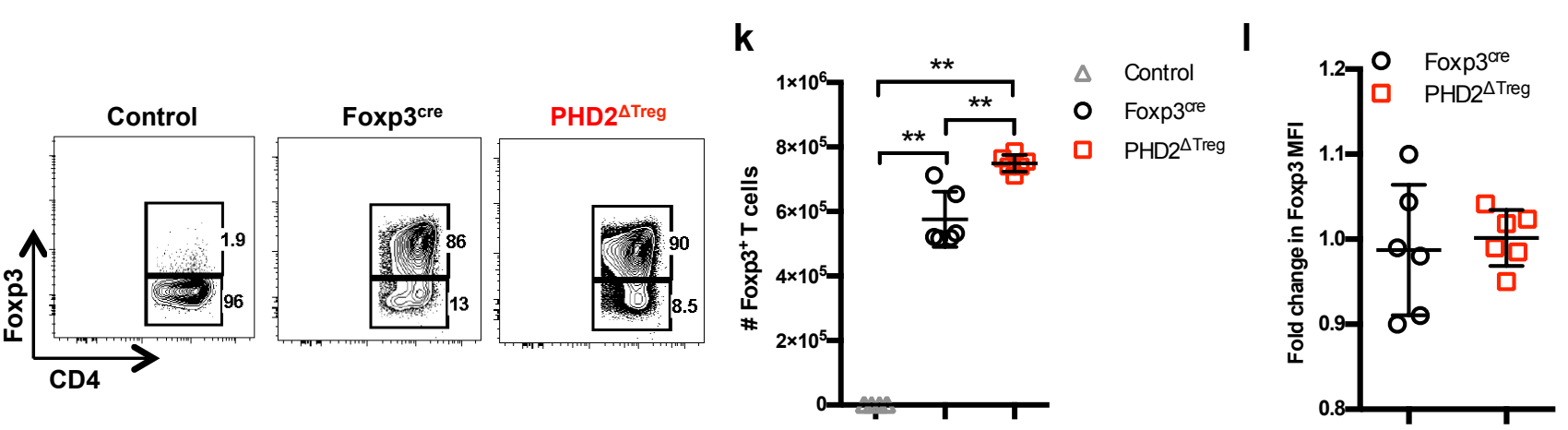

Figure 2. Increased number, but altered phenotype of PHD2-deficient Treg cells. 
a

b

- $\quad$ Treg WT (Foxp3 $\left.{ }^{+} \mathrm{YFP}^{-}\right)$

- Treg PHD2KO $\left(\right.$ Foxp3 $^{+}$YFP $\left.^{+}\right)$

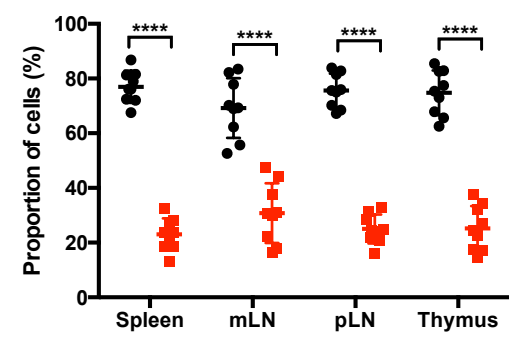

d

- $\quad$ Treg WT (Foxp3 ${ }^{+}$YFP- $\left.^{-}\right)$

- Treg PHD2KO (Foxp3 ${ }^{+}$YFP $^{+}$)

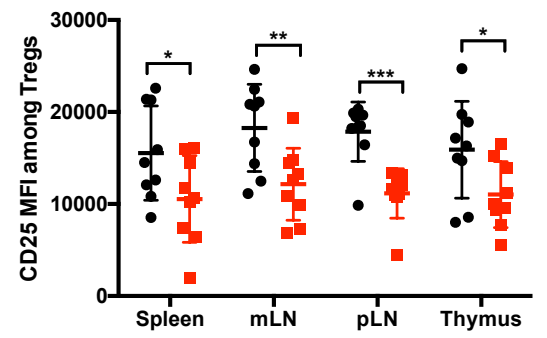

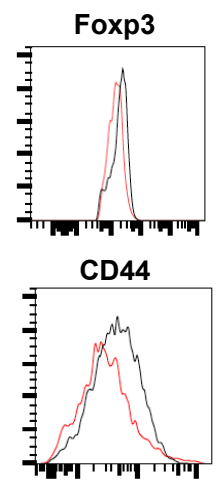

CD25

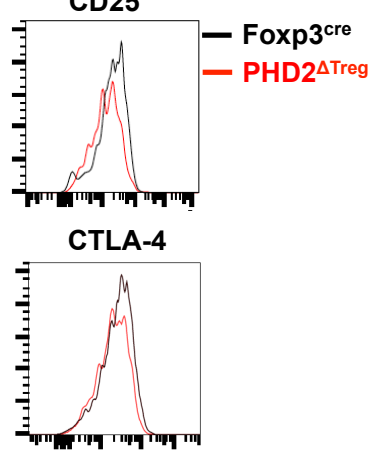

e

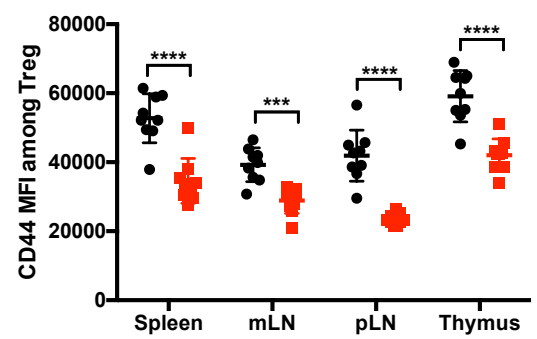

C

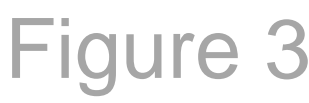

Treg WT (Foxp3 ${ }^{+}$YFP- $\left.^{-}\right)$

- Treg PHD2KO (Foxp3 $\left.{ }^{+} \mathrm{FPP}^{+}\right)$

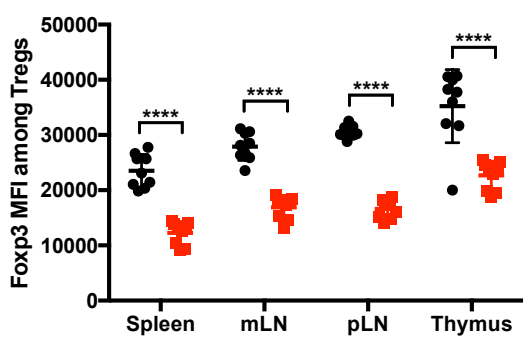

f

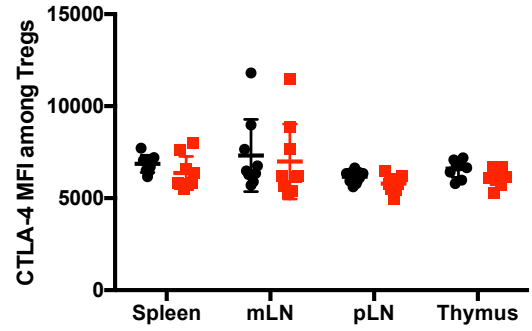

Figure 3. Cell autonomous role of PHD2 in determining Treg cells phenotype. 
a

$1 \times 10^{6} \mathrm{CD}^{+} \mathrm{CD} 25$

CD45. $1^{+}$naive cells

CFSE-labeled

$+/-$

$3.3 \times 10^{5}$ of Foxp3 $3^{\text {cre }}$ or

PHD2-deficient Treg

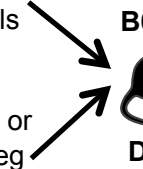

B6 Rag 2-1-

$\longrightarrow$ by flow cytometry

Day 0

Cell transfer

C

$\triangle \quad$ No Treg

- Foxp3 ${ }^{\text {cre }}$ Treg

$\square \quad$ PHD2-deficient Treg

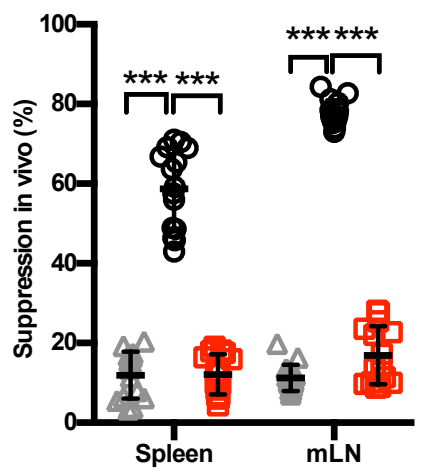

f

Treg:Tconv

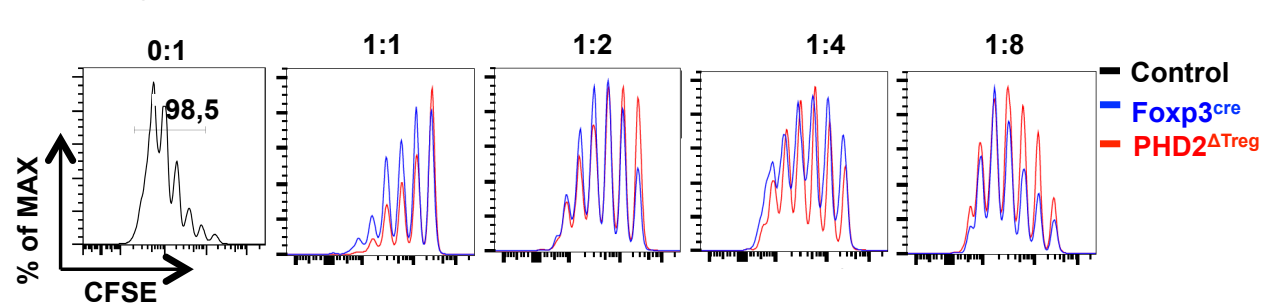

g
Day 6

d
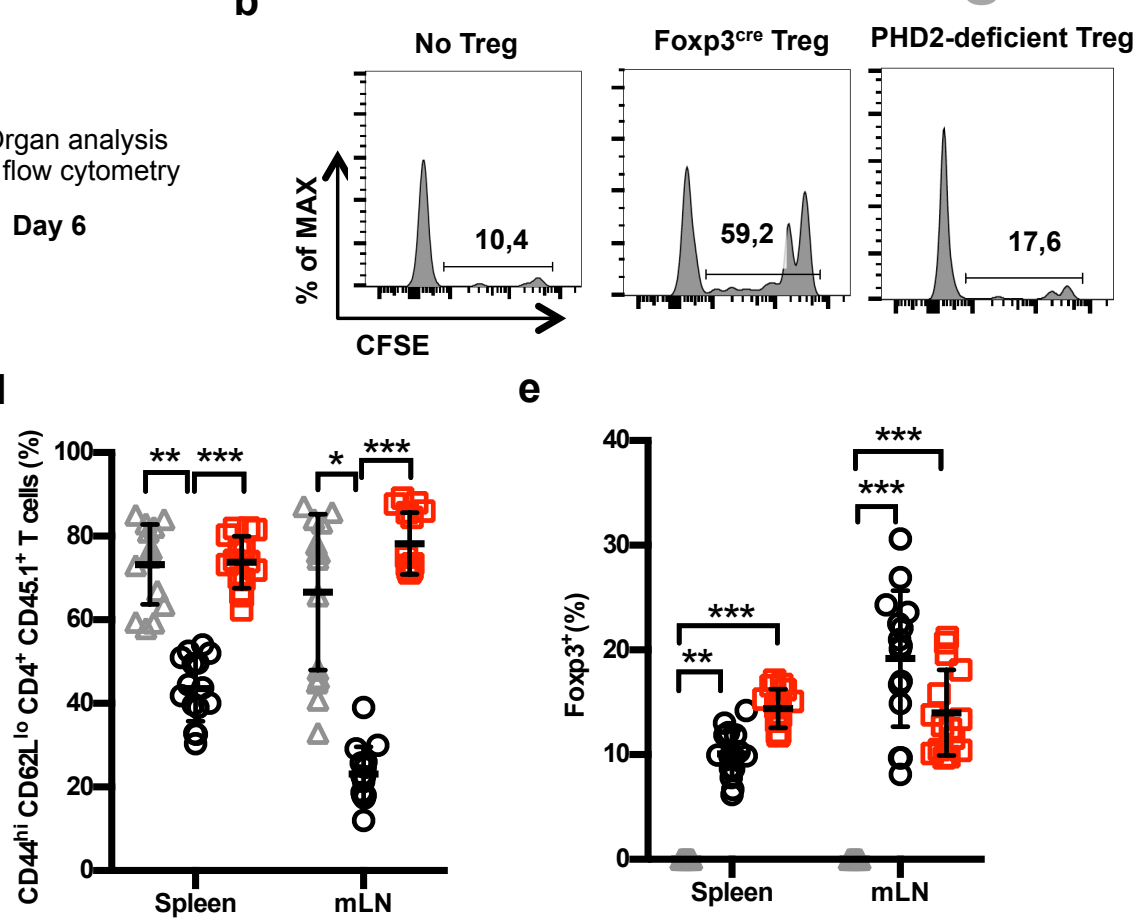

$\triangle$ No Treg O Foxp3 ${ }^{\text {cre }}$ Treg $\square$ PHD2-deficient Treg

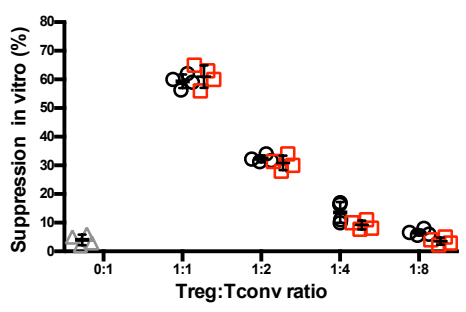

Figure 4. Reduced in vivo but not in vitro suppressive capacity of PHD2-deficient Treg. 


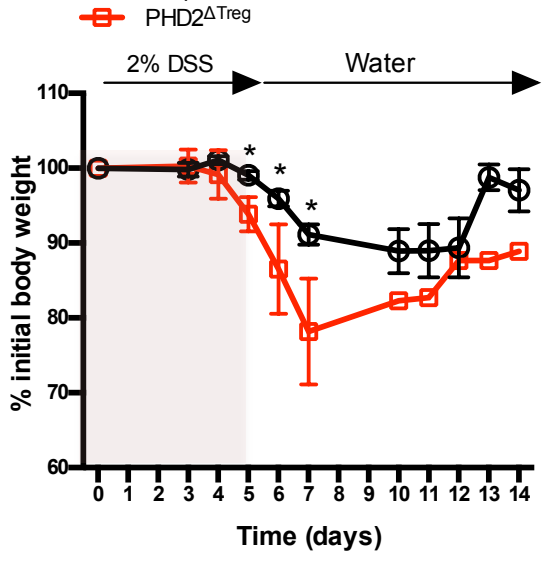

d

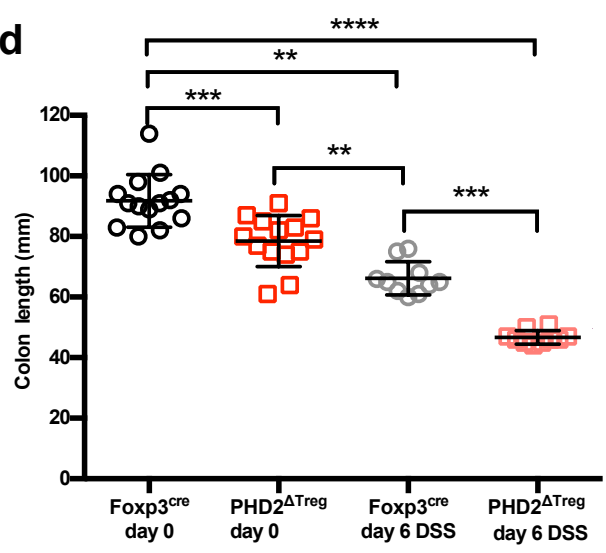

f

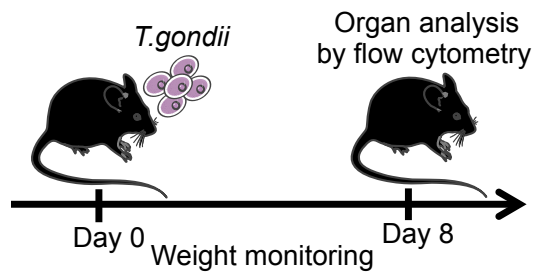

i

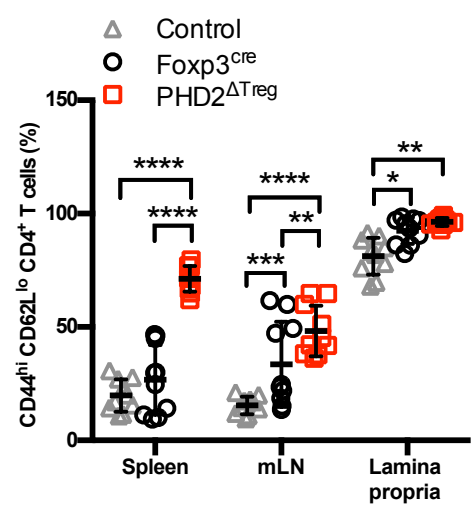

b

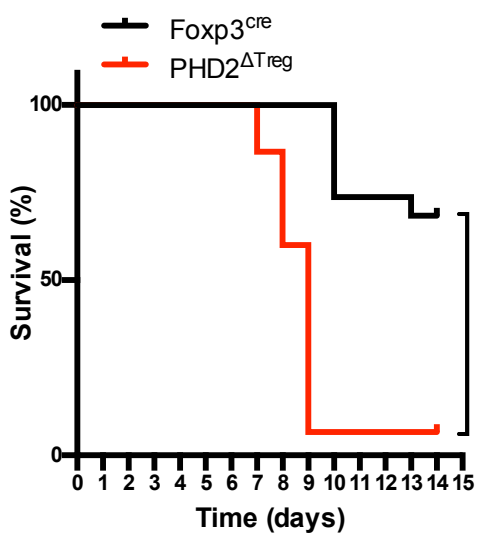

e

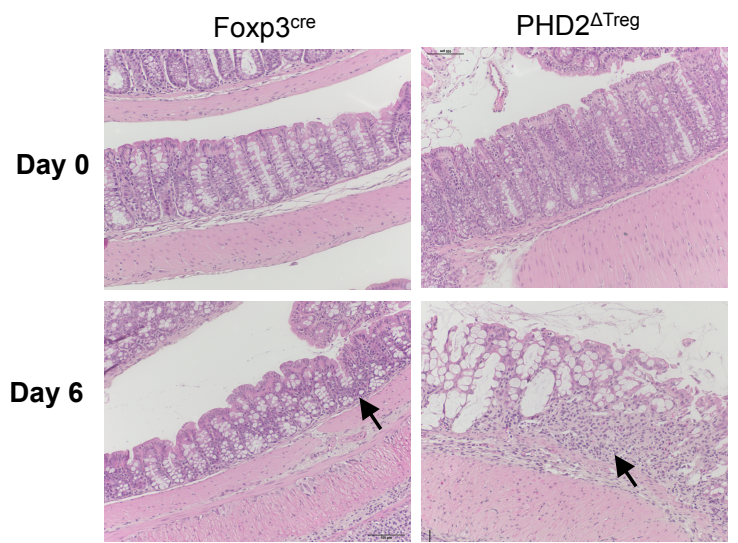

$9 \triangle$ Control

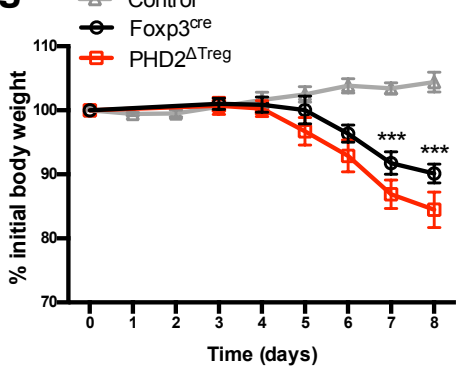

j

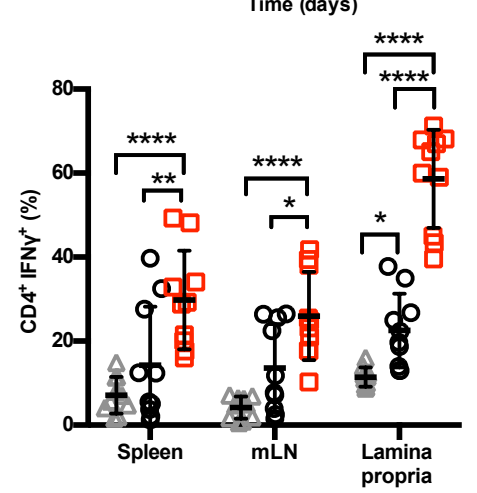

C

- Foxp3 ${ }^{\text {cre }}$

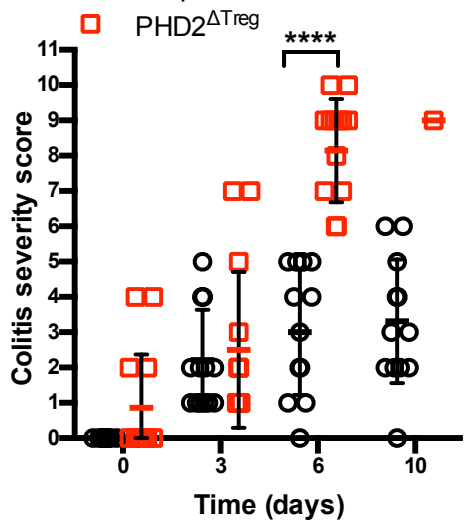

h

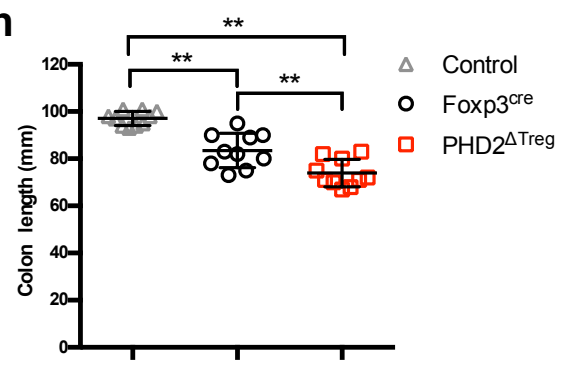

k

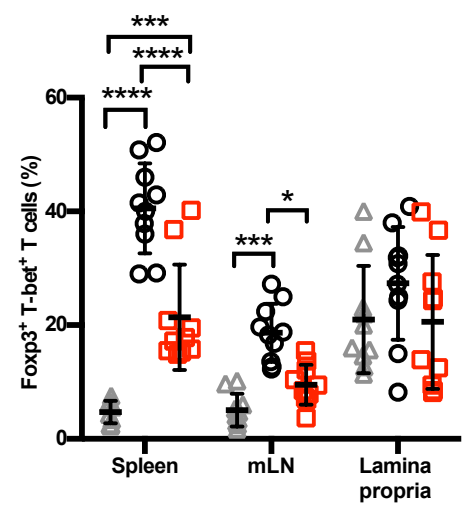

Figure 5. Increased sensitivity of PHD2 ${ }^{\Delta T r e g}$ mice to DSS-induced colitis and toxoplasmosis. 
a
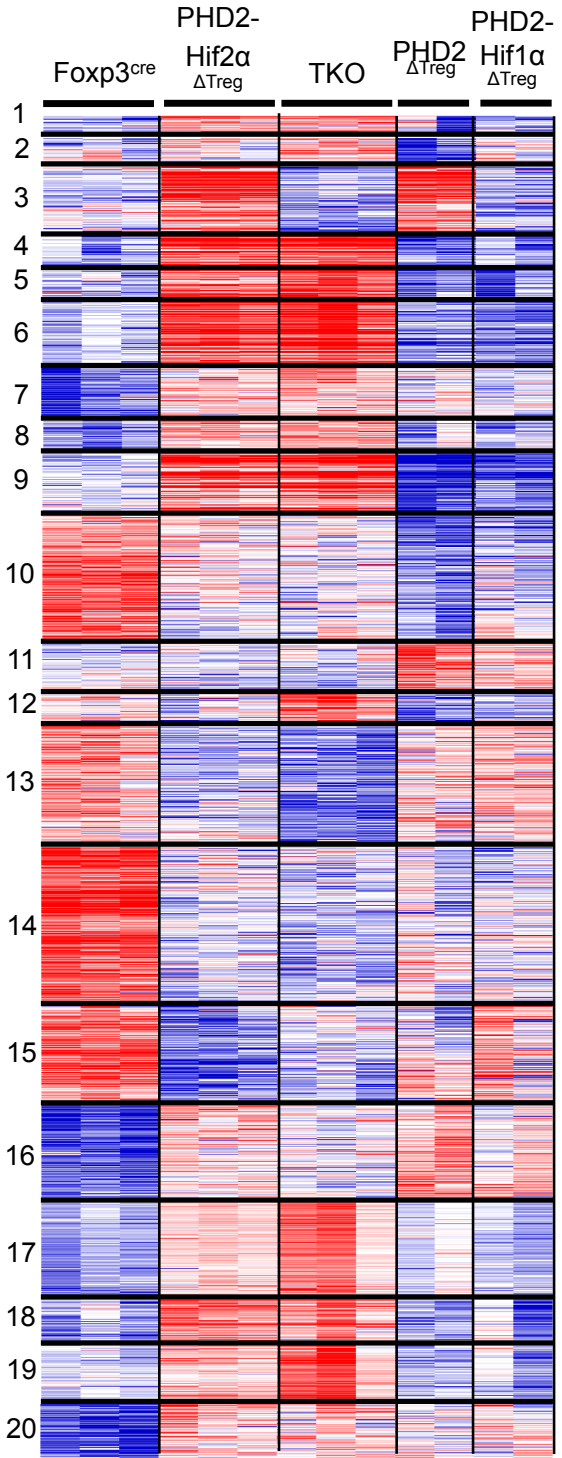

Log $_{2} \mathrm{FC}$ From median

b

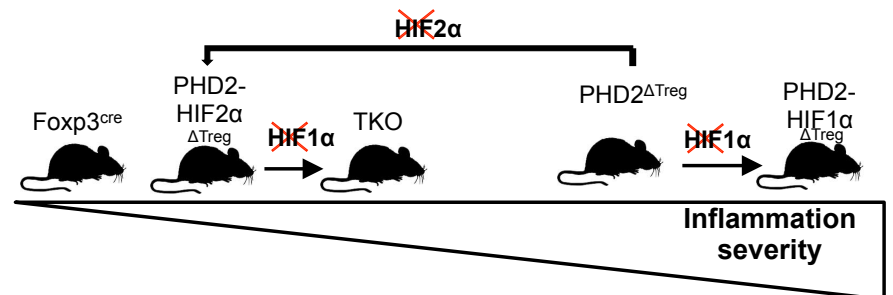

Figure 7. Anti-inflammatory response, response to chemokines and cell survival pathways represent targets of the PHD2-HIF2 $\alpha$ axis in Tregs.

\section{C} Downregulated pathways

I.

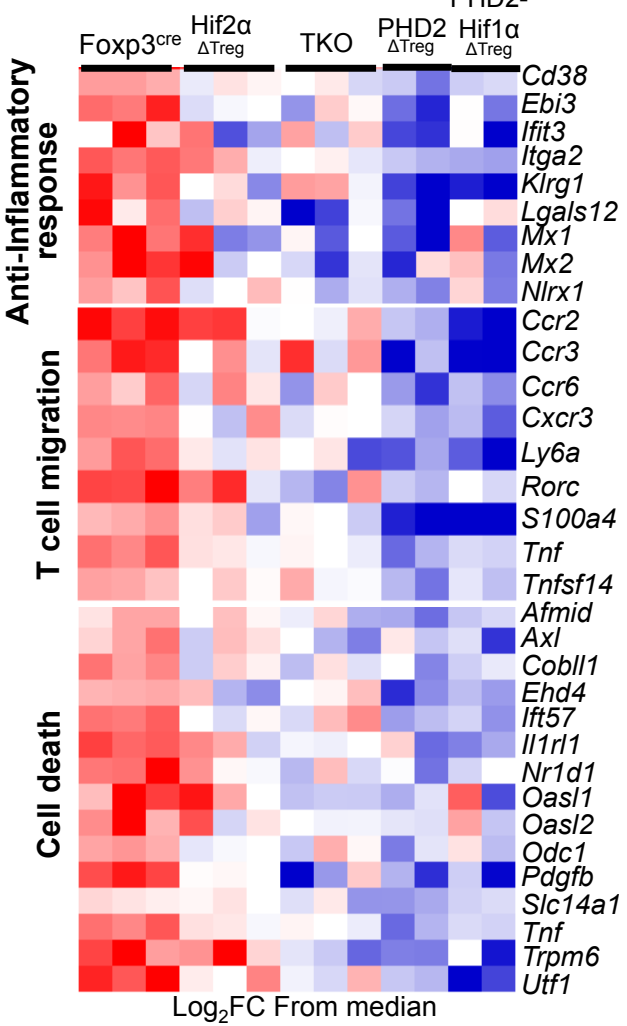

d

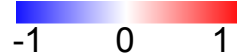

Upregulated pathway

PHD2-

PHD2-

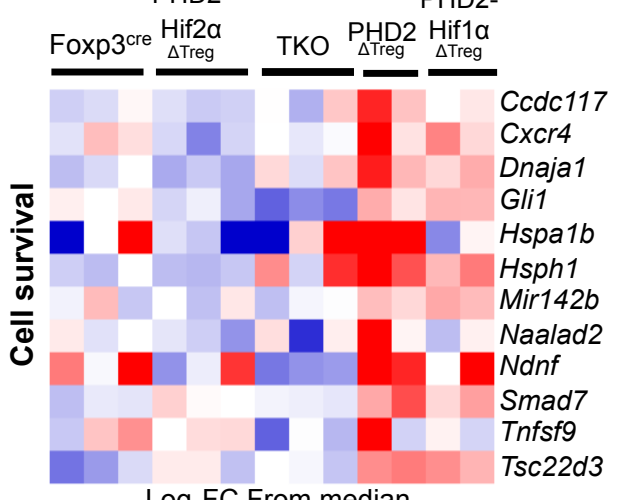

$\log _{2}$ FC From median

$$
\begin{array}{llll}
-1 & 0 & 1 & \\
\text { PHD2- } & & & \\
\text { PHD2- }
\end{array}
$$

e

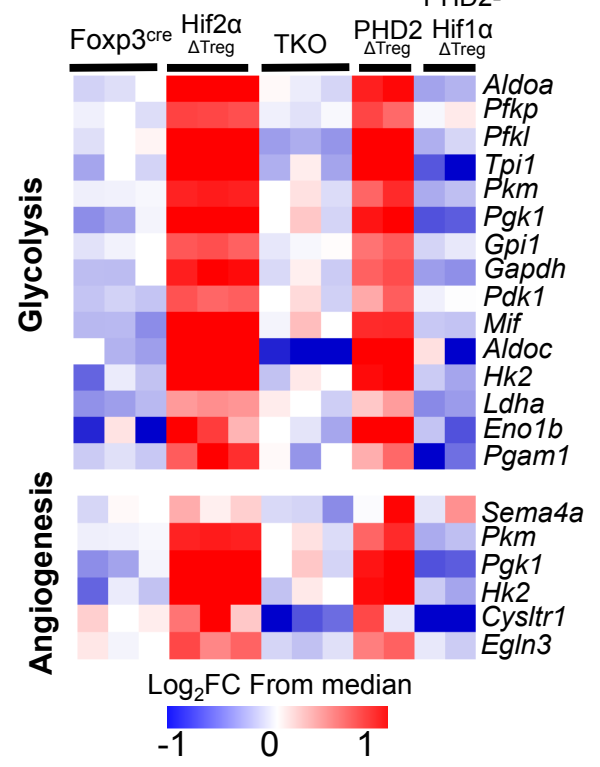


a

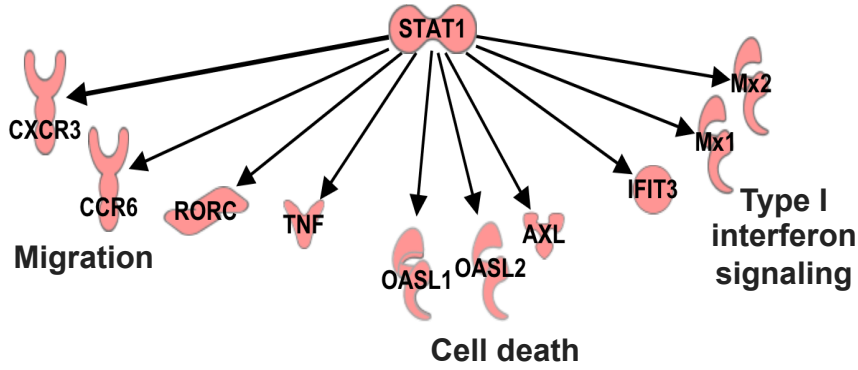

C

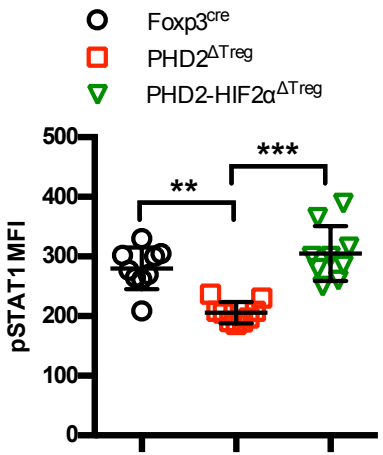

d b
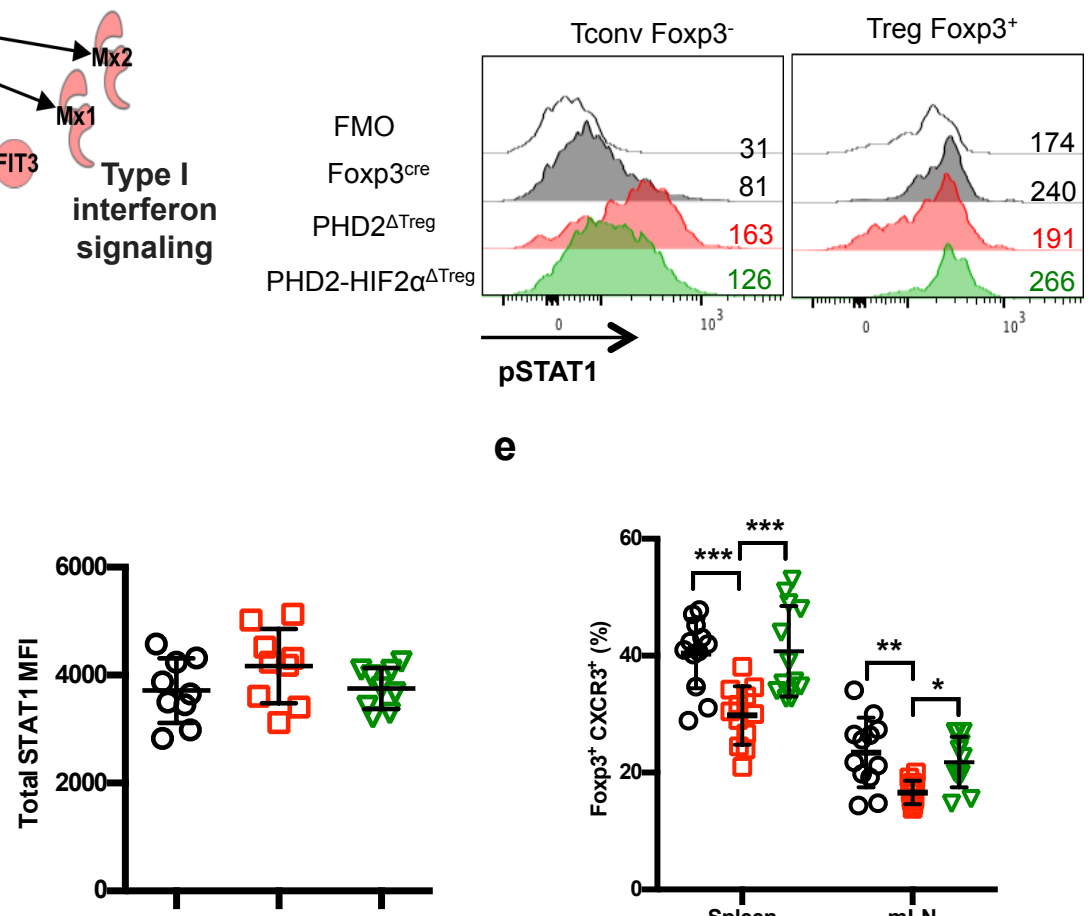

Figure 8. Identification of STAT1-mediated signaling as a target of the PHD2-HIF2 $\alpha$ axis in Tregs. 
a

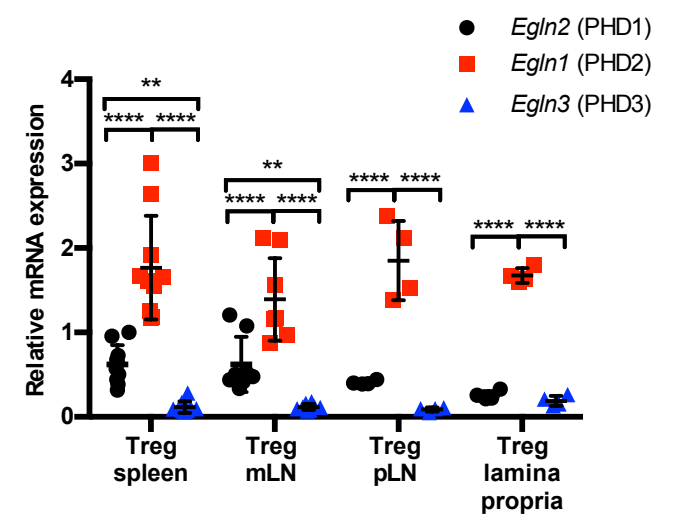

d

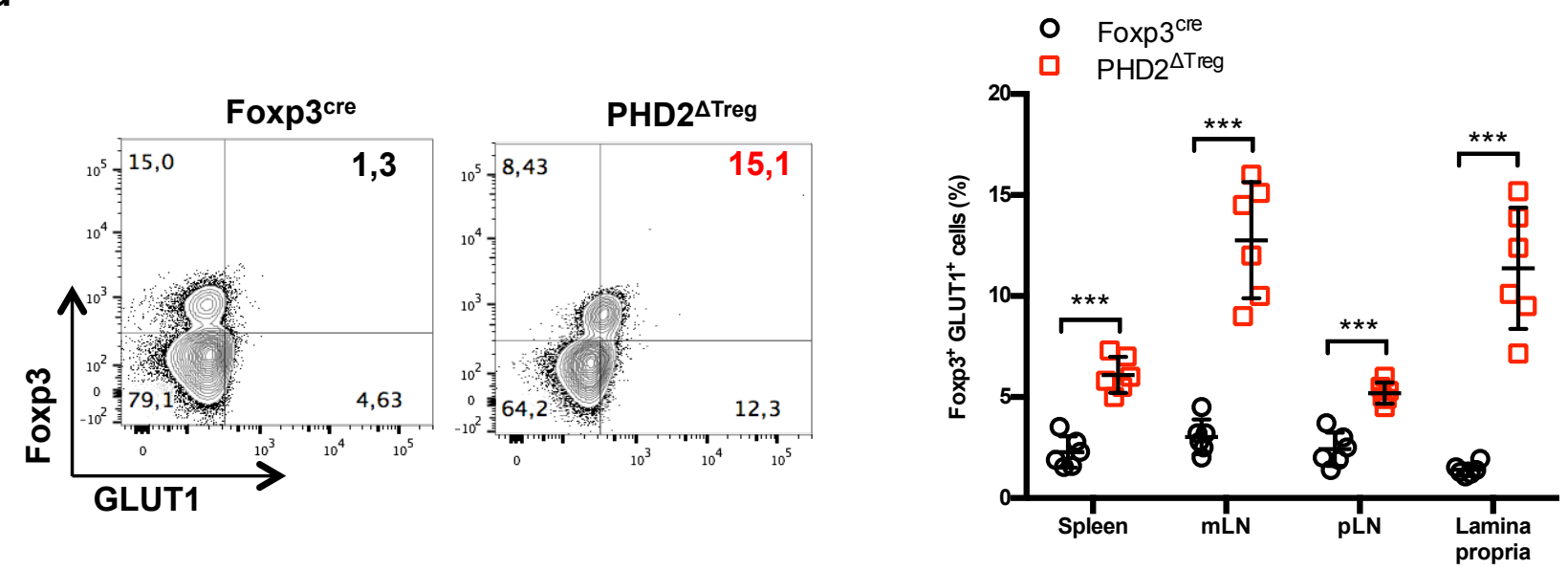

b

C

- Foxp3 $3^{\text {cre }}$
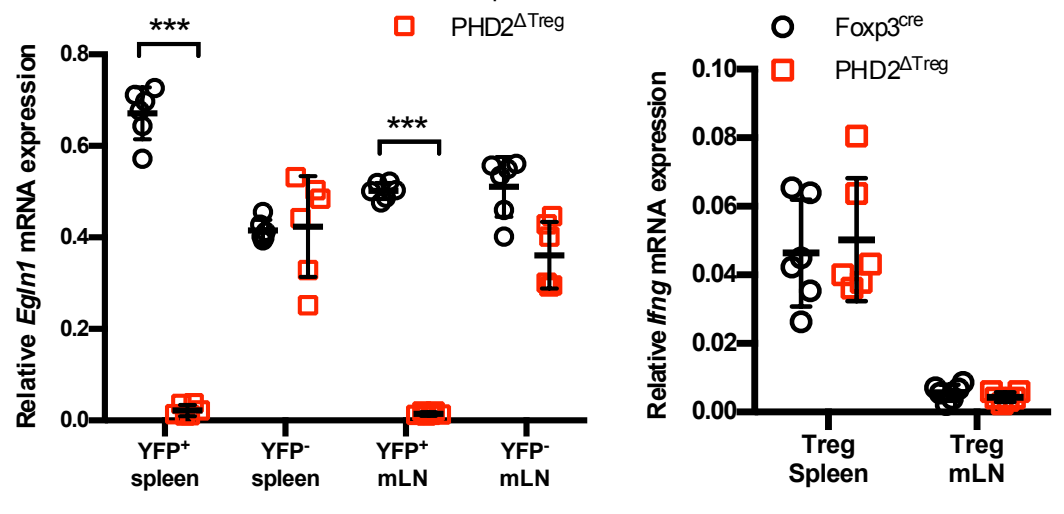

e

Figure 1-figure supplement 1. Treg-restricted loss of EgIn1 gene expression in PHD2 ${ }^{\Delta T r e g}$ mice. 
a

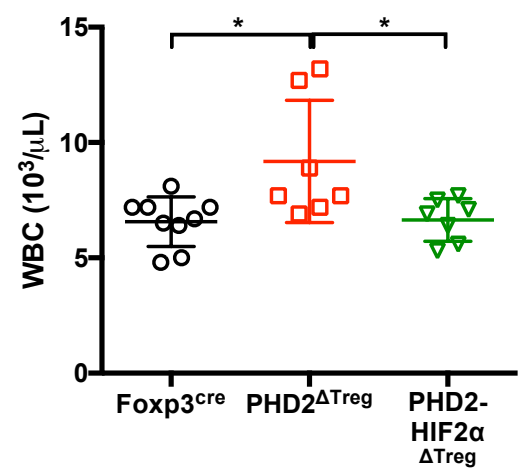

C

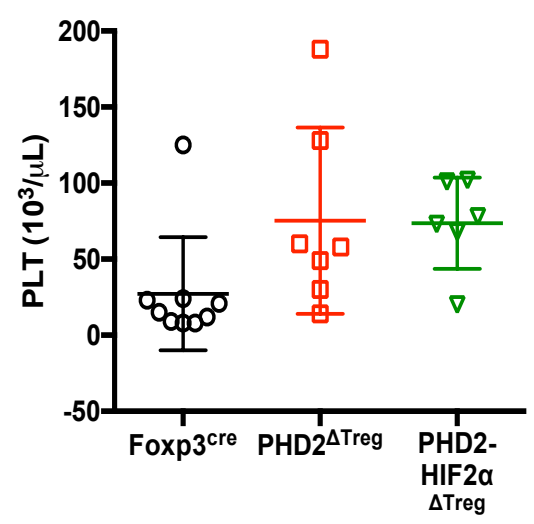

e

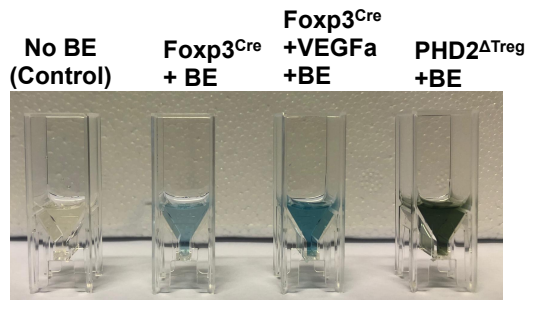

b

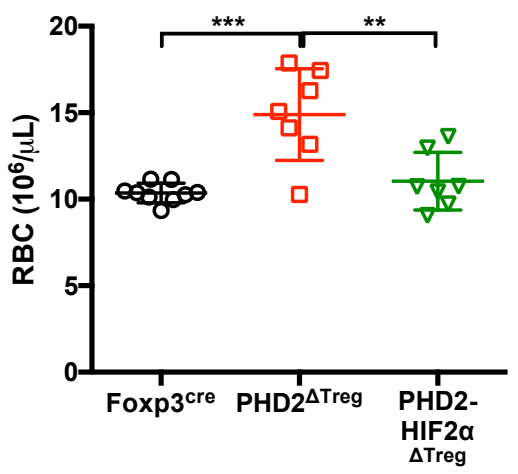

d

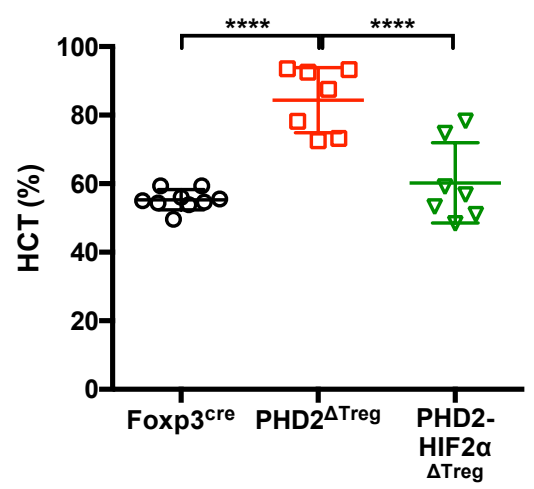

f

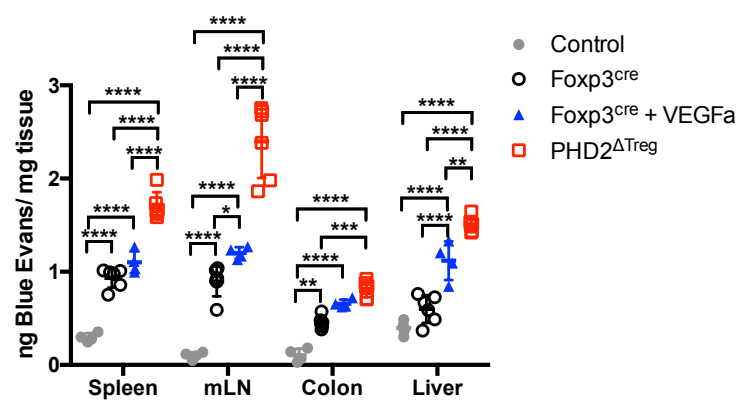

Figure 1-figure supplement 2. Increased blood cells counts and elevated hematocrit in PHD24Treg mice associated with an increase in vascular permeability. 

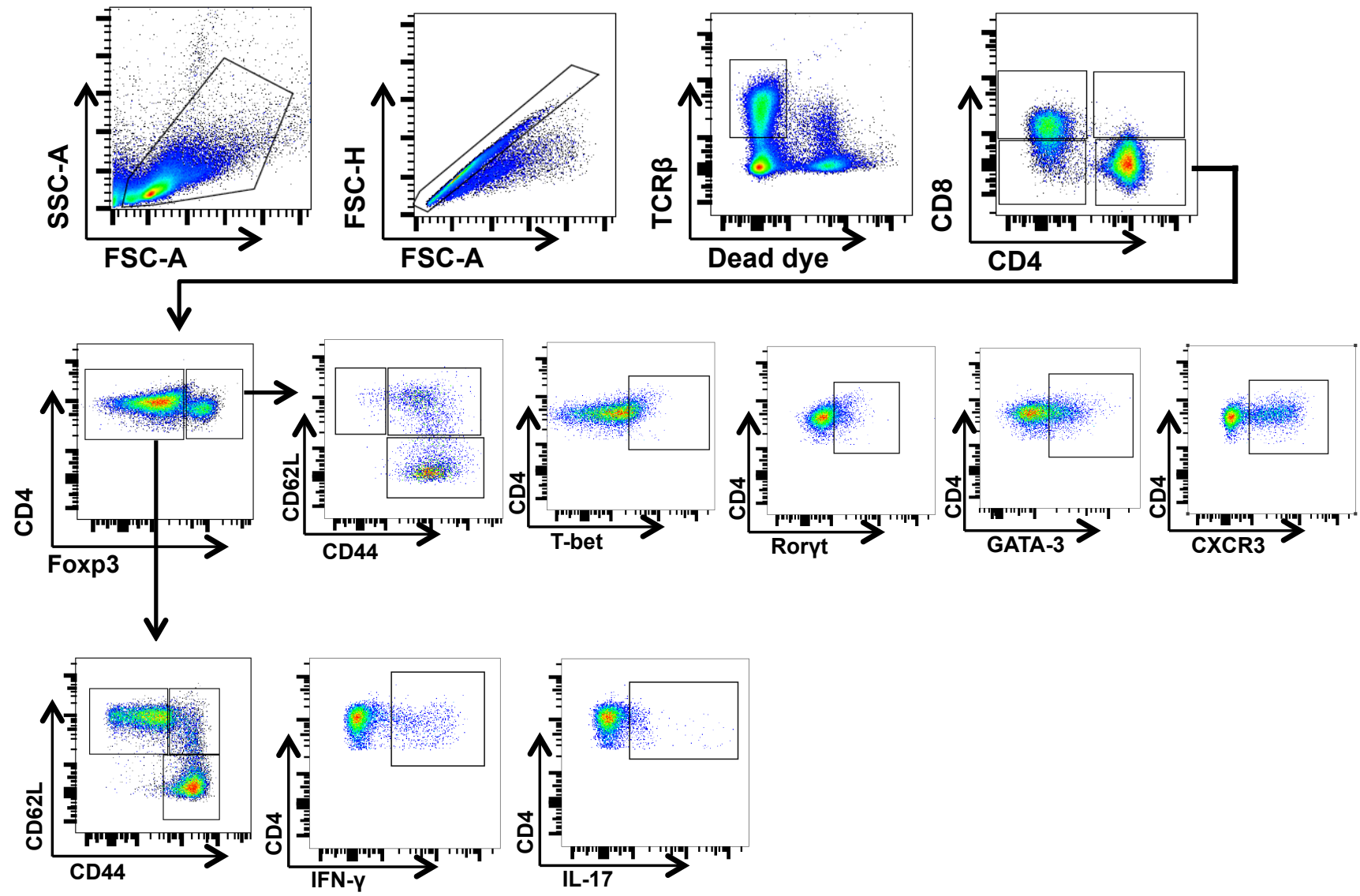

Figure 1-figure supplement 3. Gating strategy for flow cytometry data analysis. 
a

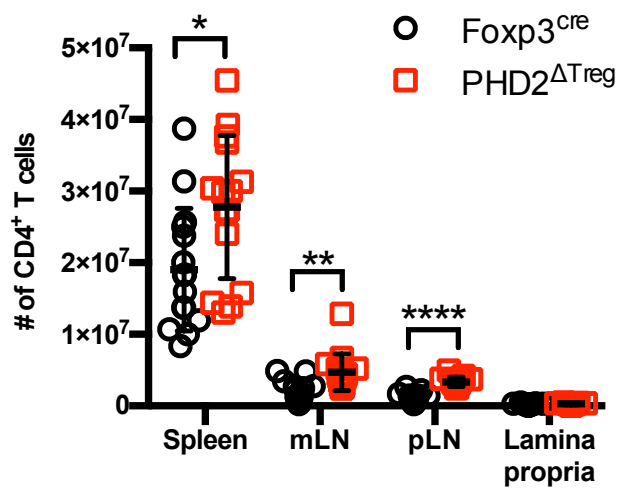

C

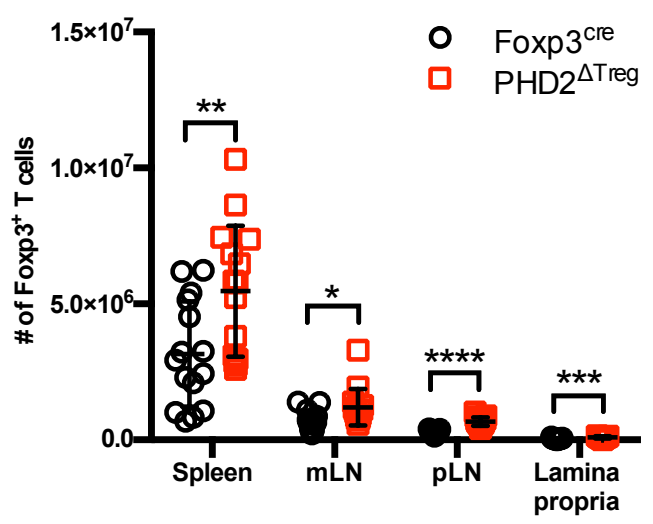

b

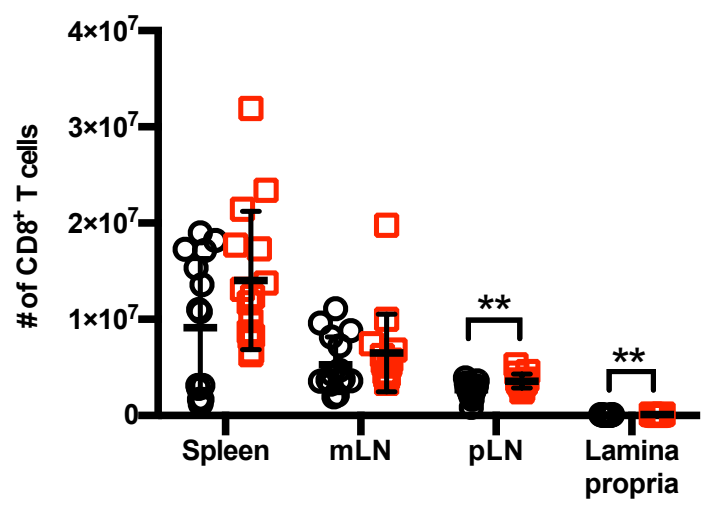

d

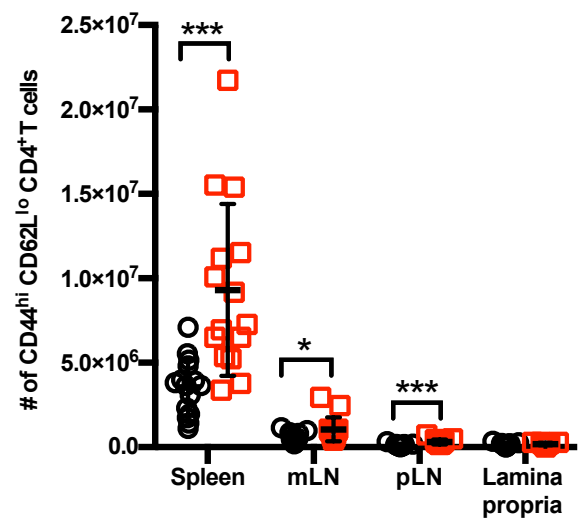

Figure 1-figure supplement 4 . Absolute cell counts. 
a

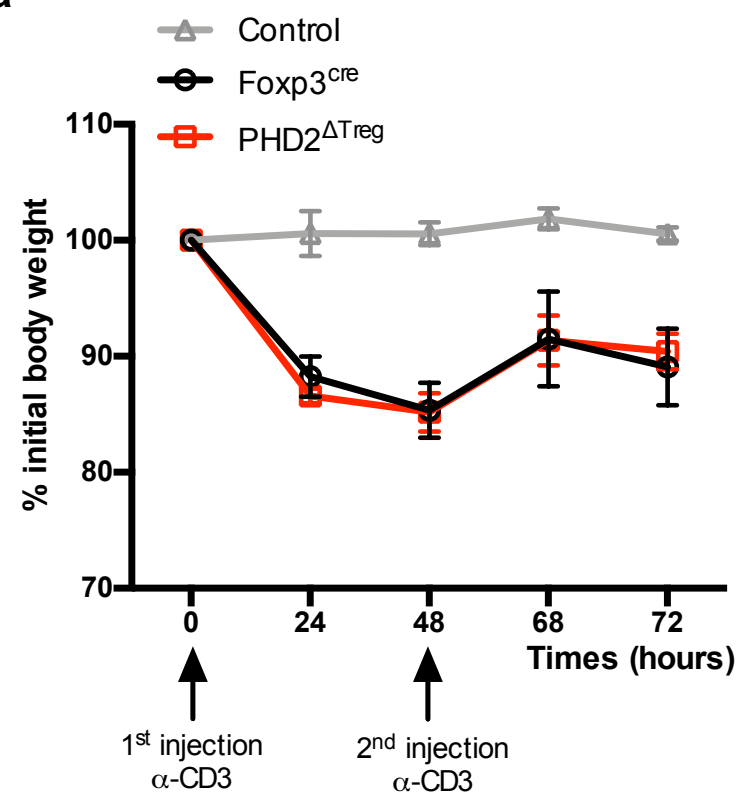

b $\quad q P C R$ on total $m L N(48 h)$
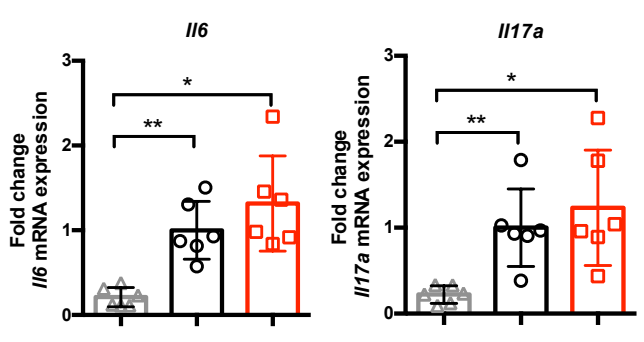

$\triangle$ Control

- Foxp3 $3^{\text {cre }}$

D $\mathrm{PHD}^{\Delta \text { Treg }}$

Figure 5-figure supplement 1. PHD2 ${ }^{\Delta T r e g}$ mice display a near-normal response to anti-CD3-induced enteritis. 
a

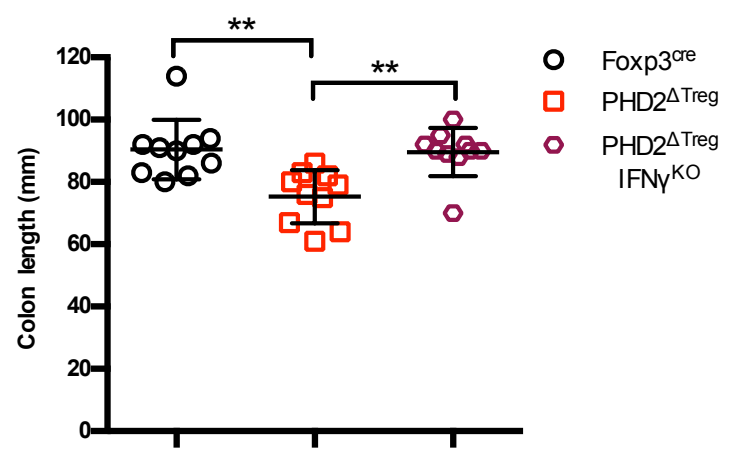

C

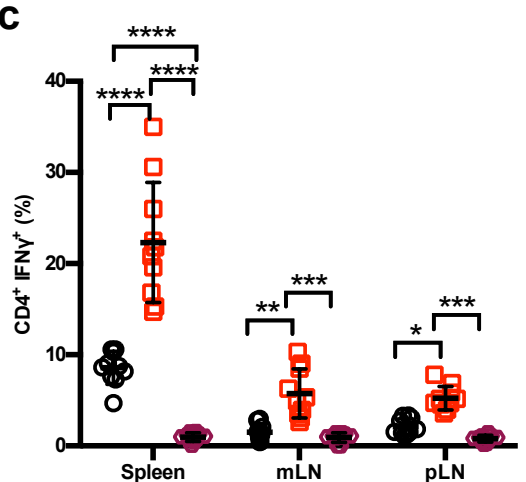

b

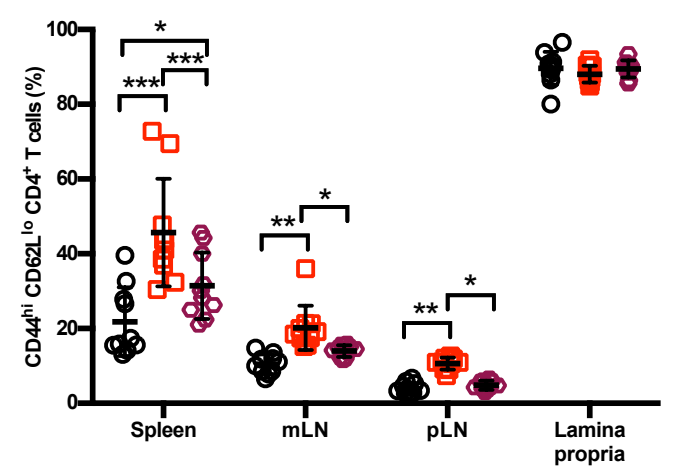

e d

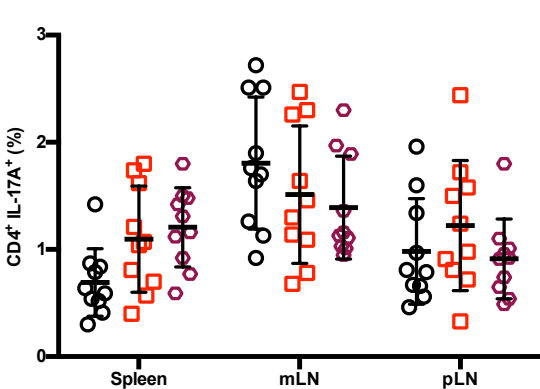

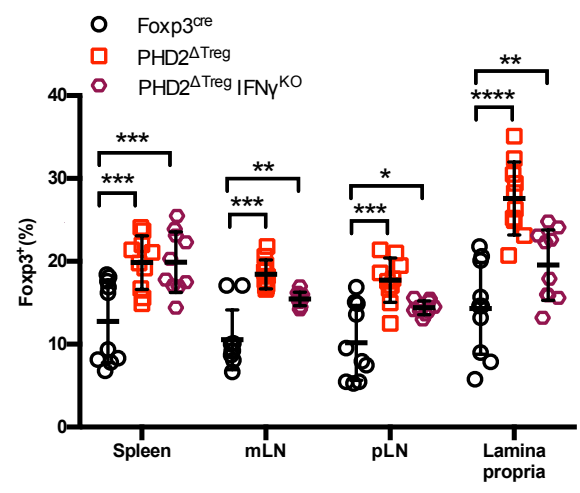

Figure 5-figure supplement 2. Loss of Ifng gene expression attenuates the pro-inflammatory phenotype of PHD2 $^{\Delta \text { Treg mice }}$ 
a
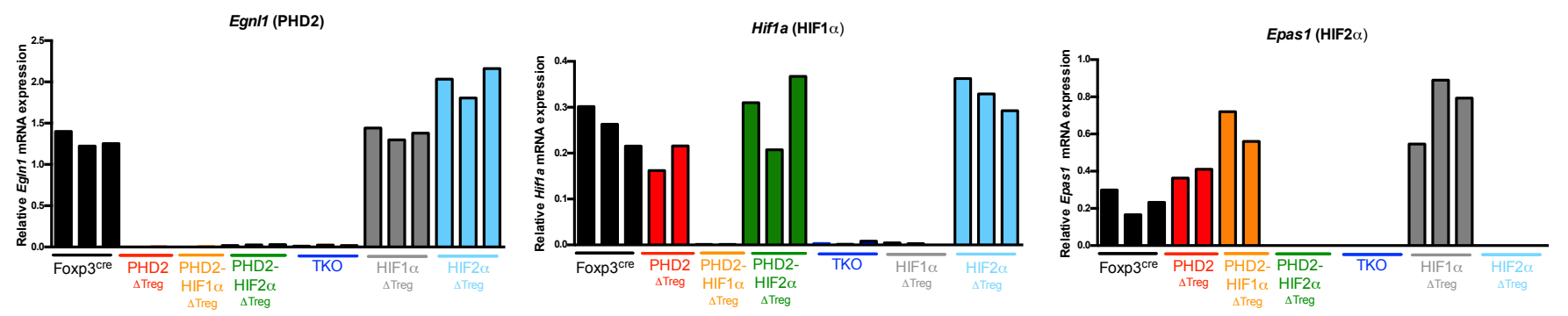

b
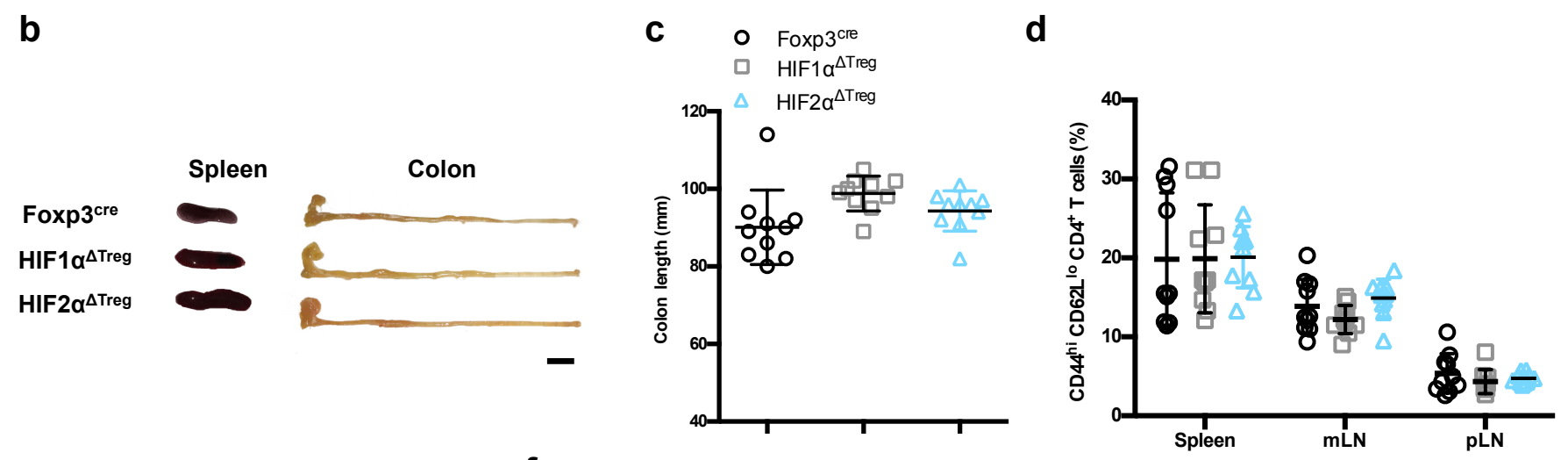

e

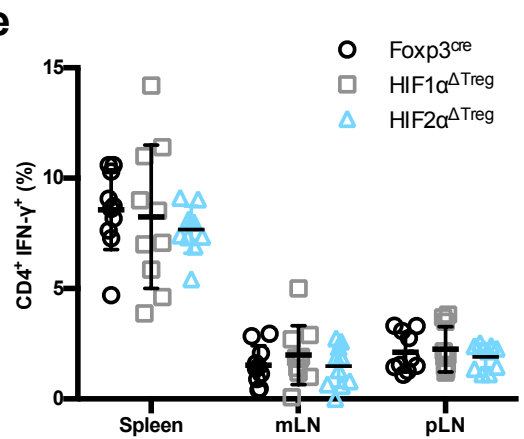

f

g
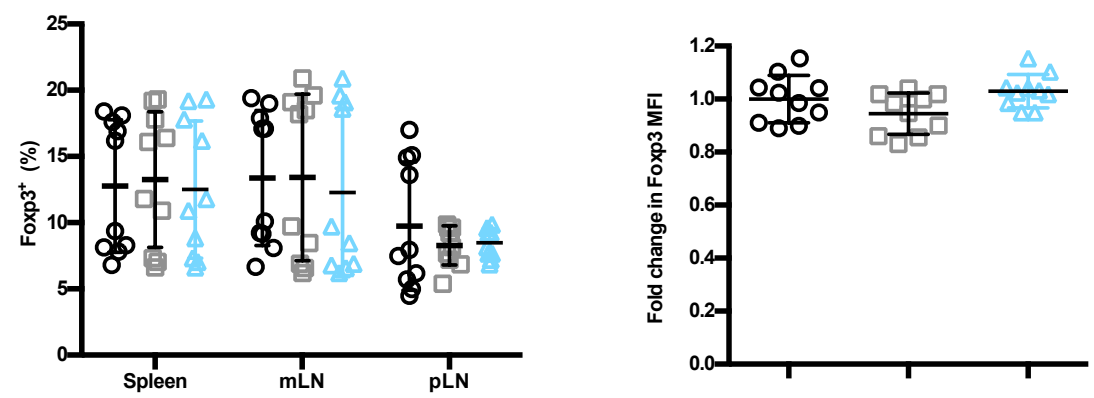

Figure 6-figure supplement 1. Treg-selective HIF1 $\alpha$ or HIF2 $\alpha$ deficiency does not affect immune homeostasis in naive mice. 


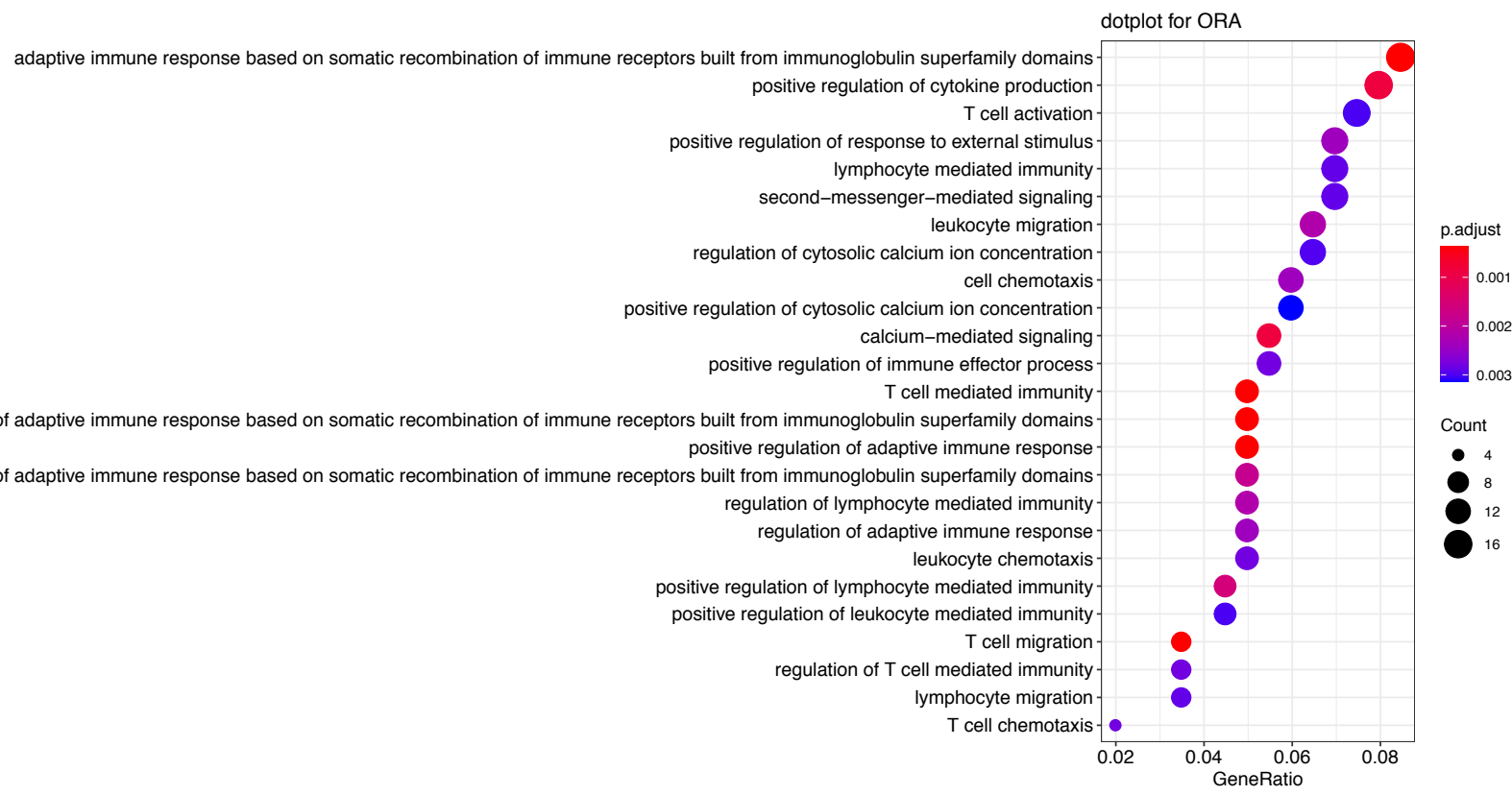

\section{b Upregulated pathways}

dotplot for ORA

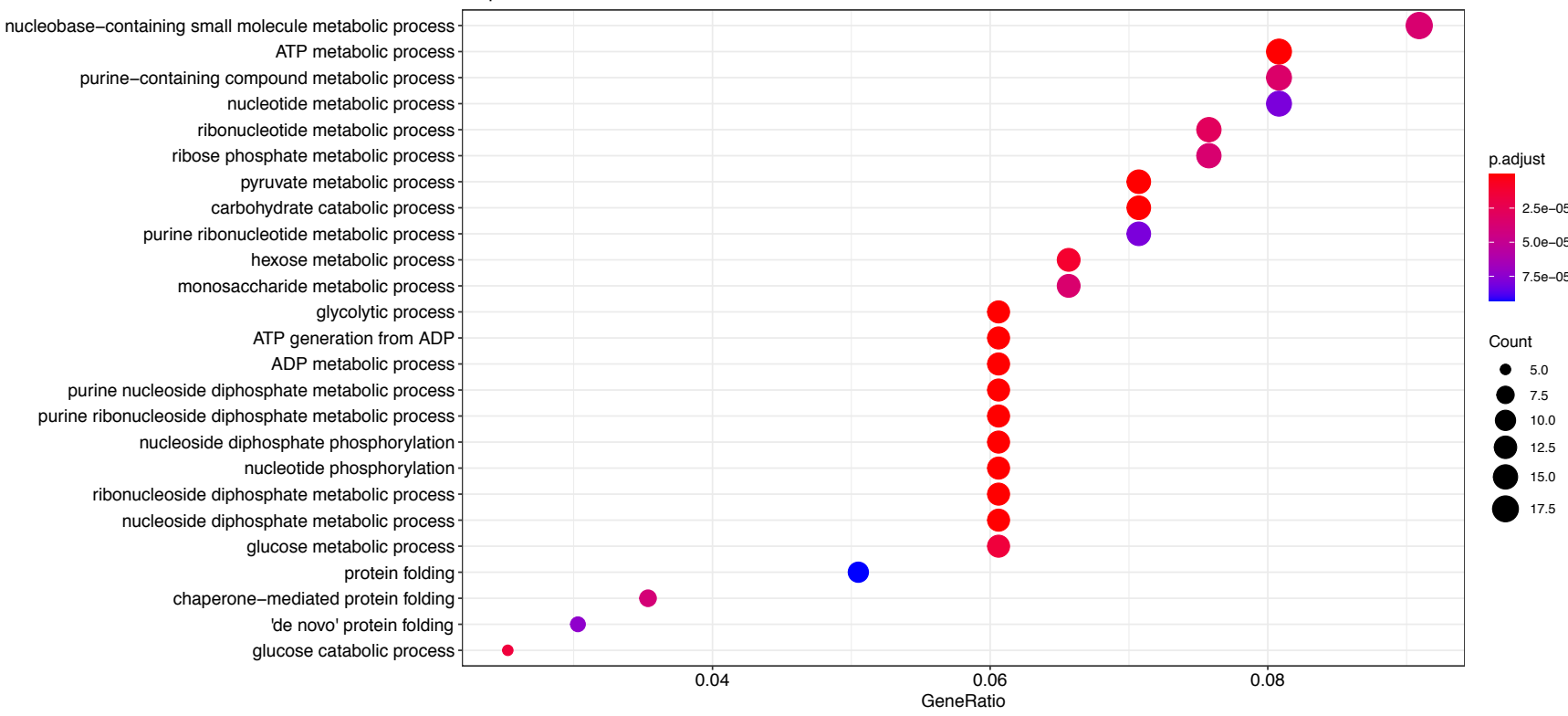

Figure 7-figure supplement 1. Signaling pathways affected by loss of PHD2-expression in Treg. 
a
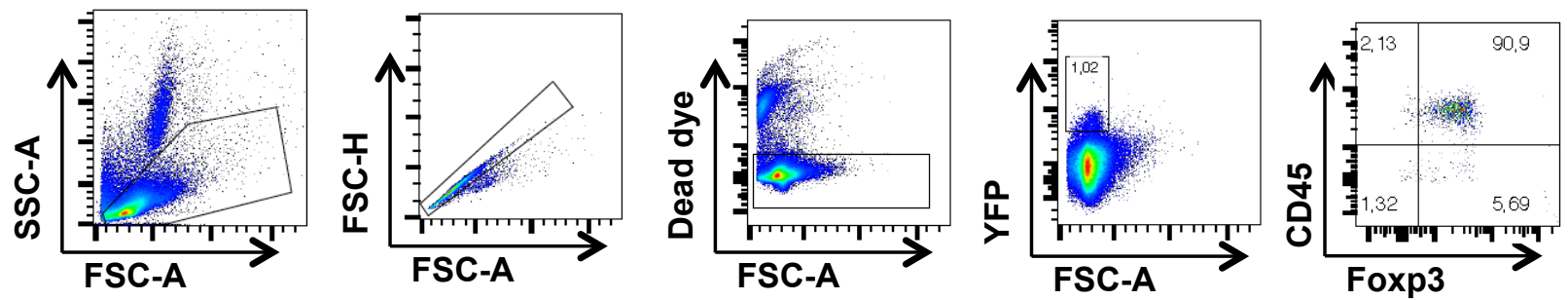

b
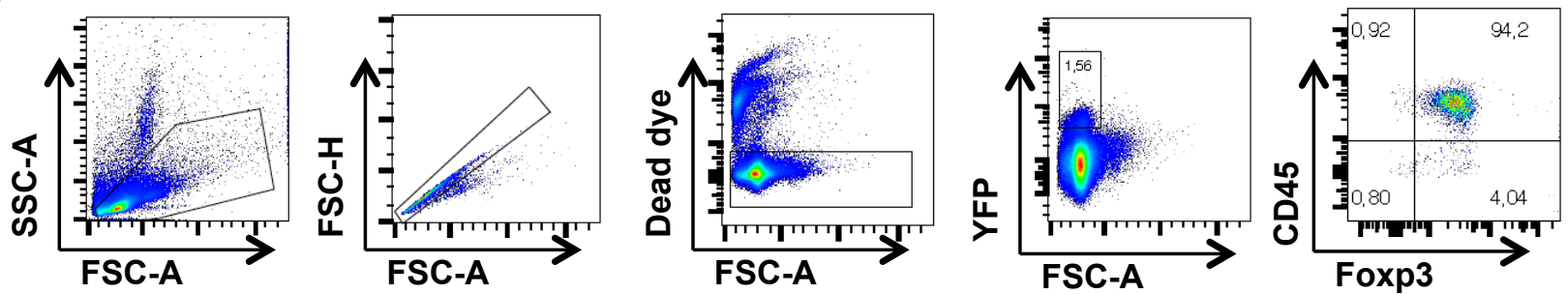

C
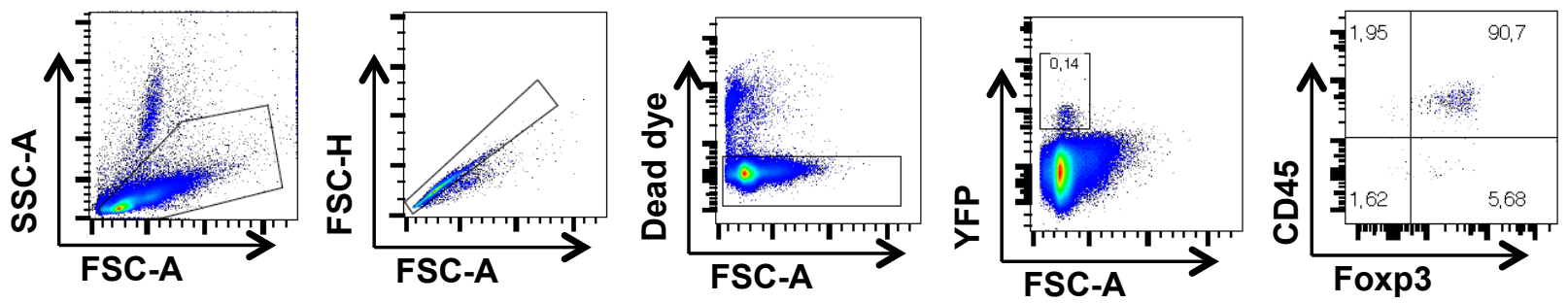

d
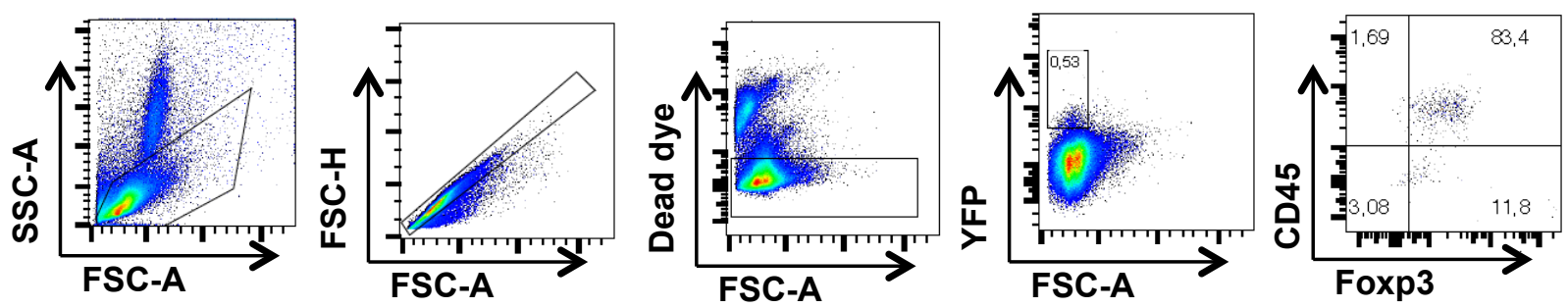

Figure 8-figure supplement 1. Gating strategy for identification of $\mathrm{YFP}^{+}$cells. 